University of Louisville

ThinkIR: The University of Louisville's Institutional Repository

$5-2021$

\title{
Urban arterial lane flow distribution: a before and after traffic microsimulation analysis on the effect of implementing new route markings and signage.
}

Larry Michael Summers

University of Louisville

Follow this and additional works at: https://ir.library.louisville.edu/etd

Part of the Civil Engineering Commons

\section{Recommended Citation}

Summers, Larry Michael, "Urban arterial lane flow distribution: a before and after traffic microsimulation analysis on the effect of implementing new route markings and signage." (2021). Electronic Theses and Dissertations. Paper 3642.

https://doi.org/10.18297/etd/3642

This Master's Thesis is brought to you for free and open access by ThinkIR: The University of Louisville's Institutional Repository. It has been accepted for inclusion in Electronic Theses and Dissertations by an authorized administrator of ThinkIR: The University of Louisville's Institutional Repository. This title appears here courtesy of the author, who has retained all other copyrights. For more information, please contact thinkir@louisville.edu. 
URBAN ARTERIAL LANE FLOW DISTRIBUTION:

A BEFORE AND AFTER TRAFFIC MICROSIMULATION ANALYSIS ON THE EFFECT OF IMPLEMENTING NEW ROUTE MARKINGS AND SIGNAGE

By

Larry Michael Summers

B.S. Civil Engineering, University of Evansville, 2006

B.S. Engineering Management, University of Evansville, 2006

\begin{abstract}
A Thesis
Submitted to the Faculty of the

J.B. Speed School of Engineering University of Louisville

in Partial Fulfillment of the Requirements

for the Degree of
\end{abstract}

Master of Science

in Civil Engineering

Department of Civil Engineering

University of Louisville

Louisville, Kentucky

May 2021 
Copyright 2021 by Larry Michael Summers

All rights reserved 

URBAN ARTERIAL LANE FLOW DISTRIBUTION:

A BEFORE AND AFTER TRAFFIC MICROSIMULATION ANALYSIS ON THE EFFECT OF IMPLEMENTING NEW ROUTE MARKINGS AND SIGNAGE

By

Larry Michael Summers

B.S. Civil Engineering, University of Evansville, 2006

B.S. Engineering Management, University of Evansville, 2006

A Thesis Approved on

April 30, 2021

by the following Thesis Committee:

Thesis Director

Dr. Robert Kluger, PE

Dr. Richard Li, PE

Dr. Nick Hawkins 


\section{DEDICATION}

This thesis is dedicated to the loving memory of my father

Mr. Larry R. Summers

who inspired me to enter engineering because of his work in the construction industry and my desire to work with him.

Furthermore, this thesis is dedicated to my mother

Mrs. Kathy S. Summers

who always inspires me to strive to be the best version of myself. 


\section{ACKNOWLEDGMENTS}

I want to thank Dr. Robert Kluger for his guidance and willingness to work with a full-time professional, full-time graduate student, and part-time researcher in the remaining hours of the day. His patience during several life events affecting my productivity was gracious. Also, I would like to thank the other committee members, Dr. Richard Li and Dr. Nick Hawkins, for taking the time and energy to serve on this committee. Without the assistance of Andy Rush from KIPDA, the invaluable Streetlight data would not have been available for this study, so I extend my gratitude to him and the organization. I appreciate Mayor Jeff Gahan for entrusting me to work for the City of New Albany while contributing to transportation research at the University of Louisville. Finally, I would like to thank my family and friends who have been extraordinarily supportive of me through this endeavor. 


\begin{abstract}
URBAN ARTERIAL LANE FLOW DISTRIBUTION:

A BEFORE AND AFTER TRAFFIC MICROSIMULATION ANALYSIS ON THE EFFECT OF IMPLEMENTING NEW ROUTE MARKINGS AND SIGNAGE
\end{abstract}

Larry Michael Summers

April 30, 2021

Urban arterials may not effectively utilize available lanes to move vehicles efficiently as drivers try to establish position along the corridor. This study evaluates lane flow distribution before and after implementing new route markings and overhead signs to utilize existing lanes better. A cellphone-based traffic data service called StreetLight gathered the traffic data used to establish the VISSIM model parameters for simulating current and projected conditions. This study shows that the lane assignment signage and route markers affected the lane flow distribution in the simulation.

The simulation indicated the existing condition had average queue lengths of 320.6 meters, average travel times of 389.5 seconds, an average stop delay of 259.6 seconds, and an average lane flow distribution in the right lane of $76.1 \%$. Upon implementing new route markers and sign installations, the projected simulation showed average queue lengths of 39.0 meters, average travel times of 171.4 seconds, an average delay of 92.5 seconds, and an average lane flow distribution in the right lane of $47.4 \%$. 


\section{TABLE OF CONTENTS}

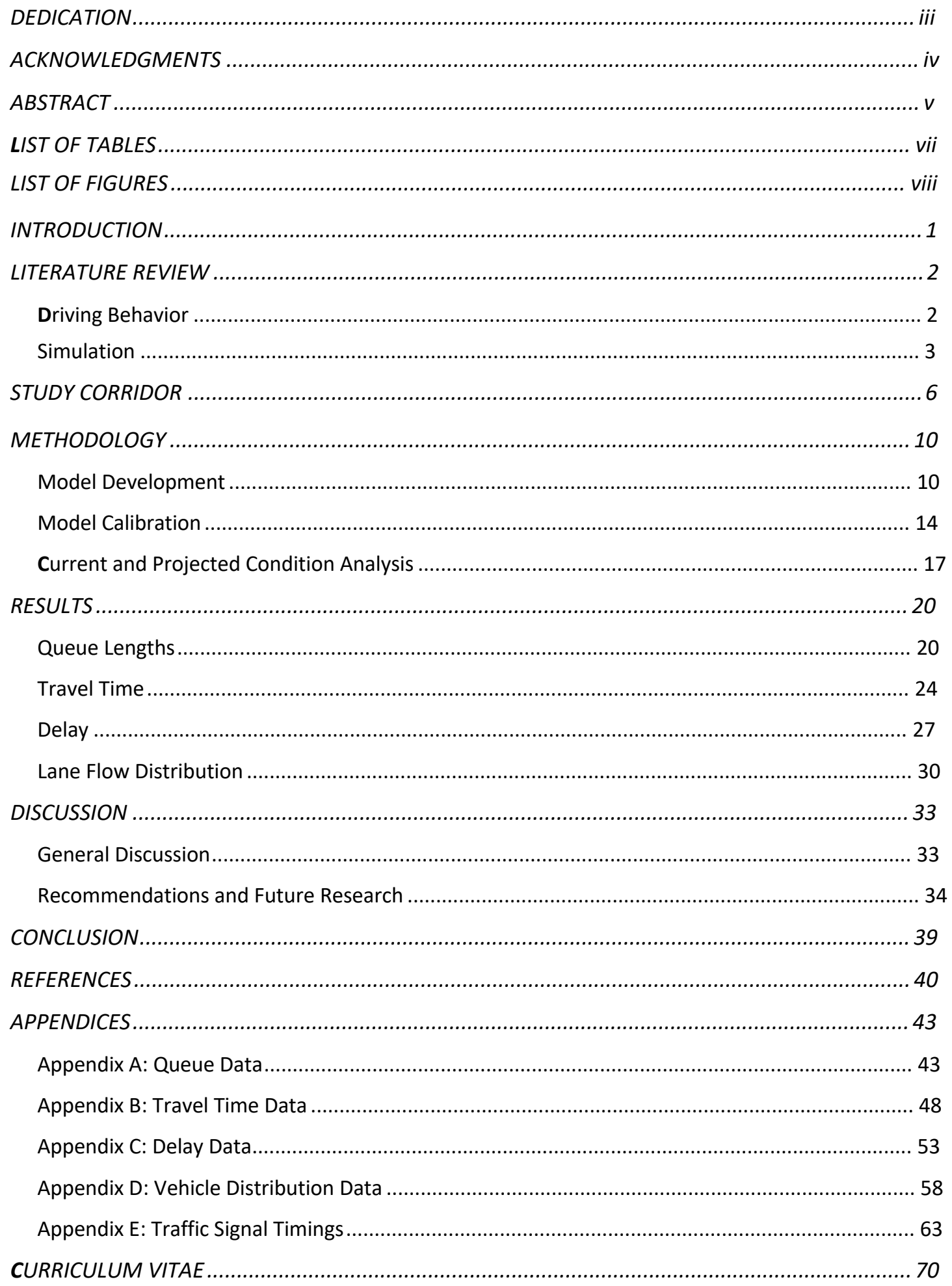




\section{LIST OF TABLES}

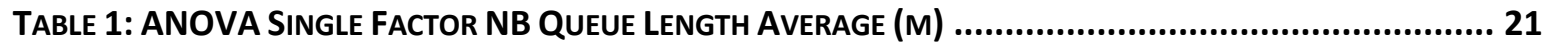

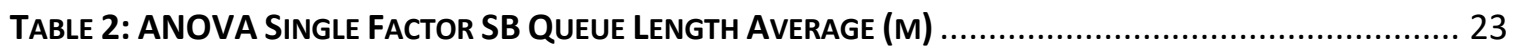

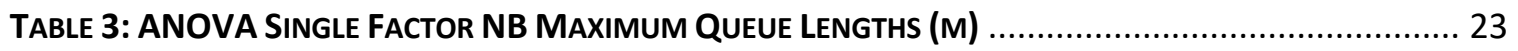

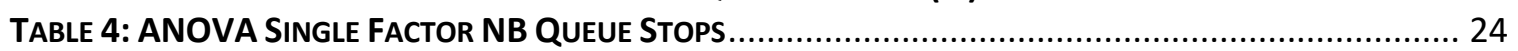

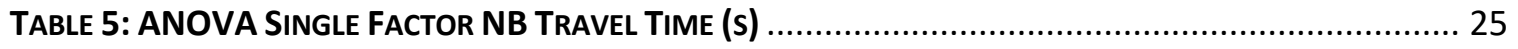

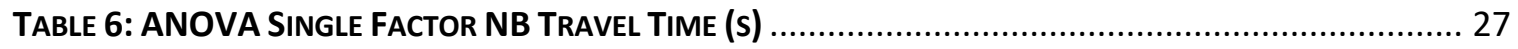

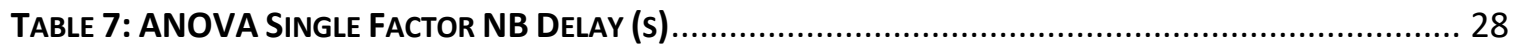

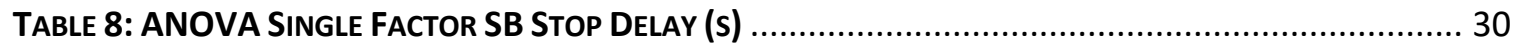

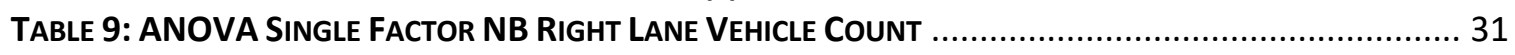

TABle 10: ANOVA Single Factor Percentage of Vehicles IN THe Right LANE .................................. 32 


\section{LIST OF FIGURES}

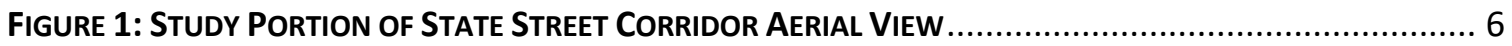

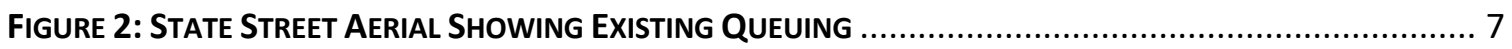

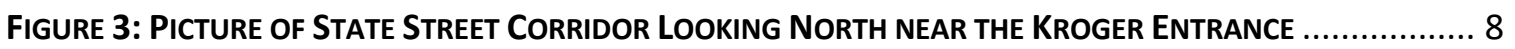

Figure 4: Picture of State Street Corridor LoOking North near the Home Depot Entrance .......... 9

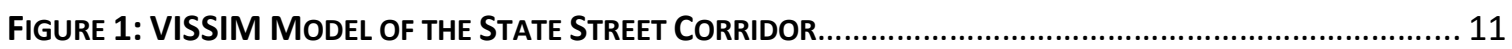

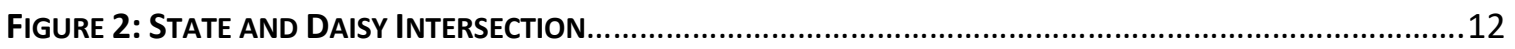

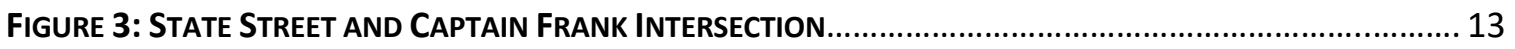

FIGURE 4: STATE STREET AND DAISY LANE VISSIM SIGNAL CONTROLLER INPUTS..................................... 14

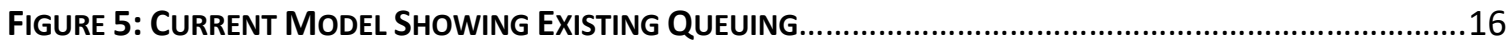

FigURE 6: Proposed Model Showing PRoJected QUEUING............................................................. 17

Figure 7: Comparative Histogram of CuRRent \& Projected NB AVerage Queue Length (M).......... 21

Figure 8: Comparative Histogram of CuRrent \& Projected SB AVerage QueUe Length (M)......... 22

Figure 9: Comparative histogram of CurRent \& Projected NB AVerage Travel Time (s).............. 25

Figure 10: Comparative histogram of CurRent \& Projected SB Average Travel Time (s)................26

Figure 11: Comparative Histogram of CuRrent \& Projected NB AVerage Delay (s)........................ 28

Figure 12: Comparative Histogram of CuRrent \& Projected SB AVERAge Delay (s)........................ 29

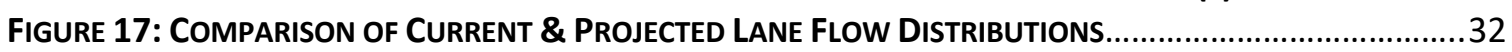

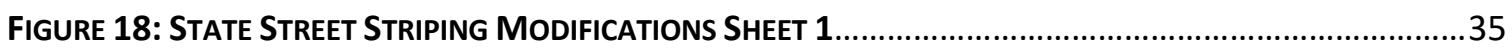

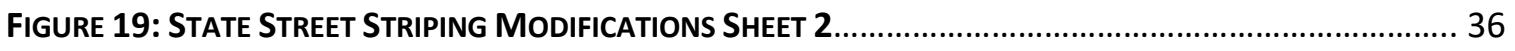

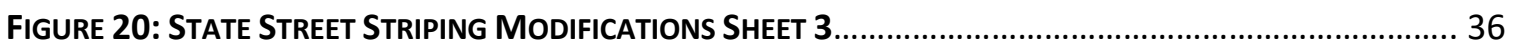

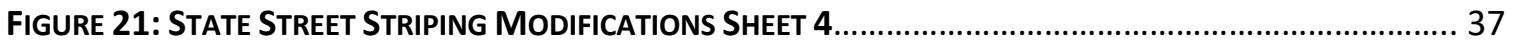

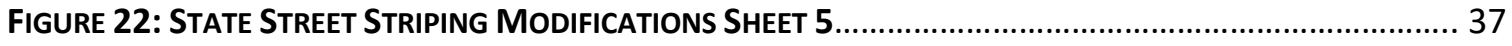

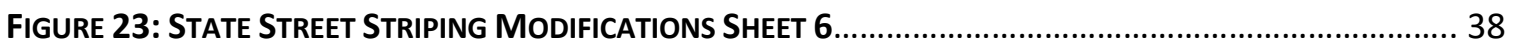

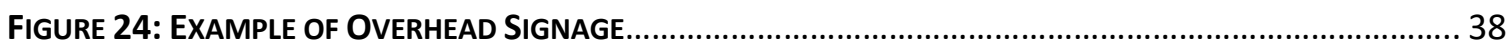




\section{INTRODUCTION}

Urban arterials may not effectively utilize available lanes to move vehicles efficiently as drivers try to establish position along the corridor. This study evaluates lane flow distribution before and after implementing new route markings and signs to utilize existing lanes better. StreetLight, a cellphone-based traffic data service, gathered the traffic data used to calibrate the VISSIM model parameters to simulate current and projected conditions.

Based on the available literature, this study appears to be the first to use Streetlight data to establish the parameters for a microsimulation model. This novel approach may make the construction of models within a traffic microsimulation environment easier-especially for use with pre- and post-modification studies. With the availability of Streetlight data, traffic counts and turning movements will not need special mobilization of equipment each time new data is required.

For this study, the State Street corridor of New Albany, Indiana, is being used to study the effects of new route markings and signs on lane flow distribution via VISSIM. A future study will evaluate the simulation findings against data gathered after the modifications to the street have been established and traffic has normalized. This study will primarily focus on the portion of the corridor from the I-265 W ramp to Green Valley Road, which is approximately 0.8 miles. 


\section{LITERATURE REVIEW}

\section{Driving Behavior}

An analysis of the lane flow distribution and the effects of various treatments are the primary focus of this study. In looking at lane flow distribution, we must look at the lane-changing process; it is a highly complex process because of the overlap of the strategy, tactical, and operational behaviors (Li \& Sun, 2017). Studies have analyzed the effectiveness of traffic control devices in affecting driver behavior and show signs affected passenger car behavior (Bai et al., 2010). In contrast, other studies have reviewed the overuse of signs and the effect on mental workload (Yang et al., 2020). With signs, the goal is to achieve clarity of the meaning to provoke fewer mistakes in the decision task (Vilchez, 2018) and to minimize the time the subjects take to recognize the sign to reduce the likelihood of committing an error in discarding the sign's message (Vilchez, 2019).

For the corridor, overhead sign locations, other than on the signal strain wires, do not exist; therefore, this study reviewed previous research about co-location of road signs. The research established that co-location did not negatively affect driving performance and had minimal impact on a driver's ability to respond appropriately to an emergency event; however, the mental workload was higher when signs were triply colocated (Filtness et al., 2017). Further studies show vertical traffic signs are looked at infrequently (Costa et al., 2014). 
Since road surface markings are placed on the surface immediately in the driver's line of sight, they are more effective in influencing driver behavior, considering drivers fix their eyes mainly on the center of the road (Costa et al., 2014). Pavement markings can communicate information to road users like no other traffic control device. They provide constant messages to roadway users related to alignment, vehicle positioning, and other critical driving-related tasks (Carlson et al., 2009). Drivers principally focus on the center area of the road, and during various experiment conditions, all drivers' percent focusing on the center of the road exceeded 60\% (Yuan et al., 2011).

When implementing traffic control devices in a simulation study, a study determined that treatments positively affected driver behavior (Babić \& Brijs, 2021). This impact continued when implemented in the field, with results indicating pavement markings had positive effects on drivers' behaviors at signalized intersections. In particular, signs affected traffic volume on lane-changing behaviors in simulations, and the recommendation is to install signs $500 \mathrm{~m}$ upstream from the required changed condition (Hang et al., 2018). Additional studies show pavement markings affect drivers' behavior-particularly with respect to lateral position on a roadway. (Akbari \& Haghighi, 2020; Ariën et al., 2017; Daniels et al., 2010; Godley, 1999; Hussain et al., 2021; Van Driel et al., 2004).

\section{Simulation}

Microsimulation methods are used productively in the field of modeling vehicular flows on urban road networks. These methods provide the fundamental cornerstone for investigating traffic flow characteristics (Bandi \& George, 2020). For the 
average queue length estimated by various traffic microsimulation programs, VISSIM has closer simulation results to the actual situation (Sun et al., 2013). The primary benefit of VISSIM is that it achieves a high level of detail and flexibility in modeling roadway design, vehicle performance, and drivers' behavior. VISSIM uses a psychophysical car-following basis for longitudinal vehicle movement and a rule-based algorithm for lateral movement (Huang et al., 2013). Given the plethora of benefits of using VISSIM in the literature reviewed, this study performed the modeling within the VISSIM modeling package.

Large datasets of trajectory information are required to develop new lanechanging models and improve the accuracy of the current lane-changing models (Moridpour et al., 2010). Many studies use aggregate data, which do not describe individual drivers or vehicle behavior, due to difficulties obtaining more granular data (Hollander \& Liu, 2008). In the calibration process, parameters are adjusted so the model outputs are similar to observed data. Appropriate adaptation of the input data to generate results as close as possible to the field data is the first state of calibration (Karakikes et al., 2017).

Lane utilization, a macroscopic characteristic, helps reflect traffic capacity, discharge capacity, the degree of congestion, and the running state of vehicles. The definition of lane utilization is the number of vehicles on the lane divided by the number of vehicles on all lanes (Lv et al., 2013). The calibrated models are evaluated with a new set of field data under untried conditions, including the input volumes, traffic composition, and other required data (Siddharth \& Ramadurai, 2013). Furthermore, 
lane flow distribution (LFD) is an effective calibration and validation method for models

(Duret et al., 2012). 


\section{STUDY CORRIDOR}

The study segment of the State Street corridor is a four-lane, urban typical section with left-turn lanes at select locations. In 2020, the Indiana Department of Transportation (INDOT) performed traffic counts showing a 27,469 AADT; however, INDOT noted the counts were likely lower than usual because of the COVID-19 pandemic(Traffic Count Database System (TCDS), n.d.). There are two interstate ingress ramps along the corridor, two interstate egress ramps, seven signalized intersections, three unsignalized side streets, and 12 commercial entrances on the northbound side of the street and 15 commercial entrances along on the southbound side of the road.

Figure 13: Study Portion of State Street Corridor Aerial View

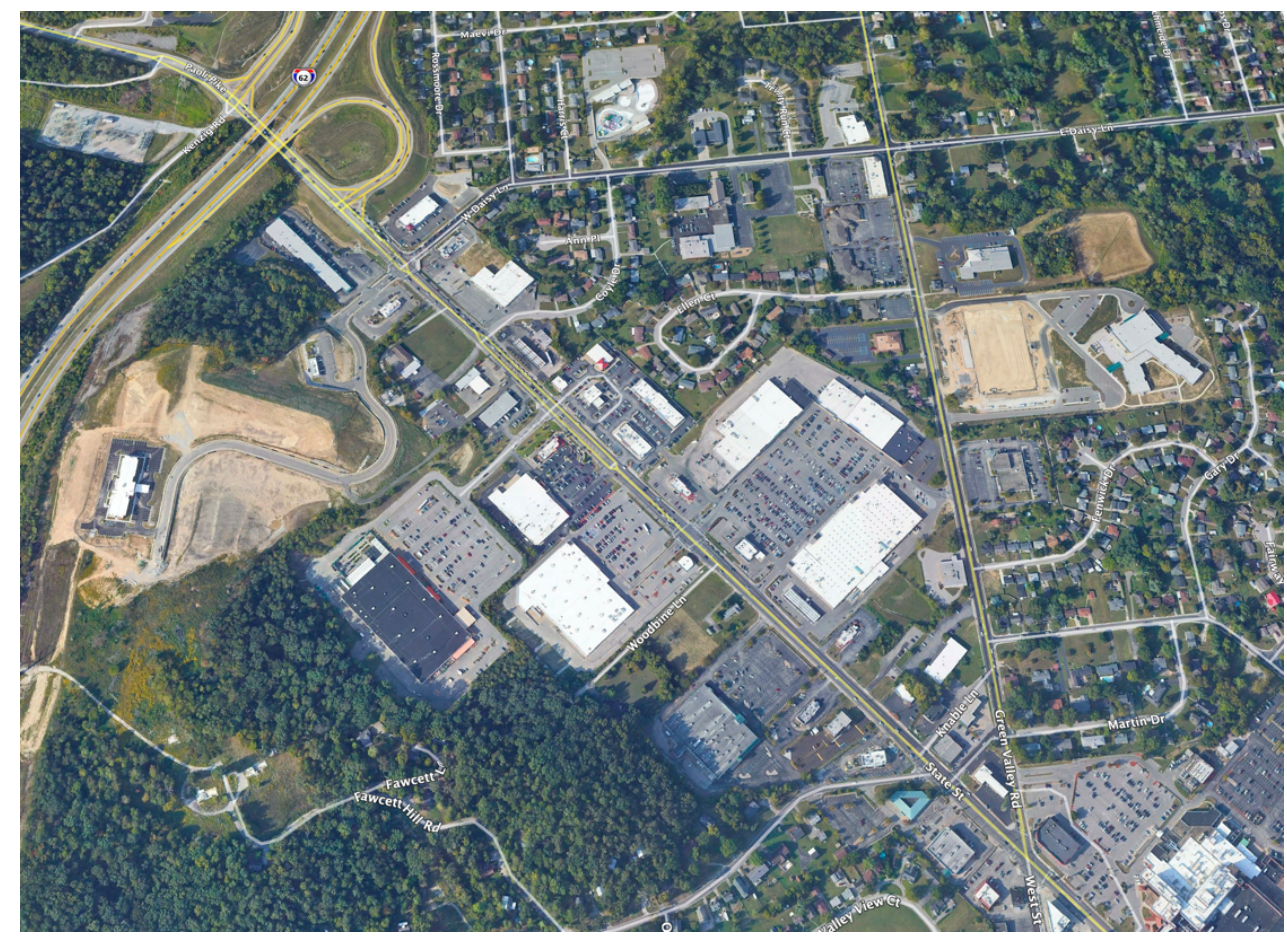


During lunch and PM peak hours, traffic moving in the northbound direction can queue 0.7 of the 0.8 -mile segment. The majority of northbound traffic attempts to establish position in the right lane to gain access to the interstate ramps, both on the right side of the street. The previously mentioned position-establishing creates a situation in which the left lane becomes a de facto passing lane rather than conveying traffic in conjunction with the right lane. Further exacerbating the queuing along the corridor, as northbound traffic attempts to access the westbound I-265 ramp, traffic queues along State Street, thereby severing traffic from the I-265 eastbound ramp. Given this condition, the City of New Albany has requested methods to improve traffic flow so the vibrant commercial corridor can further flourish. The simulation and the results of this study will focus on the northbound traffic since it is the condition causing the most concern for the City of New Albany.

Figure 14: State Street Aerial Showing Existing Queuing

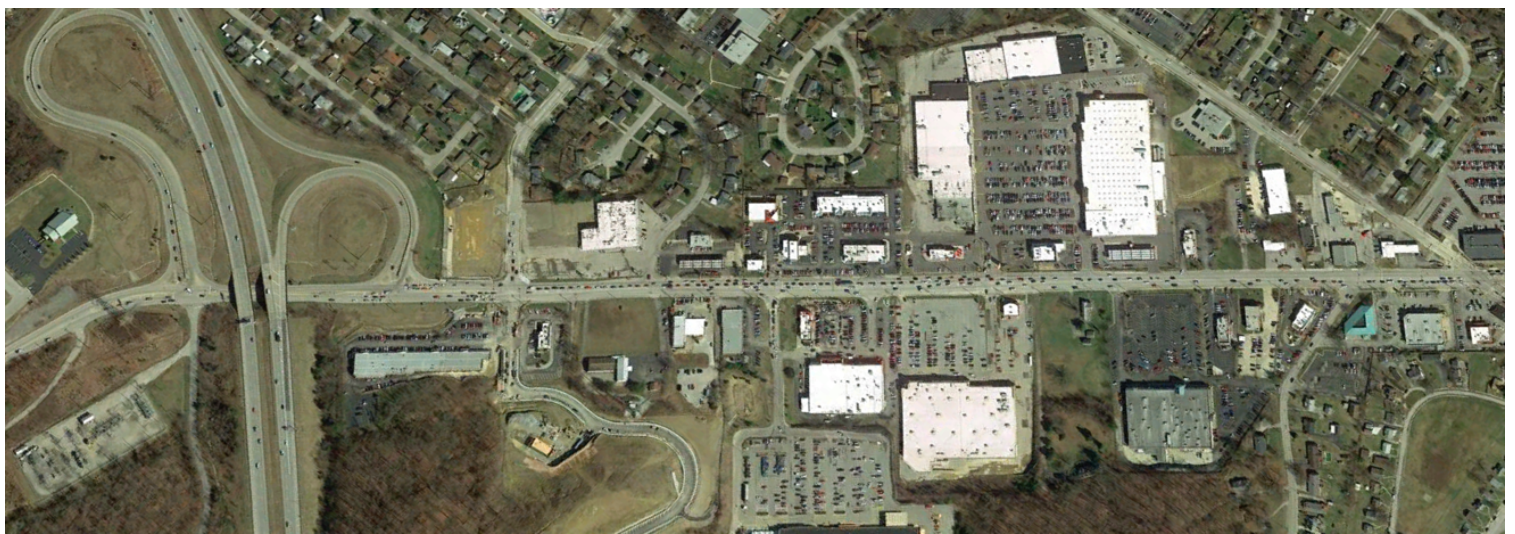

For the corridor, overhead sign locations, other than on signal strain wires, do not exist as is visible in Figures 3 and 4; therefore, this study reviewed previous research about co-location of road signs. The research established that co-location did not negatively affect driving performance and had minimal impact on a driver's ability to 
respond appropriately to an emergency event (Filtness et al., 2017). Further studies show vertical traffic signs are looked at infrequently (Costa et al., 2014).

Also apparent in Figures 3 and 4, the lane flow distribution for NB traffic along the State Street corridor is not evenly distributed among the lanes. This uneven distribution causes issues with queuing, longer travel times, and additional delay for the corridor, as reported by the City of New Albany.

Figure 15: Picture of State Street Corridor Looking North near the Kroger Entrance

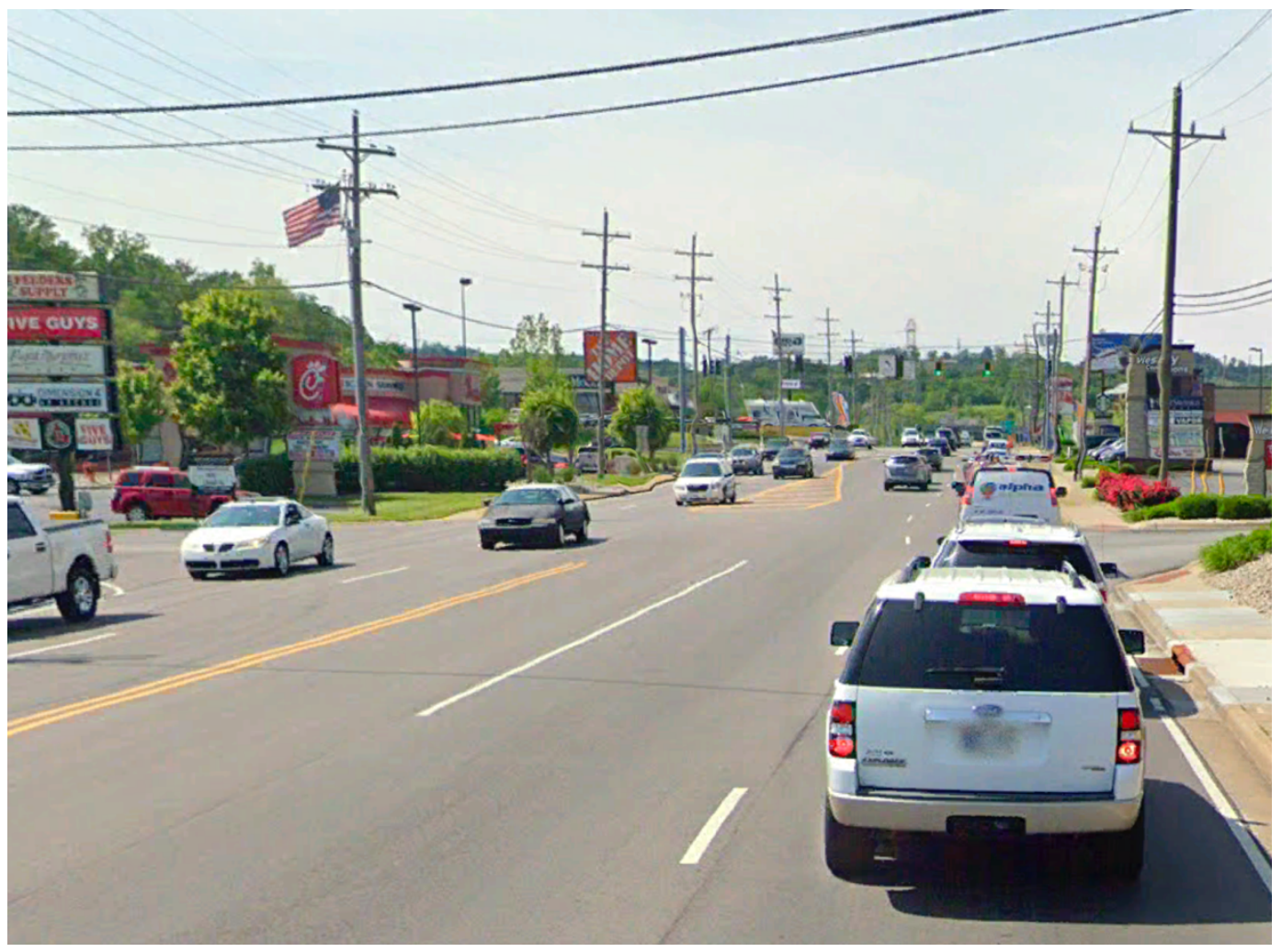


Figure 16: Picture of State Street Corridor Looking North near the Home Depot Entrance

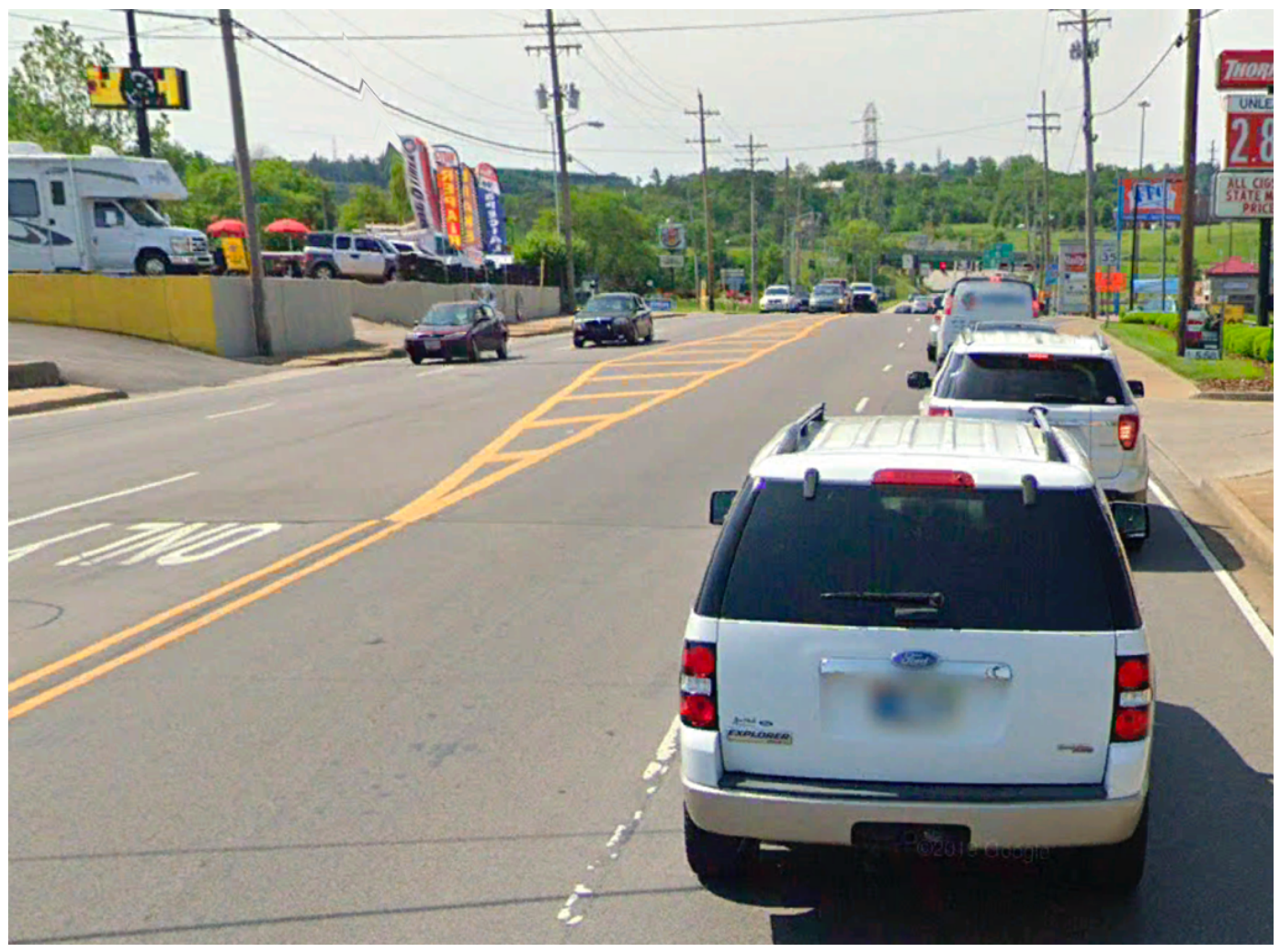




\section{METHODOLOGY}

\section{Model Development}

The State Street corridor was modeled in VISSIM using satellite imagery. The VISSIM model focused on simulating the seven signalized intersections because the origin-destination data provided traffic volumes and turning movements at each of the signalized intersections. One unsignalized intersection was also evaluated because data was available via a previous traffic study.

Field observations established the signal configuration for the simulation, and Google Street View provided confirmation. Priority rules, conflict areas, and speed decisions were all established based on field observations and applicable traffic laws; the model established reduced speed areas within turning movements to more accurately depict speed reductions that would occur during turns. The data as mentioned above established the signalized corridor within VISSIM, which matched the actual signalized corridor based on field observations. 
Figure 17: VISSIM Model of the State Street Corridor

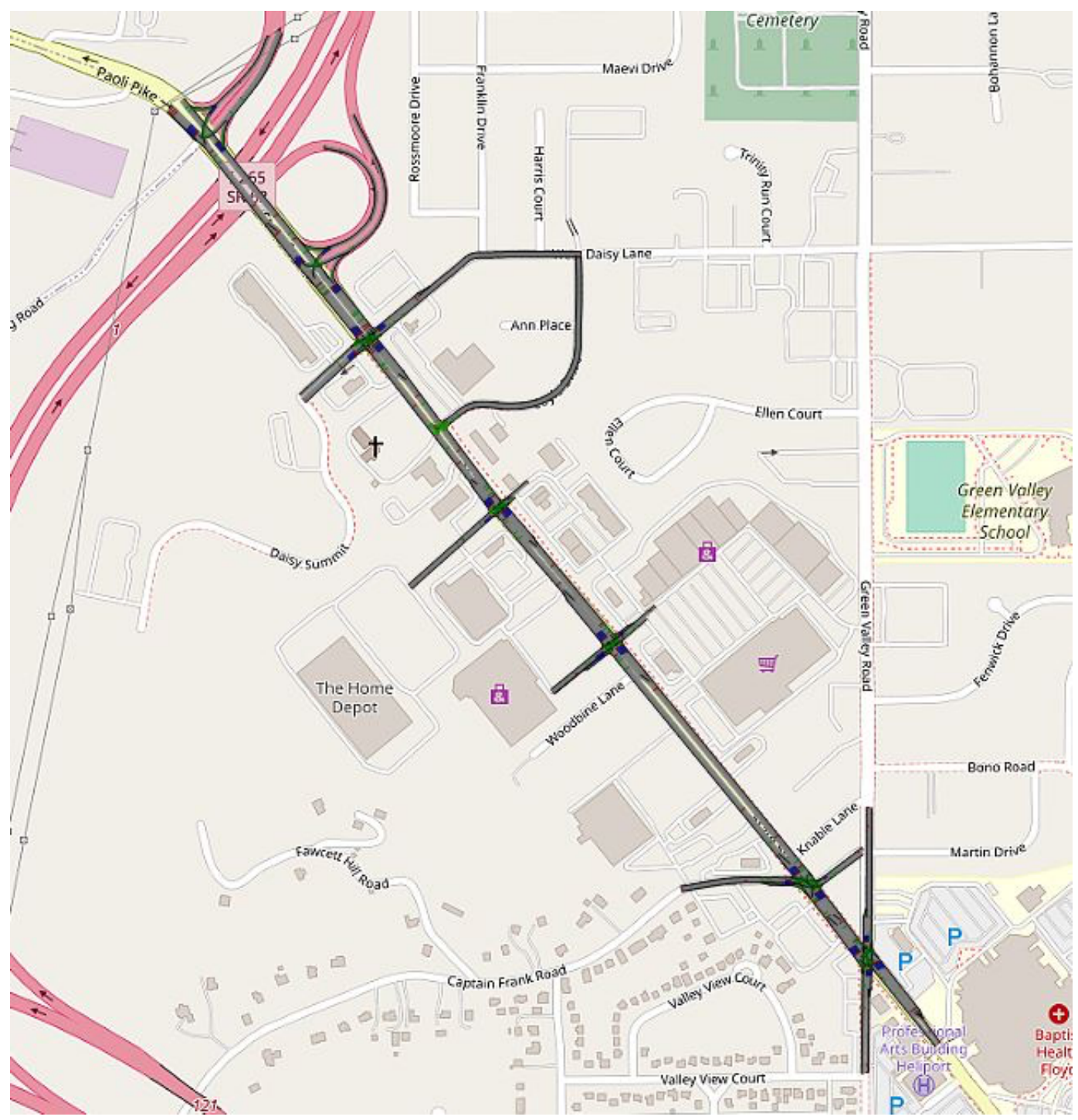

The onus of this study was to determine the effects of lane flow distribution in the NB lanes of State Street with the ultimate goal of reducing travel time, delay, and queue lengths for NB traffic. Given the proximity of the interstate ramps to the intersection at Daisy Lane, the study focuses on the effects of queuing and vehicle distribution of NB traffic near the Daisy Lane intersection.

The model for the State Street corridor had queue counters for the NB and SB directions for the intersection of State Street and Daisy Lane, which can be seen directly 
behind the stop bars in Figure 6. The queue counter for the NB traffic was to determine the difference in the queue in the current condition and the projected condition; however, the counters in the SB direction were primarily used as a control

Figure 18: State and Daisy Intersection

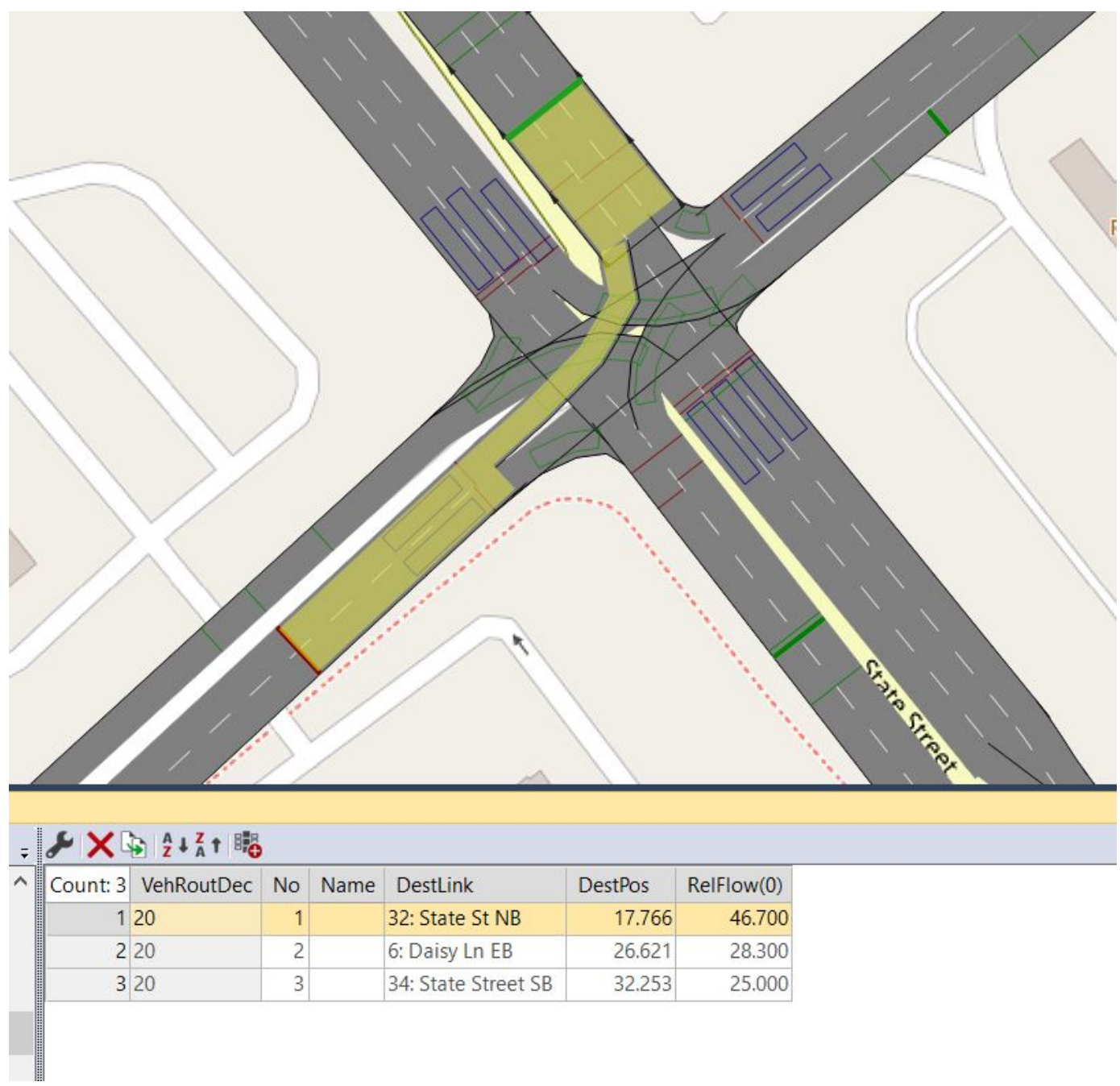

Vehicle travel time collection points were placed in the NB and SB direction at matching locations south of the Daisy Lane intersection and north of the Captain Frank intersection, and the distance was confirmed to be the same in each direction for comparison purposes. The travel time collection points north of the Captain Frank intersection are shown in the red rectangle in Figure 7. The vehicle travel times for the 
NB traffic were to determine the difference in travel times in the current condition and the projected condition; however, the travel times in the SB direction were primarily used as a control and model validation. The travel time measurement points were used to establish delay within the corridor as well. Also shown in Figure 7 is the signal detection as denoted within a fuchsia rectangle and one set of traffic volume inputs denoted within the orange rectangle.

Figure 19: State Street and Captain Frank Intersection

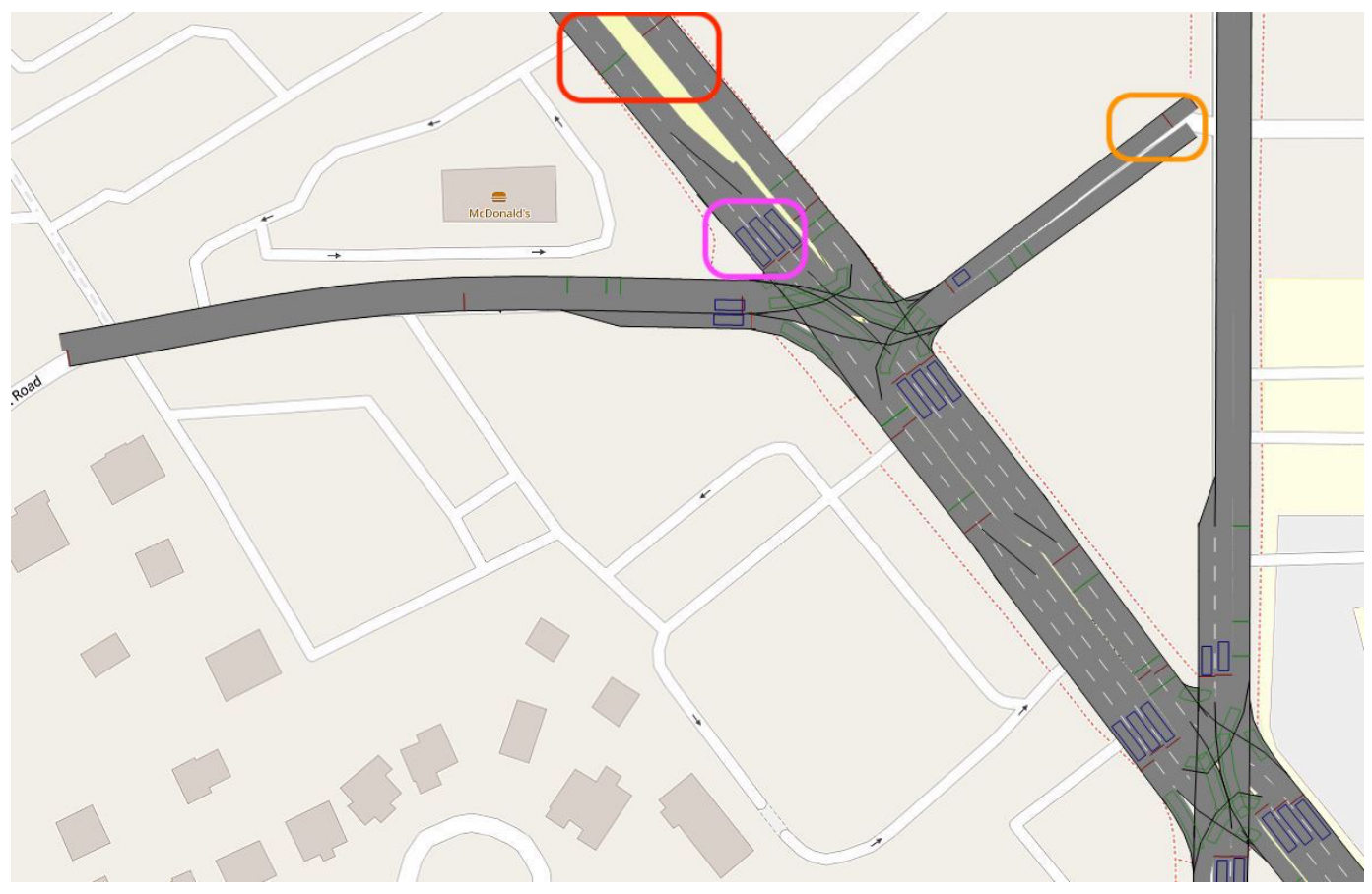

Data collection points were placed in each of the NB lanes near the intersection at Coyle Drive, used to determine the number of vehicles in each lane. This data was used to determine the lane flow distribution in the current and projected model simulations. 


\section{Model Calibration}

The City of New Albany provided signal timings for the five signalized

intersections within their jurisdiction, and INDOT provided signal timings for the two signalized intersections at the interstate ramps, which can be found in Appendix $\mathrm{E}$ :

Traffic Signal Timings. These signal timings were used to create the signal controllers for each signalized intersection within the model. See Figure 8 for an example of a signal controller input within VISSIM.

Figure 20: State Street and Daisy Lane VISSIM Signal Controller Inputs

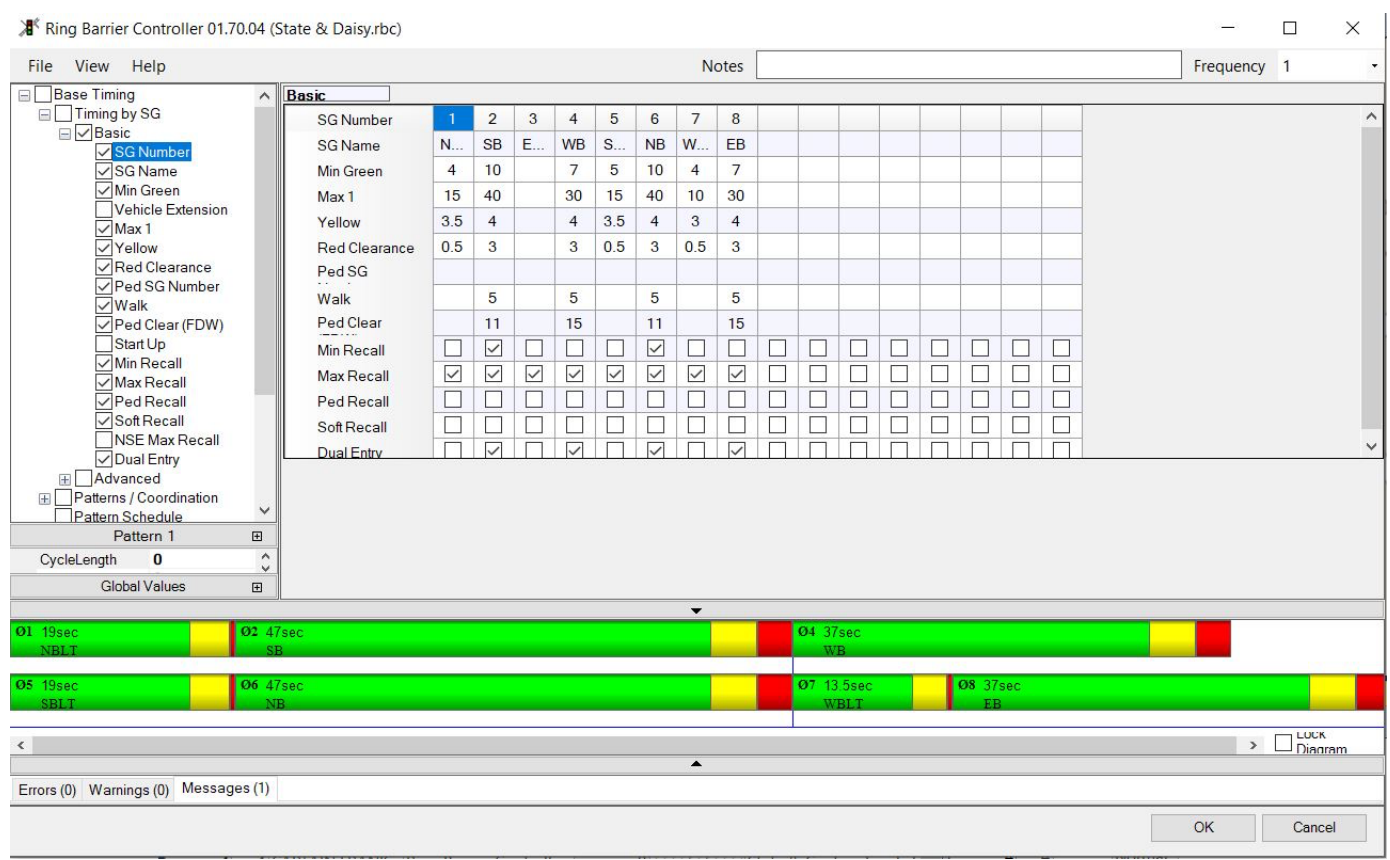

To establish the baseline traffic counts and turning movements for the State

Street corridor, the author contacted the Kentuckiana Regional Planning and

Development Agency (KIPDA). KIPDA staff provided AADT and turning movements along the State Street corridor from 2019 to allow for pre-COVID-19 traffic volumes for the simulation, from a cellphone-based on-demand traffic pattern information service, 
Streetlight. The provided data was from the average daily origin-destination volumes for multiple days and times; however, for this study, the focus was on Tuesday through Thursday to produce the most accurate representation of a typical weekday volume. This data was further filtered to volumes from a four-hour peak window of 3 PM to 7 PM, which was the highest resolution the service could provide. Subsequently, the peak hour volume was calculated from the four-hour peak volumes and compared against an existing traffic study for the corridor to determine the accuracy of the data.

For each signalized intersection, the turning movement was established with vehicle routing that ensured the appropriate proportion of traffic was turning in each direction; this can be seen in Figure 6, shown with the yellow routing for the left-turn movement from Daisy Summit onto State St. When the traffic counts and turning movements were entered into the VISSIM model with the existing signal timings for the corridor, it was not easy to achieve the existing condition because the simulation assumed the driving behavior was logical. Since much of the traffic along the corridor tends to establish position in the right lane, and the left lane becomes a de facto overtaking lane, the left lane was implemented as an overtaking lane to achieve the lane flow distribution in the model that exists along the corridor. Upon implementing this feature, the model consistently produced queues and a lane flow distribution, as seen in the field. 
Figure 21: Current Model Showing Existing Queuing

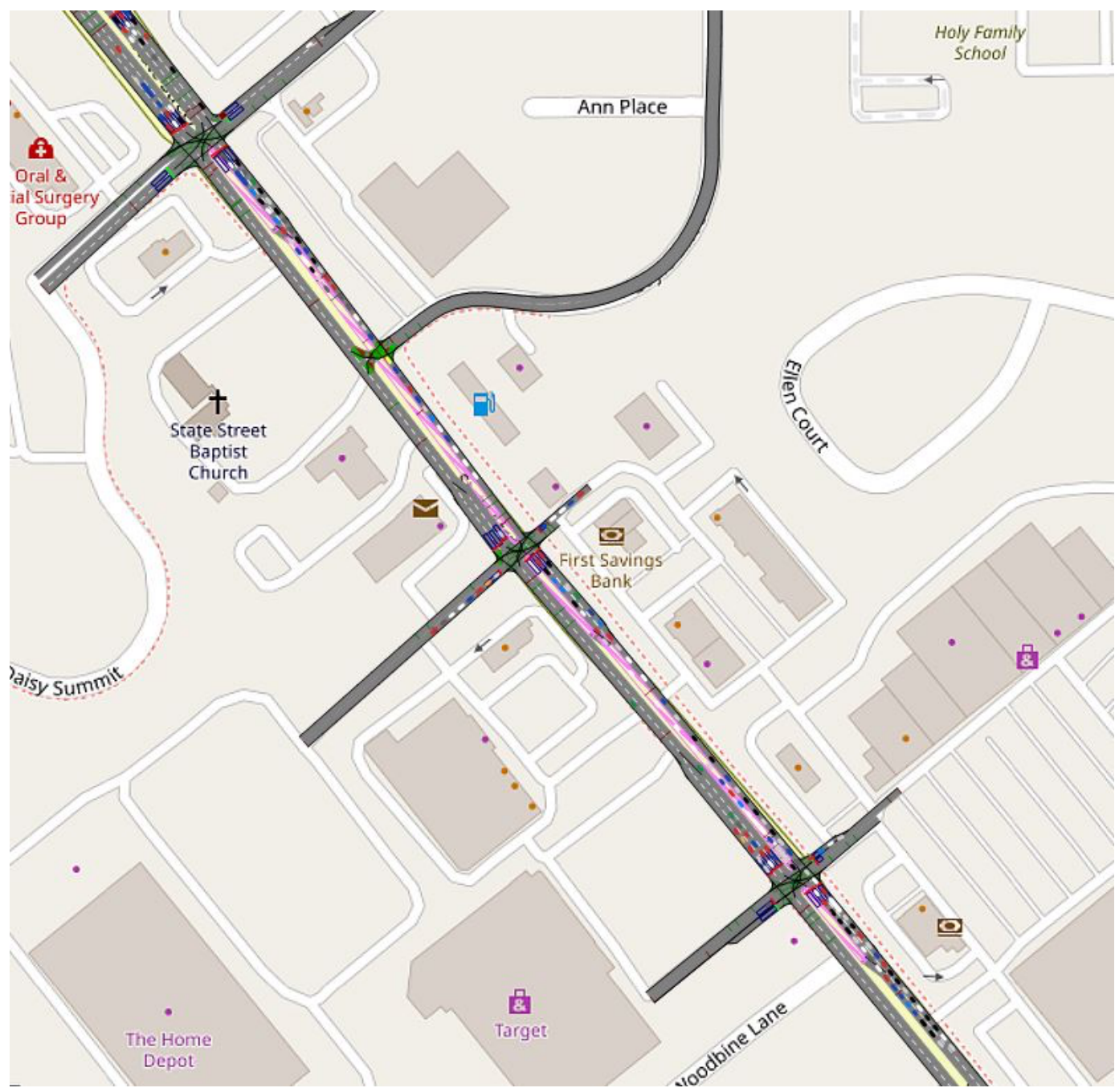

The version of the VISSIM simulation without implementing the overtaking lane showed the corridor had adequate capacity to convey the number of vehicles currently using the street. As such, it was used to show the projected lane flow distribution. If the signs and route markers achieve the desired effect, queues, travel times, and delays will be reduced in a statistically significant manner. Furthermore, the lane flow distribution will nearly equalize, which better utilizes the lanes that are present. 
Figure 22: Proposed Model Showing Projected Queuing

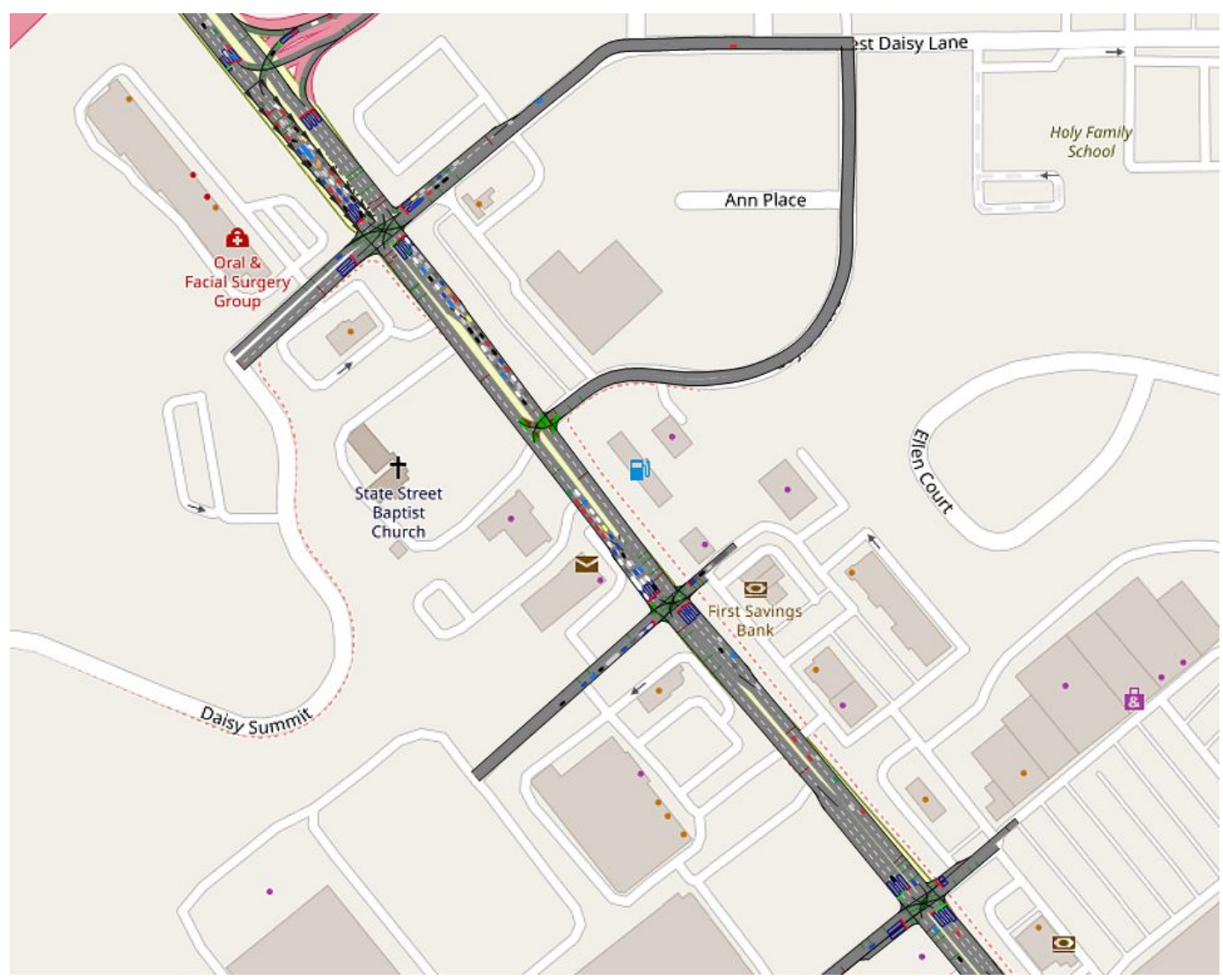

\section{Current and Projected Condition Analysis}

Each simulation began with an initial 10-minute warm-up period and then began gathering data for 60-minutes on queue lengths, travel time, delay, and vehicle counts in each northbound lane, which helped determine the lane flow distribution. The simulation ran through 70 iterations of the existing condition and 70 iterations of the projected corridor after the modifications in signage and new route markers. The primary difference between the two simulation scenarios is that the current simulation uses the left lane on State Street primarily as a passing lane rather than regular traffic conveyance. The projected model uses the VISSIM's standard lane distribution procedures to allocate vehicles among the existing lanes. 
For each parameter of the analysis, a comparative histogram was developed to show the distribution of outputs. This comparative histogram provided the opportunity to determine if each data set was normally distributed or skewed in any meaningful manner. Furthermore, it allows for comparing the current and projected data distribution on the same graph, which produces an easy method of viewing the effect the modifications had on the simulation outcomes.

This study utilizes ANOVA methods for data analysis of current and projected conditions and the differences thereof. The probability of obtaining the observed results of a particular test is the probability value ( $p$-value). For this study, assuming the null hypothesis $\left(\mathrm{H}_{0}\right)$ that there is no difference between the current and projected condition is correct, the p-value means the probability that the test statistic equals the observed value predicted by the alternative hypothesis $\left(H_{1}\right)$ that there is a difference between the current and projected condition. An option for rejecting $\mathrm{H}_{0}$ is using the $\mathrm{p}$-value for comparing the results with the significance level; the significance level is the probability of rejecting the null hypothesis when it is true. In this study, an $\alpha$ of 0.05 is used and implies a $5 \%$ danger of inferring a difference exists while there is no statistical difference. Therefore, a $p$-value less than the $\alpha$ implies evidence to support $\mathrm{H}_{1}$, and the result is statistically significant (Alassaf \& Qamar, 2021; Wasserstein \& Lazar, 2016).

A one-way ANOVA uses a feature selection (FS) filter to measure the impact of a feature on a target class. One-way ANOVA calculates a score for all features as a univariate method and then selects the highest scores (Elssied et al., 2014). If a difference between groups based on variance exists, a feature affects the target group, 
which is the average of the squared differences from the mean. This condition leads to rejecting $\mathrm{H}_{0}$, which states that all means of groups are equivalent, and accepting $\mathrm{H}_{1}$. Determining pertinent features using ANOVA requires deciding the threshold at which each feature is evaluated individually in correlation with the groups.

As a result of the ANOVA, each feature will have an F-value and a p-value to help determine statistical significance. An F-value higher than the F-critical value means a feature that impacts the group and will be considered relevant. Furthermore, a p-value lower than the initial $\alpha-0.05$ for this study - will be recognized as statistically significant. Previous studies have used the $p$-value to determine the critical features of the target classes (Arowolo et al., 2016; Elssied et al., 2014). 


\section{RESULTS}

Queue Lengths

Each simulation began with an initial 10-minute warm-up period and then began gathering data for 60-minutes on queue lengths, travel time, delay, and vehicle counts in each northbound lane, which helped determine the lane flow distribution. The simulation ran through 70 iterations of the existing condition and 70 iterations of the projected corridor after the modifications in signage and new route markers.

The model outputs for NB average queue lengths (meters) from the current condition and the projected condition are available in Appendix A: Queue Data. Figure 11 displays the frequency of the average queue length (meters) in a comparative histogram. An ANOVA single factor test was used to determine the statistical significance of the changes; see Table 1 for the analysis results. The $\mathrm{H}_{0}$ for this test was there was no difference between the current and projected condition, and the $\mathrm{H}_{1}$ that there is a difference between the current and projected condition; an $\alpha$ of 0.05 is used. The F-critical for all criteria was approximately 3.9, and the F-value between the groups for this measure was over 949.9. In conjunction with a p-value of approximately 9.69E64 , this result showed the modifications produced a statistically significant change to the NB direction with an average queue length reduction of 88 percent. 
Figure 23: Comparative Histogram of Current \& Projected NB Average Queue Length (m)

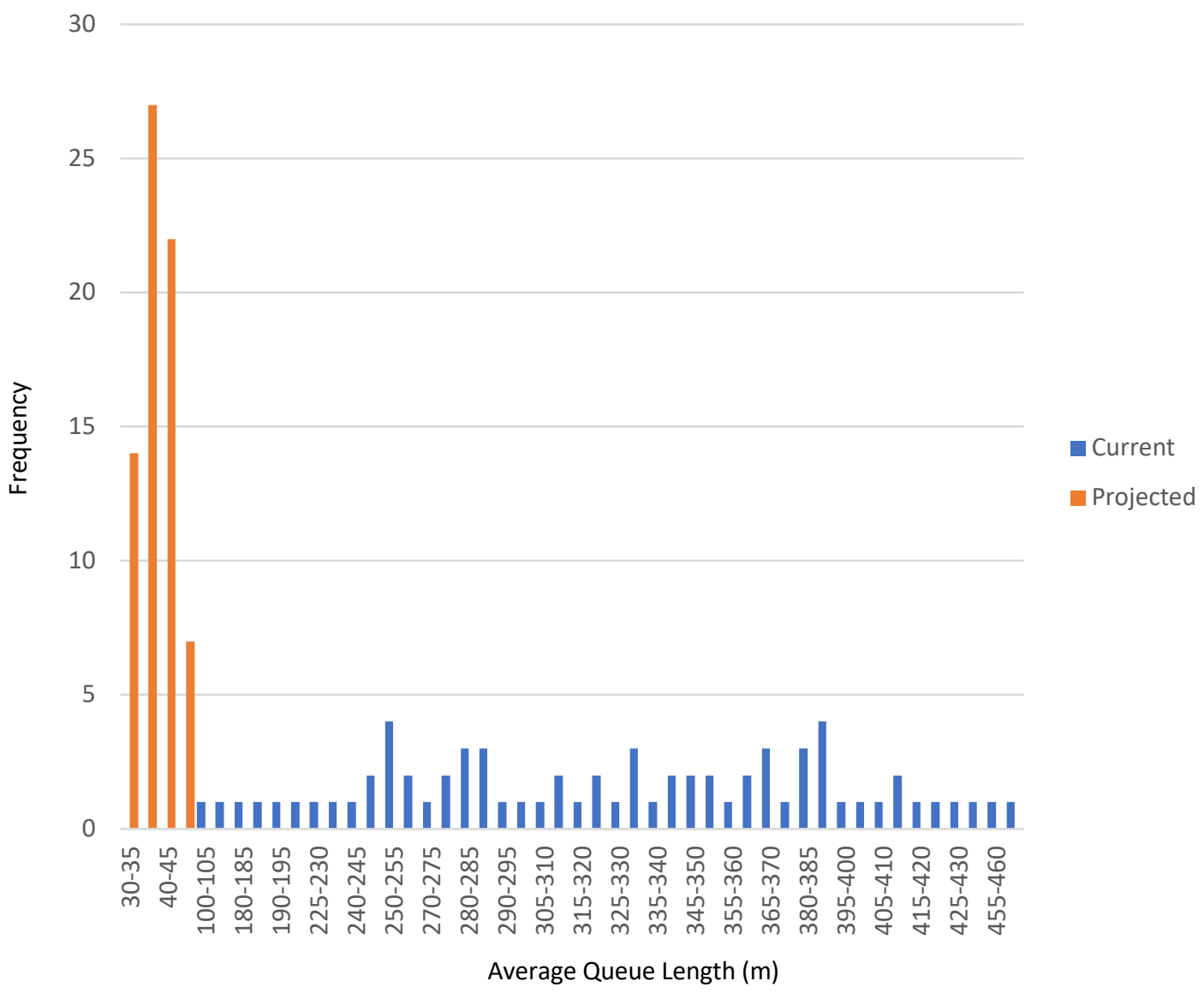

Table 1: ANova Single Factor NB Queue Length Average (m)

\begin{tabular}{lrrrr}
\multicolumn{1}{c}{ Groups } & Count & Sum & Average & Variance \\
\hline Current NB Queue Length & 70 & 22439.02 & 320.56 & 5822.94 \\
$\begin{array}{l}\text { Average }(\mathrm{m}) \\
\begin{array}{l}\text { Projected NB Queue Length } \\
\text { Average }(\mathrm{m})\end{array}\end{array}$ & 70 & 2730.63 & 39.01 & 18.38 \\
\hline
\end{tabular}

\begin{tabular}{|c|c|c|c|c|c|c|}
\hline Source of Variation & SS & $d f$ & MS & $F$ & P-value & F crit \\
\hline Between Groups & 2774433.11 & 1 & 2774433.12 & 949.93 & $9.69 \mathrm{E}-64$ & 3.91 \\
\hline Within Groups & 403051.25 & 138 & 2920.66 & & & \\
\hline Total & 3177484.37 & 139 & & & & \\
\hline
\end{tabular}


The model output distributions for the SB queue lengths (meters) from the current condition and the projected condition are shown in Figure 12. The SB queue length outputs were compared using an ANOVA single factor test to determine the statistical significance of the changes; see Table 2 for the analysis results. The $\mathrm{H}_{0}$ for this test was there was no difference between the current and projected condition, and the $\mathrm{H}_{1}$ that there is a difference between the current and projected condition; an $\alpha$ of 0.05 is used. The F-critical was approximately 3.9, and the F-value between the groups was approximately 0.18 . In conjunction with the $p$-value of approximately 0.67 , this result showed that the modifications did not produce a statistically significant change for the SB direction.

Figure 24: Comparative Histogram of Current \& Projected SB Average Queue Length (m) 45

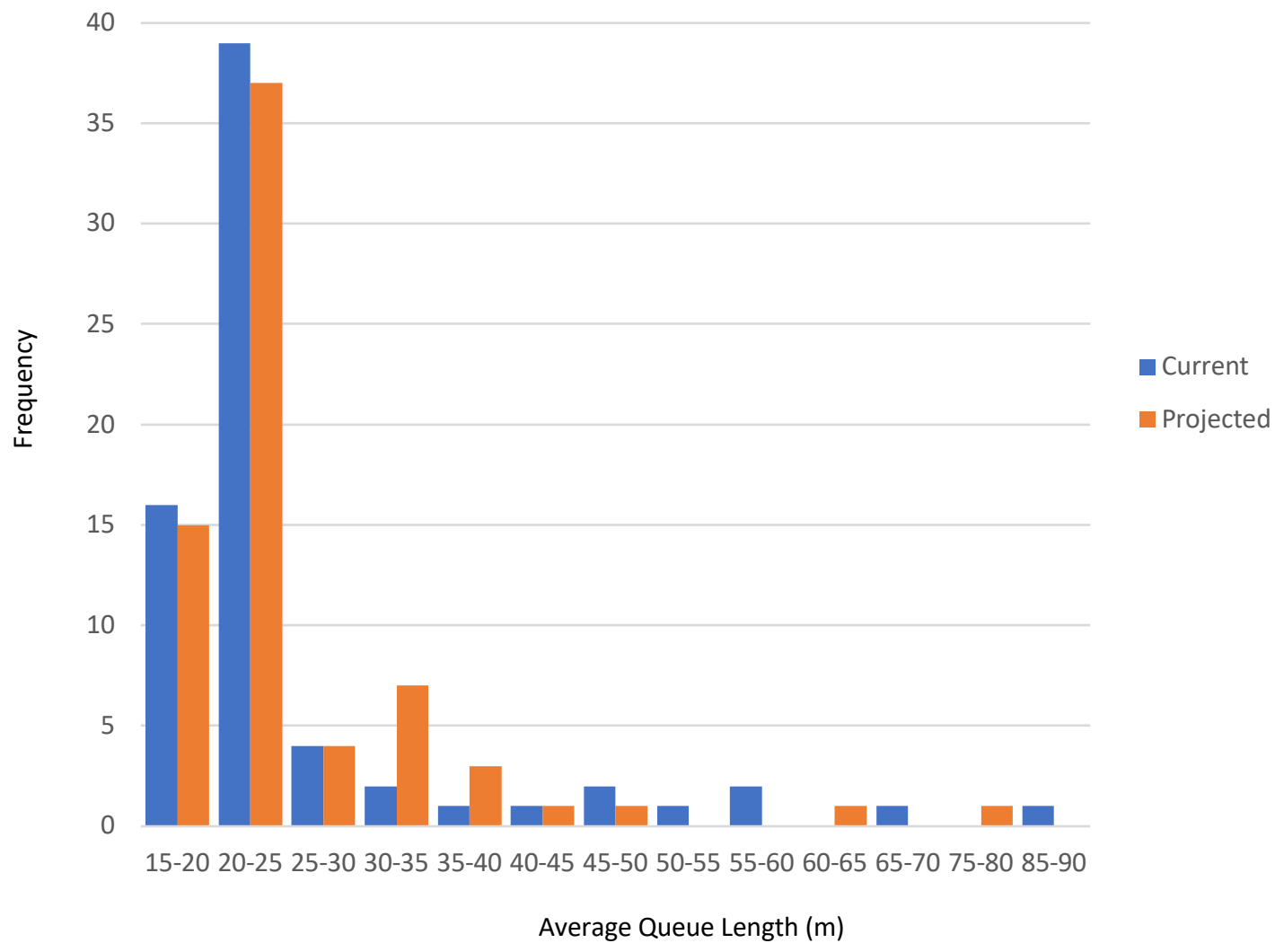




\section{Table 2: ANOVA Single Factor SB Queue Length Average (m)}

\begin{tabular}{|c|c|c|c|c|c|c|}
\hline \multirow{2}{*}{\multicolumn{7}{|c|}{$\begin{array}{c}\text { Groups } \\
\text { Current SB Queue Length }\end{array}$}} \\
\hline & & & & & & \\
\hline Average (m) & 70 & 1815.89 & 25.94 & 160.67 & & \\
\hline \multicolumn{7}{|c|}{ Projected SB Queue Length } \\
\hline Average $(\mathrm{m})$ & 70 & 1759.02 & 25.13 & 94.56 & & \\
\hline \multicolumn{7}{|l|}{ ANOVA } \\
\hline Source of Variation & SS & $d f$ & MS & $F$ & P-value & F crit \\
\hline Between Groups & 23.10 & 1 & 23.10 & 0.18 & 0.67 & 3.91 \\
\hline Within Groups & 17611.27 & 138 & 127.62 & & & \\
\hline Total & 17634.37 & 139 & & & & \\
\hline
\end{tabular}

Furthermore, the maximum queue lengths were reduced by 65 percent, and the average number of queue stops was reduced by 71 percent. Both measures were tested with a single factor ANOVA and shown to be statistically significant. See Tables 3 and 4 for the results of the ANOVA.

Table 3: ANOVA Single Factor NB Maximum Queue Lengths (m)

\begin{tabular}{lcccr}
\multicolumn{1}{c}{ Groups } & Count & Sum & Average & Variance \\
\hline Current NB Queue Length & 70 & 35435.57 & 506.22 & 28.71 \\
$\begin{array}{l}\text { Maximum }(\mathrm{m}) \\
\text { Projected NB Queue Length }\end{array}$ & 70 & 12384.15 & 176.92 & 453.91 \\
Maximum $(\mathrm{m})$ & & & \\
\hline
\end{tabular}

\begin{tabular}{lrrrrrr}
\multicolumn{1}{l}{ ANOVA } & \multicolumn{1}{c}{ SS } & \multicolumn{1}{c}{ df } & \multicolumn{1}{c}{ MS } & \multicolumn{1}{c}{ F } & P-value & F crit \\
\hline \multicolumn{1}{c}{ Source of Variation } & 3795485.46 & 1 & 3795485.46 & 15728.74 & $4.48 \mathrm{E}-144$ & 3.91 \\
Between Groups & 33300.63 & 138 & 241.31 & & & \\
Within Groups & & & & & & \\
& & & & & & \\
Total & 3828786.08 & 139 & &
\end{tabular}


Table 4: ANOVA Single Factor NB Queue Stops

\begin{tabular}{|c|c|c|c|c|c|c|}
\hline Groups & Count & Sum & Average & Variance & & \\
\hline Current NB Queue Stops & 70 & 185475 & 2649.64 & 355668.29 & & \\
\hline Projected NB Queue Stops & 70 & 54468 & 778.11 & 3737.35 & & \\
\hline \multicolumn{7}{|l|}{ ANOVA } \\
\hline Source of Variation & SS & $d f$ & MS & $F$ & P-value & F crit \\
\hline Between Groups & 122591671.8 & 1 & 122591671.8 & 682.19 & $2.90 \mathrm{E}-55$ & 3.91 \\
\hline Within Groups & 24798989.16 & 138 & 179702.82 & & & \\
\hline Total & 147390660.9 & 139 & & & & \\
\hline
\end{tabular}

Travel Time

The VISSIM model for the State Street corridor measured travel time for NB and SB traffic with equal distances. The model outputs for the NB travel times (seconds) from the current condition and the projected condition can be found in Appendix B:

Travel Time Data. Figure 13 compares the average travel time (seconds) for both conditions in a comparative histogram. An ANOVA single factor test was used to determine the statistical significance of the changes; see Table 5 for the analysis results. The $\mathrm{H}_{0}$ for this test was there was no difference between the current and projected condition, and the $\mathrm{H}_{1}$ that there is a difference between the current and projected condition; an $\alpha$ of 0.05 is used. Since the F-critical for all criteria is 3.9 and the F-value between the groups for travel time was over 373.3, in conjunction with a p-value of approximately $4.48 \mathrm{E}-41$, this result showed the modifications produced a statistically significant change to the NB direction with an average travel time reduction of approximately 56 percent. 
Figure 25: Comparative Histogram of Current \& Projected NB Average Travel Time (s)

$$
30
$$
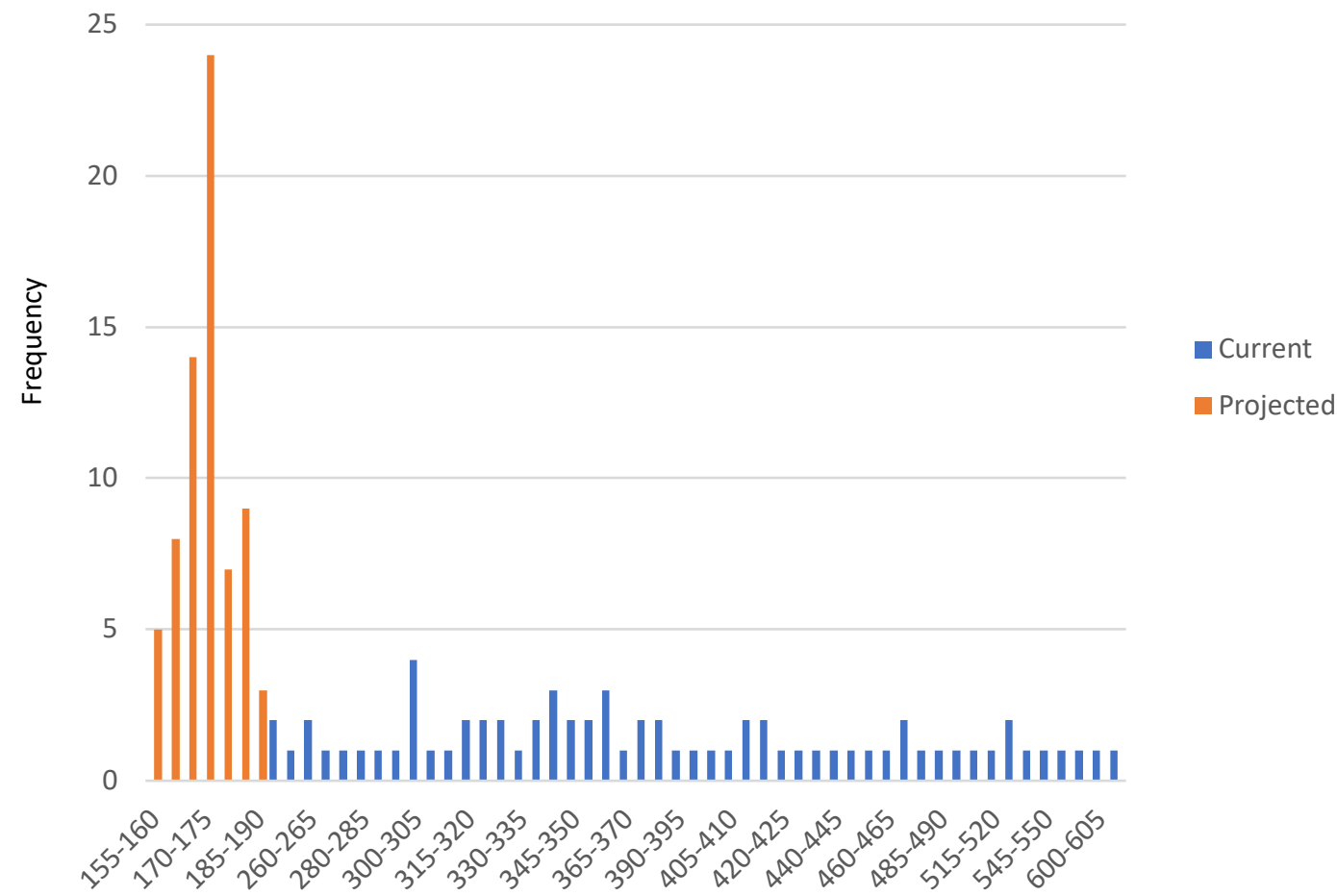

Average Travel Time (s)

\section{Table 5: ANOVA Single Factor NB Travel Time (s)}

SUMMARY

\begin{tabular}{lrrrr}
\hline \multicolumn{1}{c}{ Groups } & Count & \multicolumn{1}{c}{ Sum } & Average & \multicolumn{1}{c}{ Variance } \\
\hline Current NB Travel Time (s) & 70 & 27262.96 & 389.47 & 8864.72 \\
Projected NB Travel Time (s) & 70 & 11996.94 & 171.38 & 53.81 \\
\hline
\end{tabular}

ANOVA

\begin{tabular}{lrrrrrr}
\hline \multicolumn{1}{c}{ Source of Variation } & \multicolumn{1}{c}{ SS } & $d f$ & \multicolumn{1}{c}{ MS } & \multicolumn{1}{c}{ F } & P-value & F crit \\
\hline Between Groups & 1664652.62 & 1 & 1664652.62 & 373.30 & $4.48 \mathrm{E}-41$ & 3.91 \\
Within Groups & 615378.95 & 138 & 4459.27 & & & \\
& & & & & & \\
Total & 2280031.57 & 139 & & & \\
\hline
\end{tabular}


The model output distributions for the SB travel times (seconds) from the current condition and the projected condition are shown in Figure 14. The SB travel time outputs were compared using an ANOVA single factor test to determine the statistical significance of the changes; see Table 6 for the analysis results. The $\mathrm{H}_{0}$ for this test was there was no difference between the current and projected condition, and the $\mathrm{H}_{1}$ that there is a difference between the current and projected condition; an $\alpha$ of 0.05 is used. The F-critical was approximately 3.9, and the F-value between the groups was approximately 0.02 . In conjunction with the $p$-value of approximately 0.90 , this result showed that the modifications did not produce a statistically significant change for the SB direction.

Figure 26: Comparative Histogram of Current \& Projected SB Average Travel Time (s)

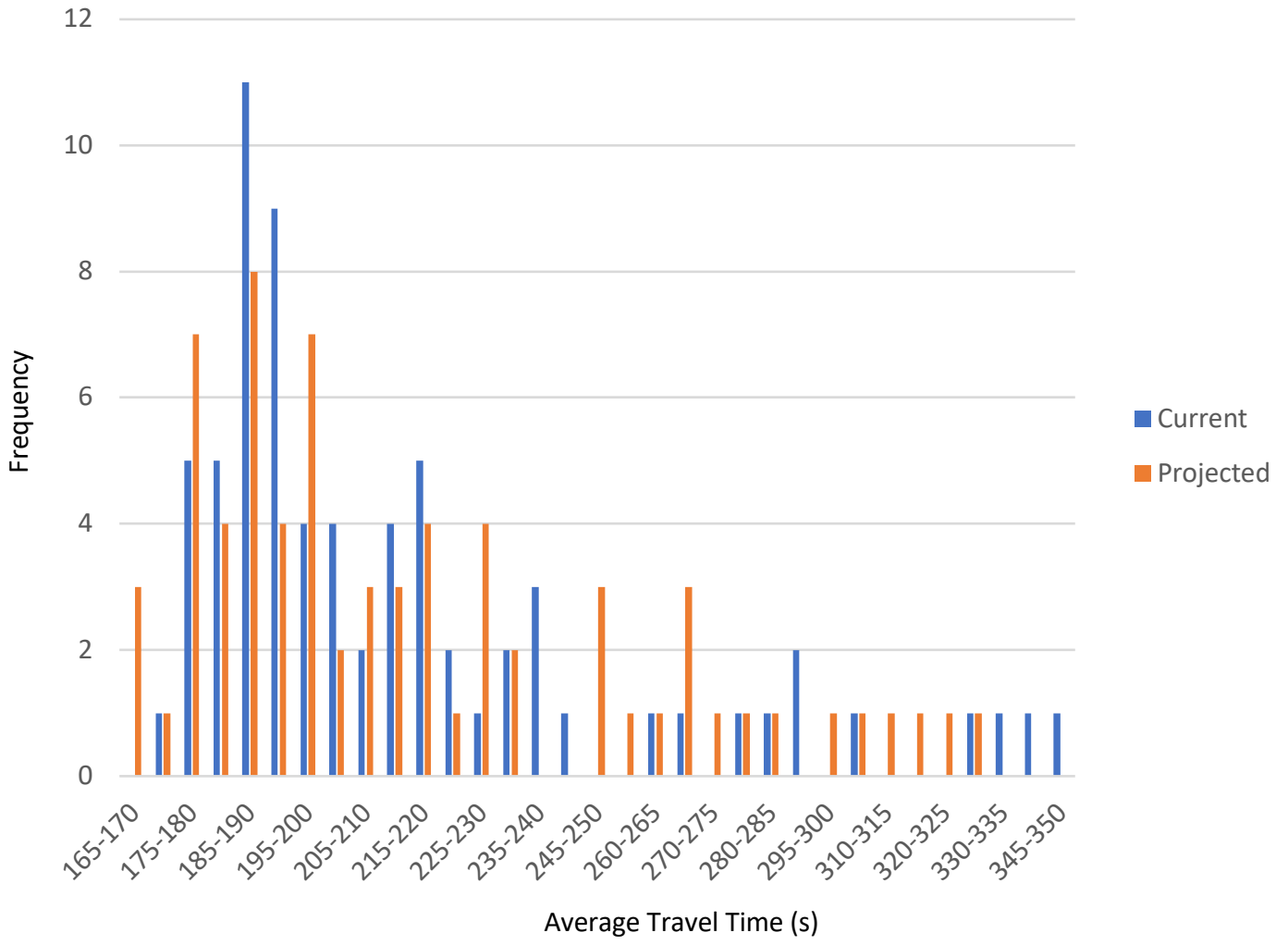


Table 6: ANOVA Single Factor SB Travel Time (s)

\begin{tabular}{|c|c|c|c|c|c|c|}
\hline Groups & Count & Sum & Average & Variance & & \\
\hline Current SB Travel Time (s) & 70 & 15139.47 & 216.28 & 1776.78 & & \\
\hline Projected SB Travel Time (s) & 70 & 15201.73 & 217.17 & 1746.90 & & \\
\hline \multicolumn{7}{|l|}{ ANOVA } \\
\hline Source of Variation & SS & $d f$ & MS & $F$ & P-value & F crit \\
\hline Between Groups & 27.69 & 1 & 27.69 & 0.016 & 0.90 & 3.91 \\
\hline Within Groups & 243133.53 & 138 & 1761.84 & & & \\
\hline Total & 243161.22 & 139 & & & & \\
\hline
\end{tabular}

Delay

The VISSIM model for the State Street corridor measured stop delay for NB and SB traffic. The model outputs for the NB stop delay (seconds) from the current condition and the projected condition can be viewed in Appendix C: Delay Data. Figure 15 compares the average stop delay (seconds) for both conditions in a comparative histogram. An ANOVA single factor test was used to determine the statistical significance of the changes; see Table 7 for the analysis results. The $H_{0}$ for this test was there was no difference between the current and projected condition, and the $\mathrm{H}_{1}$ that there is a difference between the current and projected condition; an $\alpha$ of 0.05 is used. Since the F-critical for all criteria is 3.9, and the F-value between the groups for stop delay was over 364.6 , in conjunction with a p-value of approximately $1.47 \mathrm{E}-40$, it showed the modifications produced a statistically significant change to the NB direction with an average stop delay reduction of approximately 64 percent. 
Figure 27: Comparative Histogram of Current \& Projected NB Average Delay (s) 30

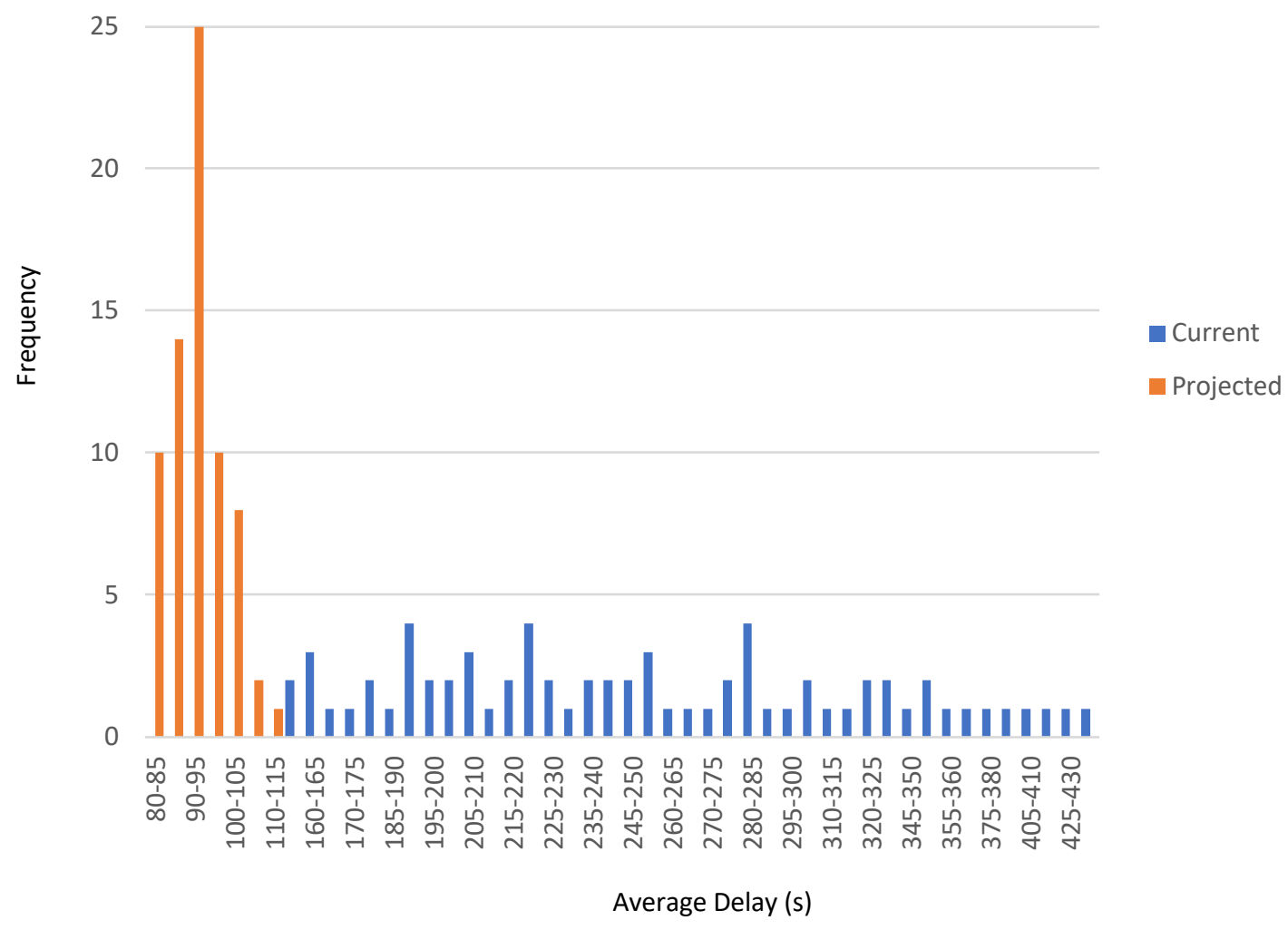

Table 7: ANOVA Single Factor NB Delay (s)

\begin{tabular}{|c|c|c|c|c|c|c|}
\hline Groups & Count & Sum & Average & Variance & & \\
\hline Current NB Stop Delay (s) & 70 & 18174.64 & 259.64 & 5318.24 & & \\
\hline Projected NB Stop Delay (s) & 70 & 6475.81 & 92.51 & 44.24 & & \\
\hline \multicolumn{7}{|l|}{ ANOVA } \\
\hline Source of Variation & SS & $d f$ & MS & $F$ & P-value & F crit \\
\hline Between Groups & 977590.17 & 1 & 977590.17 & 364.60 & 1.47E-40 & 3.91 \\
\hline Within Groups & 370010.88 & 138 & 2681.24 & & & \\
\hline Total & 1347601.05 & 139 & & & & \\
\hline
\end{tabular}

The model outputs for SB stop delay (seconds) from the current condition and the projected condition with the distribution shown in Figure 16. The SB delay outputs 
were compared using an ANOVA single factor test to determine the statistical significance of the changes; see Table 8 for the analysis results. The $\mathrm{H}_{0}$ for this test was there was no difference between the current and projected condition, and the $\mathrm{H}_{1}$ that there is a difference between the current and projected condition; an $\alpha$ of 0.05 is used. The F-critical was approximately 3.9, and the F-value between the groups was approximately 0.05 . In conjunction with the $p$-value of approximately 0.82 , this result showed that the modifications did not produce a statistically significant change for the SB direction.

Figure 28: Comparative Histogram of Current \& Projected SB Average Delay (s)

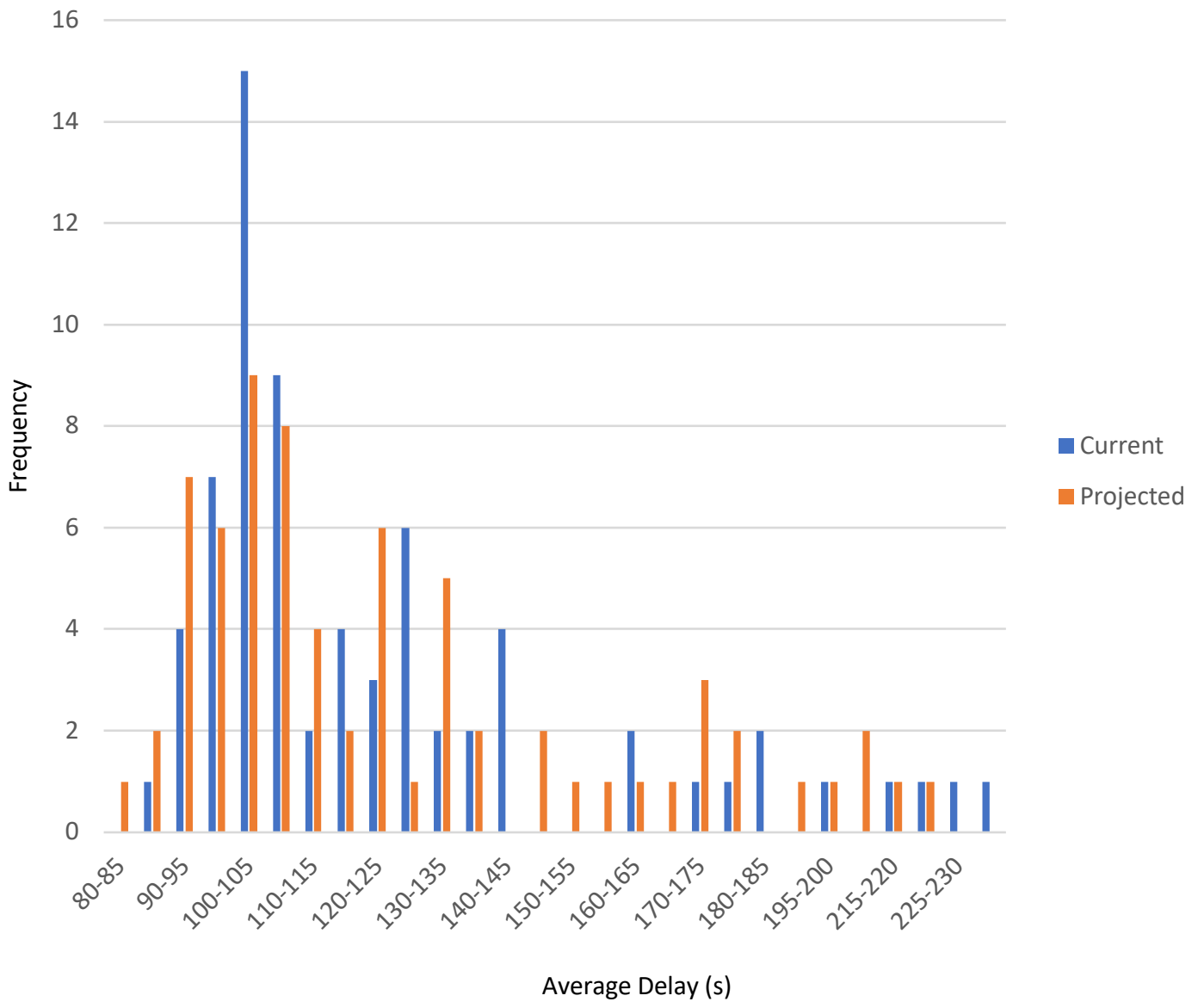


Table 8: ANOVA Single Factor SB Stop Delay (s)

\begin{tabular}{|c|c|c|c|c|c|c|}
\hline Groups & Count & Sum & Average & Variance & & \\
\hline $\begin{array}{l}\text { Current SB Stop Delay (s) } \\
\text { Projected SB Stop Delay } \\
\text { (s) }\end{array}$ & $\begin{array}{l}70 \\
70 \\
\end{array}$ & $\begin{array}{l}8714.28 \\
8806.82\end{array}$ & $\begin{array}{l}124.49 \\
125.81 \\
\end{array}$ & $\begin{array}{l}1214.85 \\
1216.07\end{array}$ & & \\
\hline \multicolumn{7}{|l|}{ ANOVA } \\
\hline Source of Variation & SS & $d f$ & MS & $F$ & $P$-value & F crit \\
\hline Between Groups & 61.17 & 1 & 61.17 & 0.05 & 0.82 & 3.91 \\
\hline Within Groups & 167733.34 & 138 & 1215.46 & & & \\
\hline Total & 167794.51 & 139 & & & & \\
\hline
\end{tabular}

Lane Flow Distribution

The VISSIM model for the State Street corridor measured the number of vehicles in each NB lane near Coyle Drive. The model outputs for the NB vehicle counts and the subsequent calculation for lane flow distribution from the current condition and the projected condition are available in Appendix D: Vehicle Distribution Data. Figure 17 shows the distribution comparison of the outputs mentioned above, which were compared using an ANOVA single factor test to determine the statistical significance of the changes. See Table 8 for the analysis results for vehicle counts and Table 9 for the results of the lane flow distribution.

\section{Equation 1: Lane Flow Distribution}

$$
\text { Lane Flow Distribution }=\frac{N L}{N T} \times 100
$$

Where:

$N L=$ Number of vehicles in the study lane

$N T=$ Number of vehicles in all lanes in that direction 
The $\mathrm{H}_{0}$ for this test was there was no difference between the current and projected condition, and the $\mathrm{H}_{1}$ that there is a difference between the current and projected condition; an $\alpha$ of 0.05 is used. Since the F-critical for all criteria is 3.9 , and the F-value between the groups for the right lane vehicle count was over 1,935, it showed, in conjunction with a p-value of approximately $4.43 \mathrm{E}-83$, the modifications produced a statistically significant change to the NB direction right lane vehicle counts.

Furthermore, the F-critical for all criteria is 3.9, and the F-value between the groups for the percentage of overall vehicles in the right lane was over 5,302. In conjunction with a p-value of approximately 5.37E-112, this result showed that the modifications produced a statistically significant change to the percentage of overall NB vehicles in the right lane.

Table 9: ANOVA Single Factor NB Right Lane Vehicle Count

\begin{tabular}{|c|c|c|c|c|c|c|}
\hline Groups & Count & Sum & Average & Variance & & \\
\hline $\begin{array}{l}\text { Current Right Lane } \\
\text { Vehicle Count } \\
\text { Projected Right Lane } \\
\text { Vehicle Count }\end{array}$ & 70 & 44997 & 642.81 & 1372.82 & & \\
\hline \multicolumn{7}{|l|}{ ANOVA } \\
\hline Source of Variation & SS & $d f$ & MS & $F$ & P-value & Fcrit \\
\hline Between Groups & 1607357.15 & 1 & 1607357.15 & 1935.42 & $4.43 E-83$ & 3.91 \\
\hline Within Groups & 114608.07 & 138 & 830.49 & & & \\
\hline Total & 1721965.22 & 139 & & & & \\
\hline
\end{tabular}


Figure 17: Comparison of Current \& Projected Lane Flow Distributions

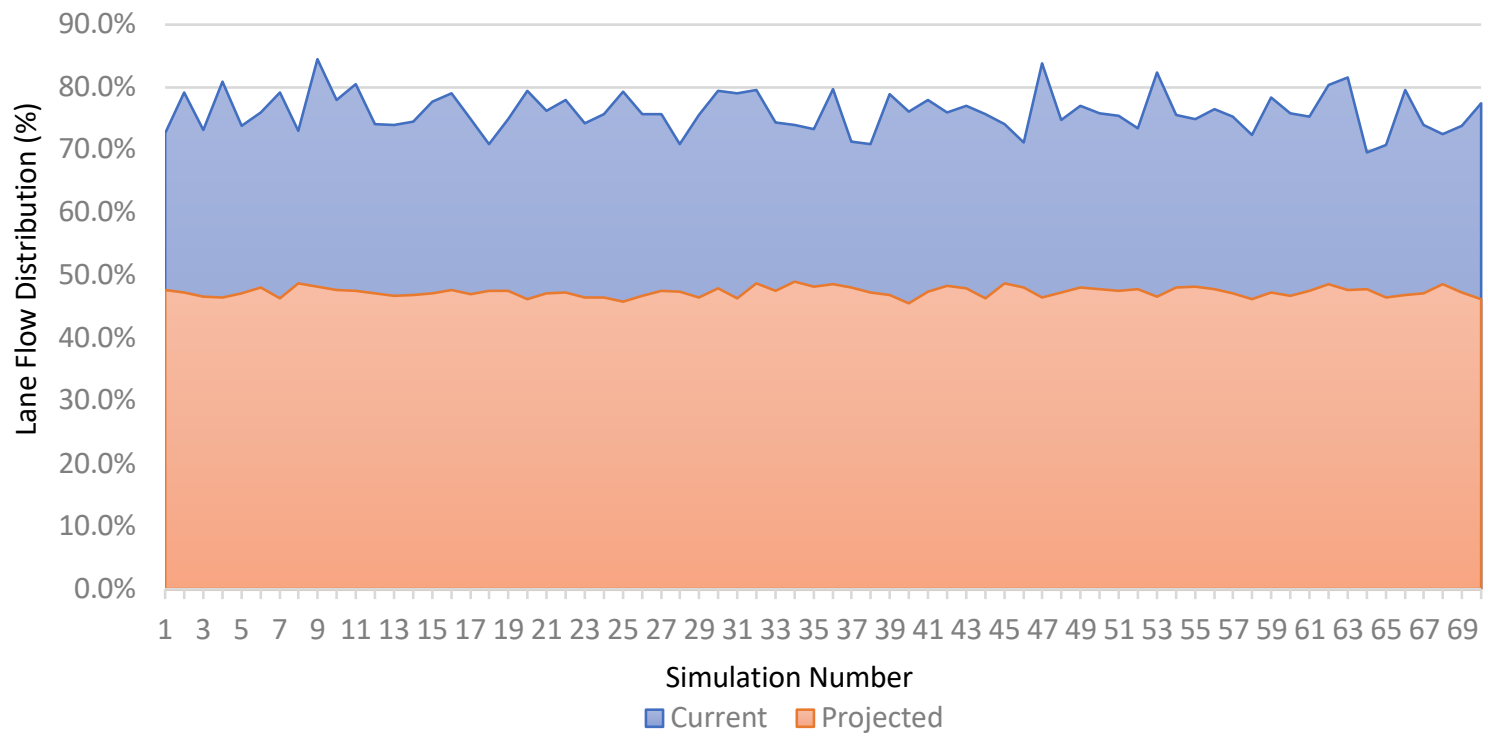

Table 10: ANOVA Single Factor Percentage of Vehicles in the Right Lane

SUMMARY

\begin{tabular}{|c|c|c|c|c|}
\hline Groups & Count & Sum & Average & Variance \\
\hline \multicolumn{5}{|l|}{ Current Percentage of Vehicles in the } \\
\hline Right Lane & 70 & $5327.90 \%$ & $76.11 \%$ & $0.10 \%$ \\
\hline $\begin{array}{l}\text { Projected Percentage of Vehicles in } \\
\text { the Right Lane }\end{array}$ & 70 & $3316.09 \%$ & $47.37 \%$ & $0.01 \%$ \\
\hline
\end{tabular}

\begin{tabular}{|c|c|c|c|c|c|c|}
\hline Source of Variation & SS & $d f$ & $M S$ & $F$ & P-value & F crit \\
\hline Between Groups & 2.89 & 1 & 2.89 & 5302.37 & 5.37E-112 & 3.91 \\
\hline Within Groups & 0.08 & 138 & 0.00 & & & \\
\hline Total & 2.97 & 139 & & & & \\
\hline
\end{tabular}




\section{DISCUSSION}

\section{General Discussion}

From the outset, the purpose of this study was to evaluate measures that could improve the queuing, travel times, and delays associated with traveling on the State Street corridor; however, the primary cause of these issues appears to be an uneven lane flow distribution. Consequently, this uneven lane flow distribution causes vehicles to queue, which creates longer travel times and increases delay. The hope is that this treatment will be ubiquitous enough to implement on other urban arterials that have uneven lane flow distribution.

During lunch and PM peak hours, traffic moving in the northbound direction can queue 0.7 miles of the 0.8 -mile segment. The majority of northbound traffic attempts to establish position in the right lane to gain access to the interstate ramps, both on the right side of the street. The previously mentioned position-establishing creates a situation in which the left lane becomes a de facto passing lane rather than conveying traffic in conjunction with the right lane. Further exacerbating the queuing along the corridor, as northbound traffic attempts to access the westbound I-265 ramp, traffic queues along State Street, thereby severing traffic from the I-265 eastbound ramp.

Knowing this condition intimately, the City of New Albany has requested methods to improve traffic flow so the vibrant commercial corridor can further flourish. The simulation and the results of this study will focus on the northbound traffic since it 
is the condition causing the most concern for the City. It was determined that overhead signs and route markings could affect driver behavior to improve the lane flow distribution. When the traffic counts and turning movements were entered into the VISSIM model, it was not easy to achieve the existing condition because the simulation assumed the driving behavior was logical. The left lane was implemented as an overtaking lane to achieve the lane flow distribution that exists along the corridor. Upon implementing this feature, the model consistently produced queues and a lane flow distribution, as seen in the field.

The VISSIM simulation showed the corridor had adequate capacity to convey the number of vehicles currently using the street. If the signs and route markers achieve the desired effect, queues, travel times, and delays will be reduced in a statistically significant manner. Furthermore, the lane flow distribution will nearly equalize, which better utilizes the lanes that are present.

\section{Recommendations and Future Research}

Based on the simulation results and the statistical significance thereof, it is the recommendation to the City of New Albany to install overall head signs and route markers along the State Street corridor to achieve better lane flow distribution. Given the existing literature, the new route markers and overhead signs should be installed at least 500 meters from the critical intersection(Huang et al., 2013).

The City of New Albany has already produced plans and specifications for the recommended modifications; see Figures 18 through 24 for plan documents. The anticipated timeframe for the project is to bid the modifications in June 2021, with 
construction/installation slated to occur late summer of 2021. Once the new pavement markings and signs have been installed and traffic has normalized, a follow-up study will evaluate the simulation findings against empirical data collected in lane flow distribution, queues, travel times, and delay.

Additionally, if the entirety of the desired outcome is not obtained, potential further modification to the corridor may require the I-265 WB traffic to utilize the left lane to obtain the desired lane flow distribution, thereby improved queuing, travel times, and delay. Evaluating the pre-improvement and post-improvement conditions of the modification above could yield further research.

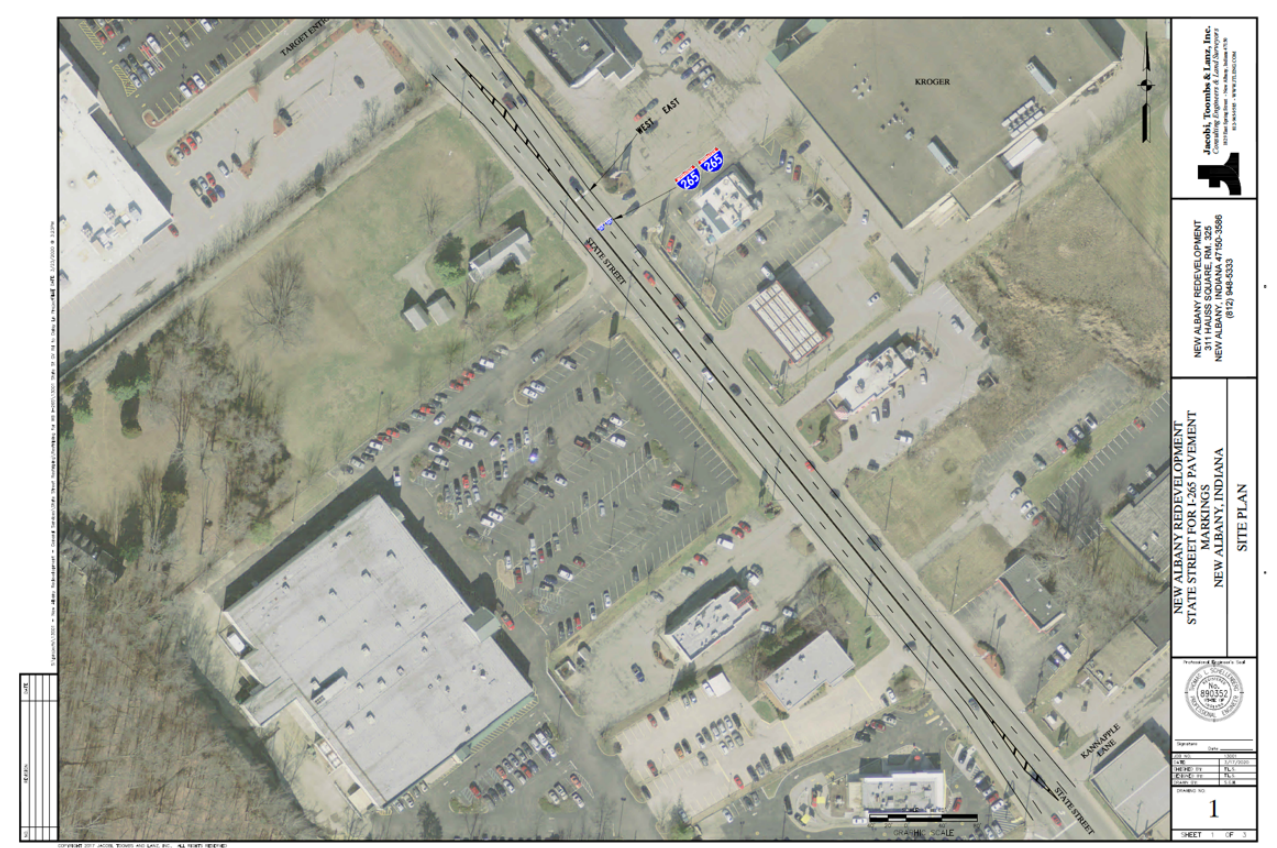


Figure 19: State Street Striping Modifications Sheet 2

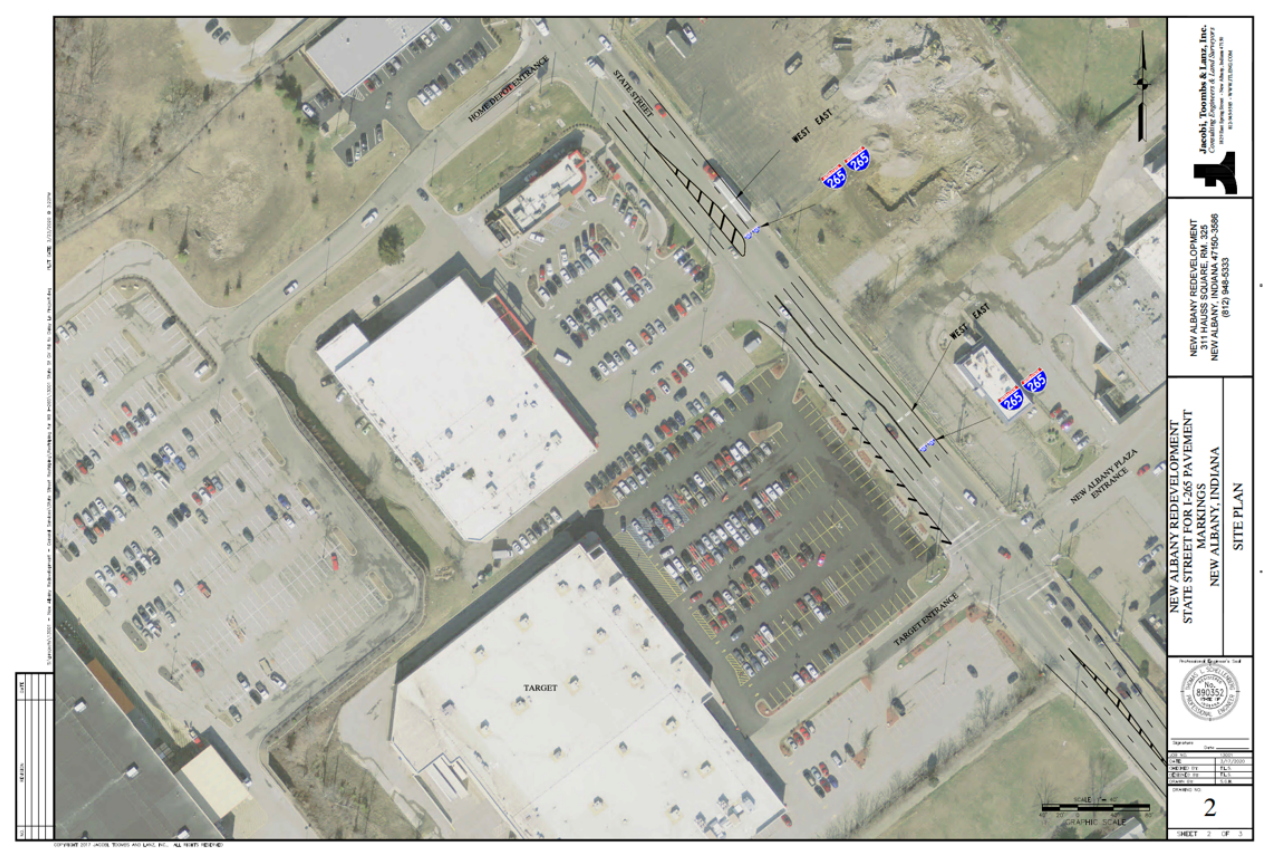

Figure 20: State Street Striping Modifications Sheet 3

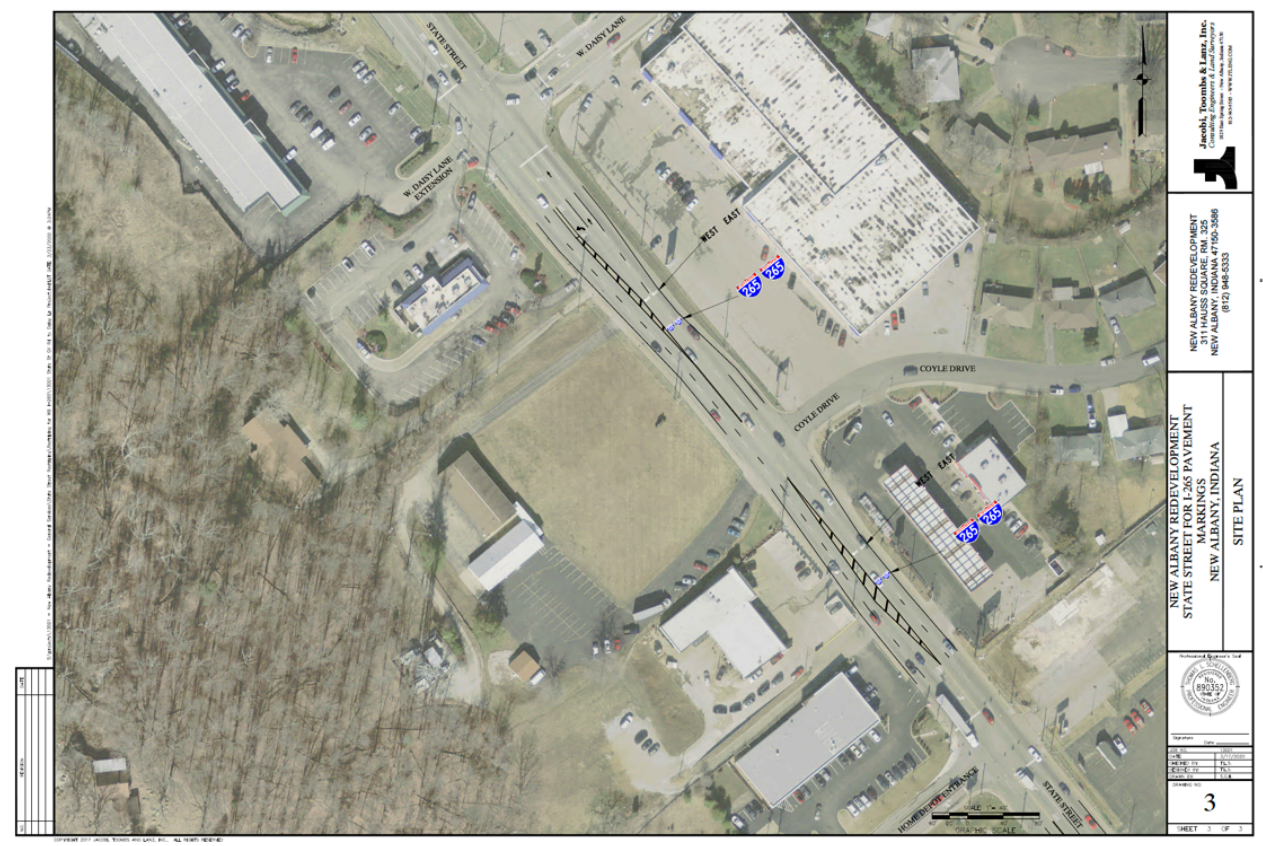


Figure 21: State Street Striping Modifications Sheet 4

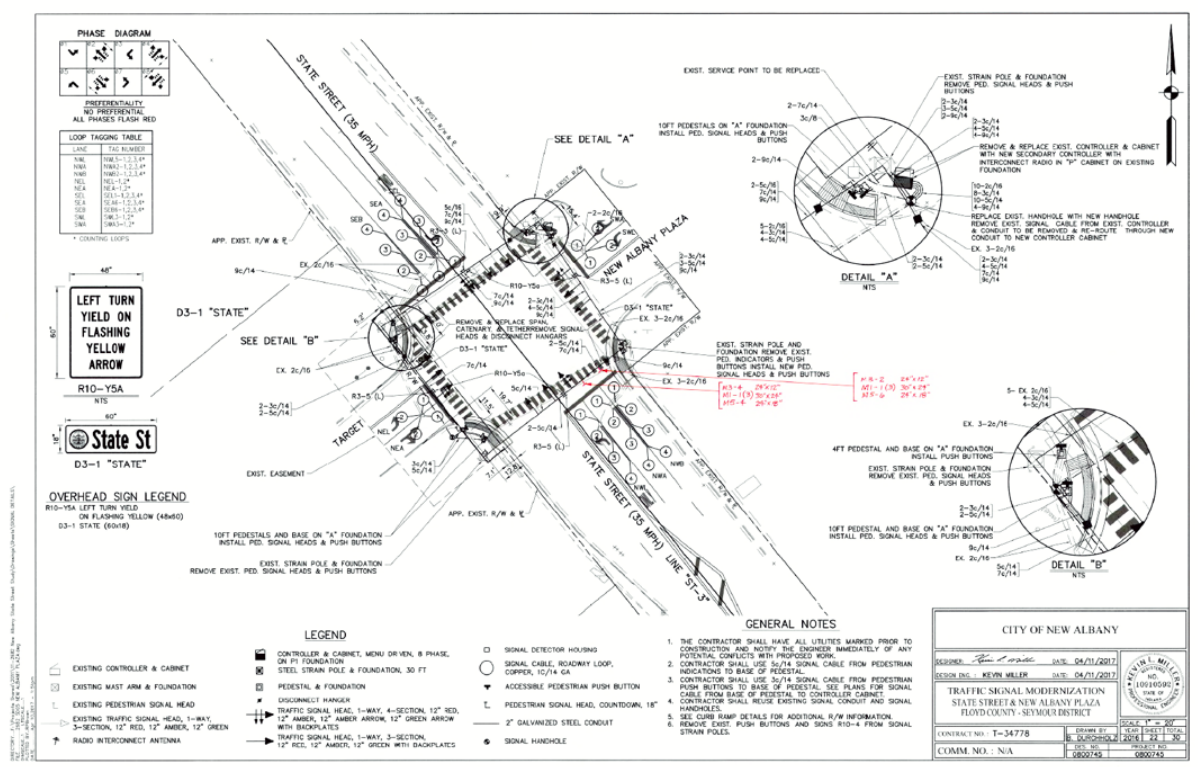

Figure 22: State Street Striping Modifications Sheet 5

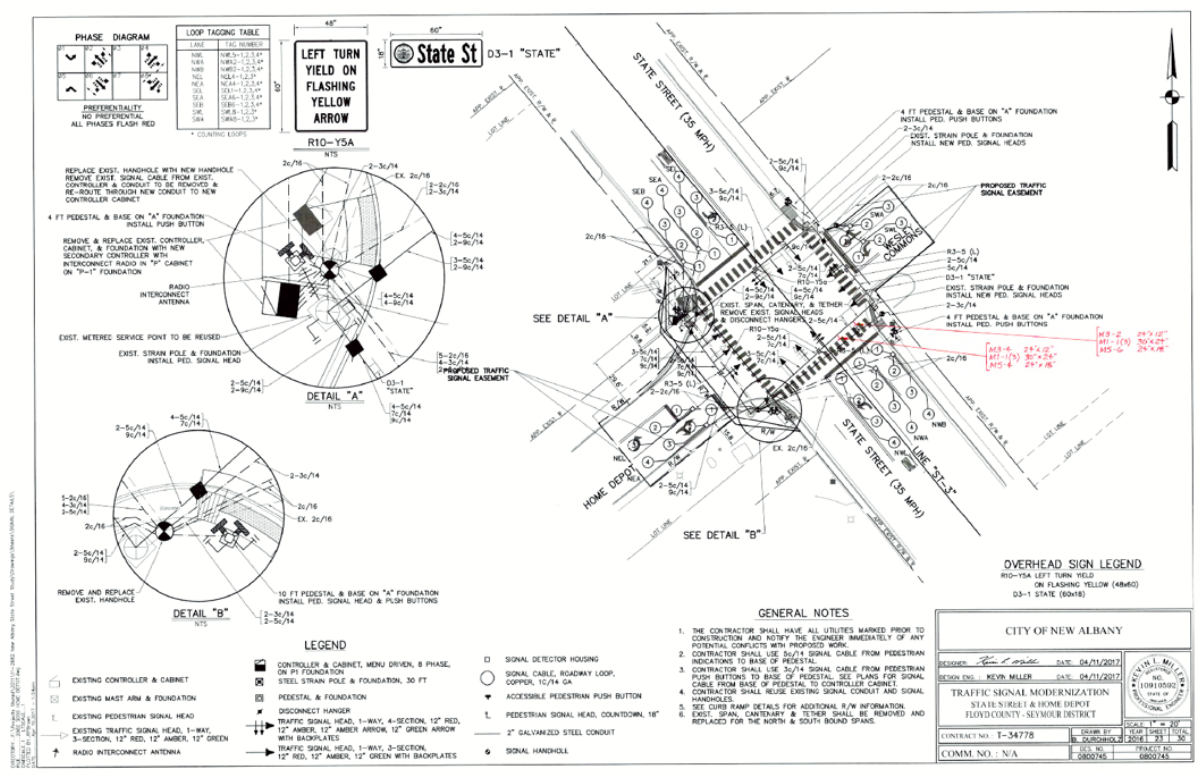


Figure 23: State Street Striping Modifications Sheet 6

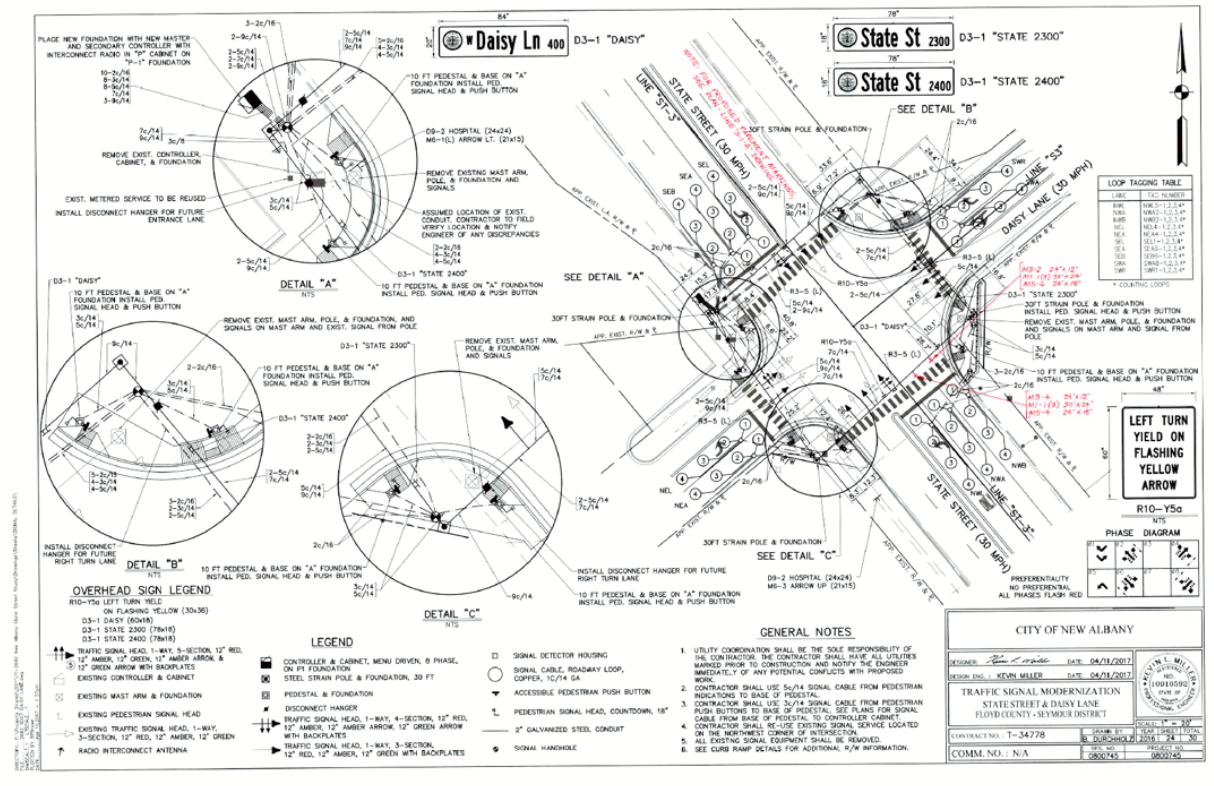

Figure 24: Example of Overhead Signage

\begin{tabular}{|c|c|}
\hline WEST & M3-4 \\
\hline & $\begin{array}{l}(24 \times 12 \\
\text { M1-1 }\end{array}$ \\
\hline & $\begin{array}{l}\text { M6-3 } \\
(30 \times 21\end{array}$ \\
\hline
\end{tabular}




\section{CONCLUSION}

While urban arterials may not effectively utilize available lanes to move vehicles

efficiently, this study evaluated lane flow distribution before and after implementing new route markings and overhead signs to utilize existing lanes better and show the modifications affected the lane flow distribution in the VISSIM simulation. The simulation indicated the existing condition had average queue lengths of 320.6 meters, average travel times of 389.5 seconds, an average stop delay of 259.6 seconds, and an average lane flow distribution in the right lane of $76.1 \%$.

The projected simulation showed average queue lengths were reduced to 39.0 meters, average travel times reduced to 171.4 seconds, average stop delay was reduced to 92.5 seconds, and the average lane flow distribution in the right lane was $47.4 \%$. The VISSIM simulation of the proposed State Street corridor yielded statistically significant improvements in each of the abovementioned measures. 


\section{REFERENCES}

Akbari, A., \& Haghighi, F. (2020). Traffic calming measures: An evaluation of four lowcost TCMs' effect on driving speed and lateral distance. IATSS Research, 44(1), 6774. https://doi.org/10.1016/j.iatssr.2019.07.002

Alassaf, M., \& Qamar, A. M. (2021). Improving Sentiment Analysis of Arabic Tweets by One-way ANOVA. Journal of King Saud University - Computer and Information Sciences. https://doi.org/10.1016/j.jksuci.2020.10.023

Ariën, C., Brijs, K., Vanroelen, G., Ceulemans, W., Jongen, E. M. M., Daniels, S., Brijs, T., \& Wets, G. (2017). The effect of pavement markings on driving behaviour in curves: a simulator study. Ergonomics, 60(5), 701-713.

https://doi.org/10.1080/00140139.2016.1200749

Arowolo, M. O., Abdulsalam, S. O., Saheed, Y. K., \& Salawu, M. D. (2016). A feature selection based on one-way-anova for microarray data classification. Al- Hikmah J. Pure Appl. Sci., 3, 30-35.

Babić, D., \& Brijs, T. (2021). Low-cost road marking measures for increasing safety in horizontal curves: A driving simulator study. Accident Analysis and Prevention, 153, 106013. https://doi.org/10.1016/j.aap.2021.106013

Bai, Y., Finger, K., \& Li, Y. (2010). Analyzing motorists' responses to temporary signage in highway work zones. Safety Science, 48(2), 215-221. https://doi.org/10.1016/j.ssci.2009.08.005

Bandi, M. M., \& George, V. (2020). Microsimulation Modelling in VISSIM on Short-term and Long-term Improvements for Mangalore City Road Network. Transportation Research Procedia, 48, 2725-2743. https://doi.org/10.1016/j.trpro.2020.08.243

Carlson, P. J., Park, E. S., \& Andersen, C. K. (2009). Benefits of Pavement Markings. Transportation Research Record: Journal of the Transportation Research Board, 2107(1), 59-68. https://doi.org/10.3141/2107-06

Costa, M., Simone, A., Vignali, V., Lantieri, C., Bucchi, A., \& Dondi, G. (2014). Looking behavior for vertical road signs. Transportation Research Part F: Traffic Psychology and Behaviour, 23, 147-155. https://doi.org/10.1016/j.trf.2014.01.003

Daniels, S., Vanrie, J., Dreesen, A., \& Brijs, T. (2010). Additional road markings as an indication of speed limits: Results of a field experiment and a driving simulator study. Accident Analysis and Prevention, 42(3), 953-960. https://doi.org/10.1016/j.aap.2009.06.020

Duret, A., Ahn, S., \& Buisson, C. (2012). Lane flow distribution on a three-lane freeway: General features and the effects of traffic controls. Transportation Research Part C: Emerging Technologies, 24, 157-167. https://doi.org/10.1016/j.trc.2012.02.009

Elssied, N. O. F., Ibrahim, O., \& Osman, A. H. (2014). A novel feature selection based on one-way ANOVA F-test for e-mail spam classification. Research Journal of Applied 
Sciences, Engineering and Technology, 7(3), 625-638.

https://doi.org/10.19026/rjaset.7.299

Filtness, A. J., Larue, G., Schramm, A., Fuller, J., Rakotonirainy, A., Han, C., \& Cairney, P. (2017). Safety implications of co-locating road signs: A driving simulator investigation. Transportation Research Part F: Traffic Psychology and Behaviour, 47, 187-198. https://doi.org/10.1016/j.trf.2017.04.007

Godley, S. T. (1999). A driving simulator investigation of perceptual countermeasures to speeding. Monash University Melbourne,, Australia.

Hang, J., Yan, X., Ma, L., Duan, K., \& Zhang, Y. (2018). Exploring the effects of the location of the lane-end sign and traffic volume on multistage lane-changing behaviors in work zone areas: A driving simulator-based study. Transportation Research Part F: Traffic Psychology and Behaviour, 58, 980-993. https://doi.org/10.1016/j.trf.2018.07.024

Hollander, Y., \& Liu, R. (2008). The principles of calibrating traffic microsimulation models. Transportation, 35(3), 347-362. https://doi.org/10.1007/s11116-0079156-2

Huang, F., Liu, P., Yu, H., \& Wang, W. (2013). Identifying if VISSIM simulation model and SSAM provide reasonable estimates for field measured traffic conflicts at signalized intersections. Accident Analysis and Prevention, 50, 1014-1024. https://doi.org/10.1016/j.aap.2012.08.018

Hussain, Q., Alhajyaseen, W. K. M., Reinolsmann, N., Brijs, K., Pirdavani, A., Wets, G., \& Brijs, T. (2021). Optical pavement treatments and their impact on speed and lateral position at transition zones: A driving simulator study. Accident Analysis and Prevention, 150, 105916. https://doi.org/10.1016/j.aap.2020.105916

Karakikes, I., Spangler, M., \& Margreiter, M. (2017). Designing a Vissim-Model for a motorway network with systematic calibration on the basis of travel time measurements. Transportation Research Procedia, 24, 171-179. https://doi.org/10.1016/j.trpro.2017.05.086

Li, X., \& Sun, J. Q. (2017). Studies of vehicle lane-changing dynamics and its effect on traffic efficiency, safety and environmental impact. Physica A: Statistical Mechanics and Its Applications, 467, 41-58. https://doi.org/10.1016/j.physa.2016.09.022

Lv, W., Song, W. G., Fang, Z. M., \& Ma, J. (2013). Modelling of lane-changing behaviour integrating with merging effect before a city road bottleneck. Physica A: Statistical Mechanics and Its Applications, 392(20), 5143-5153. https://doi.org/10.1016/j.physa.2013.06.034

Moridpour, S., Sarvi, M., \& Rose, G. (2010). Lane changing models: A critical review. In Transportation Letters (Vol. 2, Issue 3, pp. 157-173). Maney Publishing. https://doi.org/10.3328/TL.2010.02.03.157-173

Siddharth, S. M. P., \& Ramadurai, G. (2013). Calibration of VISSIM for Indian Heterogeneous Traffic Conditions. Procedia - Social and Behavioral Sciences, 104, 380-389. https://doi.org/10.1016/j.sbspro.2013.11.131

Sun, D., Zhang, L., \& Chen, F. (2013). Comparative study on simulation performances of CORSIM and VISSIM for urban street network. Simulation Modelling Practice and Theory, 37, 18-29. https://doi.org/10.1016/j.simpat.2013.05.007 
Traffic Count Database System (TCDS). (n.d.). Retrieved April 21, 2021, from https://indot.public.ms2soft.com/tcds/tsearch.asp?loc=Indot\&mod=tcds\&local_id= 220563

Van Driel, C. J. G., Davidse, R. J., \& Van Maarseveen, M. F. A. M. (2004). The effects of an edgeline on speed and lateral position: A meta-analysis. Accident Analysis and Prevention, 36(4), 671-682. https://doi.org/10.1016/S0001-4575(03)00090-3

Vilchez, J. L. (2018). Representativity and univocity of traffic signs and their effect on trajectory movement in a driving-simulation task: Regulatory signs. Journal of Safety Research, 66, 101-111. https://doi.org/10.1016/j.jsr.2018.06.007

Vilchez, J. L. (2019). Mental representation of traffic signs and their classification: Warning signs. Transportation Research Part F: Traffic Psychology and Behaviour, 64, 447-462. https://doi.org/10.1016/j.trf.2019.06.004

Wasserstein, R. L., \& Lazar, N. A. (2016). The ASA's Statement on p-Values: Context, Process, and Purpose. In American Statistician (Vol. 70, Issue 2, pp. 129-133). American Statistical Association. https://doi.org/10.1080/00031305.2016.1154108

Yang, Y., Chen, Y., Wu, C., Easa, S. M., Lin, W., \& Zheng, X. (2020). Effect of highway directional signs on driver mental workload and behavior using eye movement and brain wave. Accident Analysis and Prevention, 146, 105705. https://doi.org/10.1016/j.aap.2020.105705

Yuan, W., Fu, R., Ma, Y., \& Guo, Y. (2011). Effects of vehicle speed and traffic sign text height on drivers' visual search patterns. Undefined. 


\section{APPENDICES}

Appendix A: Queue Data 


\begin{tabular}{|c|c|c|c|c|c|c|c|c|c|}
\hline \multicolumn{5}{|c|}{ Current Queue (Location: 1 NB, 4 SB) } & \multicolumn{5}{|c|}{ Proposed Queue (Location: 1 NB, 4 SB) } \\
\hline Simulation & Location & $\begin{array}{l}\text { Q Length Average } \\
(\mathrm{m})\end{array}$ & $\begin{array}{l}\text { Q Length Max } \\
(m)\end{array}$ & $\begin{array}{c}Q \\
\text { Stops }\end{array}$ & Simulation & Location & Q Length Average $(\mathrm{m})$ & $\begin{array}{l}\text { Q Length Max } \\
(\mathrm{m})\end{array}$ & $\begin{array}{c}Q \\
\text { Stops }\end{array}$ \\
\hline 1 & 1 & 392.06 & 510.04 & 3348 & 1 & 1 & 43.79 & 171.06 & 862 \\
\hline 2 & 1 & 218.19 & 504.69 & 1986 & 2 & 1 & 42.13 & 225.62 & 803 \\
\hline 3 & 1 & 413.17 & 510.16 & 3356 & 3 & 1 & 37.66 & 161.42 & 761 \\
\hline 4 & 1 & 194.04 & 504.37 & 1554 & 4 & 1 & 35.26 & 170.25 & 687 \\
\hline 5 & 1 & 304.63 & 510.15 & 2907 & 5 & 1 & 38.76 & 170.04 & 772 \\
\hline 6 & 1 & 332.24 & 504.75 & 2699 & 6 & 1 & 41.63 & 196.75 & 819 \\
\hline 7 & 1 & 358.16 & 504.62 & 2480 & 7 & 1 & 36.45 & 188.12 & 729 \\
\hline 8 & 1 & 345.21 & 510.05 & 2767 & 8 & 1 & 46.19 & 190.44 & 834 \\
\hline 9 & 1 & 253.04 & 510.15 & 1995 & 9 & 1 & 36.52 & 183.18 & 729 \\
\hline 10 & 1 & 325.91 & 504.62 & 2441 & 10 & 1 & 35.08 & 164.13 & 732 \\
\hline 11 & 1 & 354.32 & 510.1 & 2585 & 11 & 1 & 38.75 & 158.37 & 808 \\
\hline 12 & 1 & 381.04 & 508.25 & 3262 & 12 & 1 & 34.02 & 144.24 & 701 \\
\hline 13 & 1 & 235.98 & 503.85 & 2074 & 13 & 1 & 36.8 & 168.86 & 753 \\
\hline 14 & 1 & 316.66 & 509.24 & 2764 & 14 & 1 & 38.99 & 181.78 & 727 \\
\hline 15 & 1 & 366.14 & 508.82 & 2844 & 15 & 1 & 36.71 & 159.36 & 765 \\
\hline 16 & 1 & 341.58 & 504.75 & 2859 & 16 & 1 & 39.37 & 162.41 & 778 \\
\hline 17 & 1 & 305.88 & 504.64 & 2712 & 17 & 1 & 38.21 & 202.49 & 740 \\
\hline 18 & 1 & 436.42 & 510.06 & 3656 & 18 & 1 & 41.21 & 175.6 & 832 \\
\hline 19 & 1 & 250.64 & 503.9 & 2130 & 19 & 1 & 40.23 & 173.65 & 827 \\
\hline 20 & 1 & 289.33 & 510.2 & 2571 & 20 & 1 & 44.02 & 182.51 & 830 \\
\hline 21 & 1 & 330.09 & 510.18 & 2906 & 21 & 1 & 38.3 & 182.12 & 807 \\
\hline 22 & 1 & 254.88 & 503.76 & 1959 & 22 & 1 & 38.46 & 170.02 & 759 \\
\hline 23 & 1 & 283.42 & 504.74 & 2587 & 23 & 1 & 41.43 & 227.68 & 789 \\
\hline 24 & 1 & 390.18 & 504.61 & 3023 & 24 & 1 & 34.57 & 189.93 & 690 \\
\hline 25 & 1 & 246.35 & 504.74 & 1879 & 25 & 1 & 36.13 & 156 & 751 \\
\hline 26 & 1 & 310.91 & 504.53 & 2589 & 26 & 1 & 35.13 & 163.49 & 740 \\
\hline 27 & 1 & 332.68 & 504.88 & 2690 & 27 & 1 & 45.62 & 220.05 & 843 \\
\hline 28 & 1 & 409.52 & 504.76 & 3548 & 28 & 1 & 30.86 & 151.56 & 663 \\
\hline 29 & 1 & 422.65 & 509.99 & 3436 & 29 & 1 & 39.14 & 163.47 & 802 \\
\hline 30 & 1 & 464.76 & 510.19 & 3315 & 30 & 1 & 42.48 & 191.2 & 830 \\
\hline 31 & 1 & 185.72 & 493.68 & 1680 & 31 & 1 & 34.56 & 158.63 & 741 \\
\hline 32 & 1 & 321.66 & 509.99 & 2445 & 32 & 1 & 45.47 & 180.35 & 896 \\
\hline 33 & 1 & 345.49 & 504.63 & 2595 & 33 & 1 & 30.79 & 131.71 & 630 \\
\hline 34 & 1 & 291.53 & 504.68 & 2515 & 34 & 1 & 36.9 & 157.58 & 739 \\
\hline 35 & 1 & 280.81 & 497.74 & 2326 & 35 & 1 & 33.65 & 144.23 & 727 \\
\hline 36 & 1 & 267.43 & 505.59 & 2146 & 36 & 1 & 40.96 & 162.73 & 819 \\
\hline 37 & 1 & 313.8 & 504.63 & 2742 & 37 & 1 & 38.89 & 189.75 & 780 \\
\hline 38 & 1 & 384.89 & 504.73 & 3434 & 38 & 1 & 42.43 & 175.3 & 864 \\
\hline 39 & 1 & 240.41 & 504.69 & 1980 & 39 & 1 & 40.47 & 171.53 & 790 \\
\hline 40 & 1 & 364.31 & 504.74 & 2613 & 40 & 1 & 41.23 & 187.48 & 810 \\
\hline
\end{tabular}




\begin{tabular}{|c|c|c|c|c|c|c|c|c|c|}
\hline 41 & 1 & 227.92 & 504.58 & 1783 & 41 & 1 & 34.38 & 151.57 & 738 \\
\hline 42 & 1 & 342.32 & 510.21 & 2681 & 42 & 1 & 39.42 & 185.32 & 779 \\
\hline 43 & 1 & 284.46 & 509.99 & 2569 & 43 & 1 & 45.66 & 215.06 & 803 \\
\hline 44 & 1 & 391.08 & 504.62 & 2802 & 44 & 1 & 35.85 & 175.37 & 710 \\
\hline 45 & 1 & 393.25 & 504.55 & 3094 & 45 & 1 & 34.61 & 158.55 & 736 \\
\hline 46 & 1 & 457.66 & 510.2 & 3618 & 46 & 1 & 39.17 & 163.92 & 783 \\
\hline 47 & 1 & 107.13 & 471.93 & 1171 & 47 & 1 & 32.21 & 187.57 & 698 \\
\hline 48 & 1 & 252.82 & 510.12 & 2421 & 48 & 1 & 40.54 & 220.81 & 804 \\
\hline 49 & 1 & 274.84 & 504.72 & 2035 & 49 & 1 & 32.89 & 144.76 & 715 \\
\hline 50 & 1 & 248.71 & 504.63 & 2082 & 50 & 1 & 30.28 & 131.59 & 637 \\
\hline 51 & 1 & 416.92 & 510.17 & 3428 & 51 & 1 & 42.73 & 201.16 & 781 \\
\hline 52 & 1 & 353.39 & 510.13 & 3011 & 52 & 1 & 37.43 & 208.12 & 771 \\
\hline 53 & 1 & 375.36 & 508.02 & 2856 & 53 & 1 & 33.48 & 173.09 & 682 \\
\hline 54 & 1 & 368.46 & 510.18 & 3005 & 54 & 1 & 48.53 & 195.44 & 923 \\
\hline 55 & 1 & 403.88 & 510.21 & 3361 & 55 & 1 & 46.87 & 173.3 & 872 \\
\hline 56 & 1 & 279.86 & 510.18 & 2435 & 56 & 1 & 41.11 & 176.51 & 783 \\
\hline 57 & 1 & 380.27 & 506.62 & 3263 & 57 & 1 & 42.16 & 182.31 & 817 \\
\hline 58 & 1 & 367.33 & 510.18 & 2760 & 58 & 1 & 37.62 & 156.44 & 796 \\
\hline 59 & 1 & 337.02 & 507.38 & 2514 & 59 & 1 & 44.33 & 189.26 & 864 \\
\hline 60 & 1 & 396.47 & 510.19 & 3430 & 60 & 1 & 40.8 & 175.35 & 807 \\
\hline 61 & 1 & 285.97 & 504.76 & 2247 & 61 & 1 & 39.86 & 201.89 & 832 \\
\hline 62 & 1 & 266.58 & 510.13 & 2351 & 62 & 1 & 44.63 & 177.88 & 855 \\
\hline 63 & 1 & 102.79 & 504.74 & 1162 & 63 & 1 & 42.73 & 177.67 & 817 \\
\hline 64 & 1 & 429.02 & 509.99 & 3831 & 64 & 1 & 42.89 & 190.62 & 849 \\
\hline 65 & 1 & 413.81 & 504.75 & 3624 & 65 & 1 & 34.43 & 151.27 & 749 \\
\hline 66 & 1 & 183.13 & 498.27 & 1643 & 66 & 1 & 36.43 & 163.92 & 747 \\
\hline 67 & 1 & 275.28 & 510.2 & 2521 & 67 & 1 & 44.32 & 198 & 841 \\
\hline 68 & 1 & 360.39 & 505.76 & 3265 & 68 & 1 & 45.72 & 214.43 & 866 \\
\hline 69 & 1 & 286.35 & 508.57 & 2357 & 69 & 1 & 32.62 & 156.04 & 684 \\
\hline 70 & 1 & 320.42 & - 504.7. & 2757 & 70 & 1 & 37.68 & 181.84 & 770 \\
\hline 1 & 4 & 21.87 & 96.6 & 750 & 1 & 4 & 36.74 & 271.64 & 926 \\
\hline 2 & 4 & 22.38 & 88.54 & 736 & 2 & 4 & 32.89 & 158.81 & 775 \\
\hline 3 & 4 & 20.45 & 91.29 & 694 & 3 & 4 & 20.62 & 82.6 & 724 \\
\hline 4 & 4 & 20.2 & 71.34 & 655 & 4 & 4 & 19.83 & 81.79 & 670 \\
\hline 5 & 4 & 29.29 & 167.33 & 862 & 5 & 4 & 35.45 & 141.17 & 971 \\
\hline 6 & 4 & 36.15 & 179.71 & 967 & 6 & 4 & 32.58 & 188.11 & 941 \\
\hline 7 & 4 & 50.2 & 205.58 & 1184 & 7 & 4 & 21.98 & 91.13 & 757 \\
\hline 8 & 4 & 21.86 & 85.03 & 726 & 8 & 4 & 20.54 & 77.24 & 710 \\
\hline 9 & 4 & 25.04 & 200.39 & 751 & 9 & 4 & 21.09 & 79.78 & 708 \\
\hline 10 & 4 & 24.72 & 87.21 & 812 & 10 & 4 & 30.32 & 168.71 & 838 \\
\hline 11 & 4 & 20.96 & 81.51 & 698 & 11 & 4 & 21.59 & 81.51 & 720 \\
\hline 12 & 4 & 22.31 & 76.26 & 764 & 12 & 4 & 27.17 & 100.75 & 861 \\
\hline
\end{tabular}




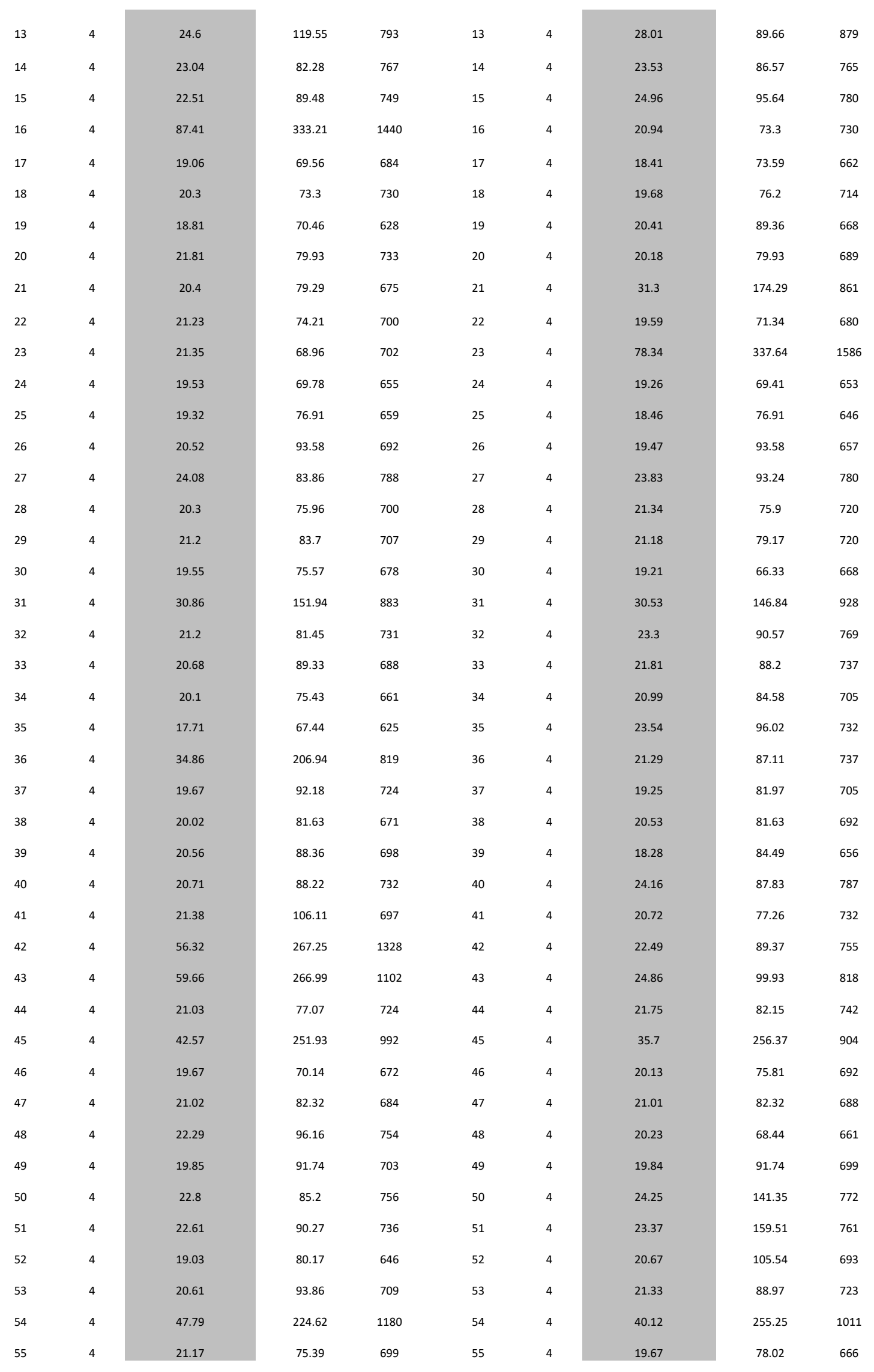




\begin{tabular}{llllllllll}
56 & 4 & 19.29 & 69.37 & 642 & 56 & 4 & 19.33 & 73.31 & 654 \\
57 & 4 & 20.32 & 74.69 & 701 & 57 & 4 & 20.69 & 89 & 731 \\
58 & 4 & 18.98 & 83.42 & 658 & 58 & 4 & 20.41 & 84.41 & 696 \\
59 & 4 & 28.25 & 178.01 & 747 & 59 & 4 & 24.99 & 171.32 & 712 \\
60 & 4 & 20.64 & 70.07 & 703 & 60 & 4 & 30.53 & 149.2 & 867 \\
61 & 4 & 19.6 & 75.42 & 674 & 61 & 4 & 20.15 & 75.42 & 701 \\
62 & 4 & 19.2 & 66.31 & 666 & 62 & 4 & 19.53 & 66.9 & 673 \\
63 & 4 & 23.59 & 85.75 & 824 & 63 & 4 & 28.22 & 151.71 & 908 \\
64 & 4 & 66.43 & 296.34 & 1359 & 64 & 4 & 30.4 & 166.53 & 908 \\
65 & 4 & 20.9 & 69.11 & 664 & 65 & 4 & 20.34 & 69.11 & 664 \\
66 & 4 & 19.93 & 81.03 & 687 & 66 & 4 & 48.92 & 251.49 & 1021 \\
67 & 4 & 18.45 & 86.36 & 642 & 67 & 4 & 18.45 & 84.02 & 635 \\
68 & 4 & 25.78 & 161.88 & 715 & 68 & 4 & 26.79 & 161.88 & 738 \\
69 & 4 & 48.21 & 212.81 & 1141 & 69 & 4 & 60.25 & 243.51 & 1402 \\
70 & 4 & 21.7 & 85.64 & 728 & 70 & 4 & 21.3 & 85.01 & 701 \\
\hline
\end{tabular}


Appendix B: Travel Time Data 


\begin{tabular}{|c|c|c|}
\hline Simulation & Direction & $\begin{array}{c}\text { Travel Time } \\
\text { (s) }\end{array}$ \\
\hline 1 & 1 & 475.22 \\
\hline 2 & 1 & 317.7 \\
\hline 3 & 1 & 576.55 \\
\hline 4 & 1 & 262.02 \\
\hline 5 & 1 & 426.87 \\
\hline 6 & 1 & 412.13 \\
\hline 7 & 1 & 324.48 \\
\hline 8 & 1 & 375.95 \\
\hline 9 & 1 & 476.87 \\
\hline 10 & 1 & 302.59 \\
\hline 11 & 1 & 418.38 \\
\hline 12 & 1 & 441.41 \\
\hline 13 & 1 & 302.11 \\
\hline 14 & 1 & 409.99 \\
\hline 15 & 1 & 347.57 \\
\hline 16 & 1 & 452.68 \\
\hline 17 & 1 & 368.71 \\
\hline 18 & 1 & 459.53 \\
\hline 19 & 1 & 322.73 \\
\hline 20 & 1 & 523.99 \\
\hline 21 & 1 & 647 \\
\hline 22 & 1 & 278.35 \\
\hline 23 & 1 & 312.03 \\
\hline 24 & 1 & 363.26 \\
\hline 25 & 1 & 284.61 \\
\hline 26 & 1 & 331.62 \\
\hline 27 & 1 & 344.07 \\
\hline 28 & 1 & 488.55 \\
\hline 29 & 1 & 484.15 \\
\hline 30 & 1 & 544.83 \\
\hline 31 & 1 & 259.55 \\
\hline 32 & 1 & 363.85 \\
\hline 33 & 1 & 303.07 \\
\hline 34 & 1 & 335.86 \\
\hline 35 & 1 & 303.18 \\
\hline 36 & 1 & 376.88 \\
\hline 37 & 1 & 344.09 \\
\hline 38 & 1 & 515.67 \\
\hline 39 & 1 & 287.05 \\
\hline
\end{tabular}

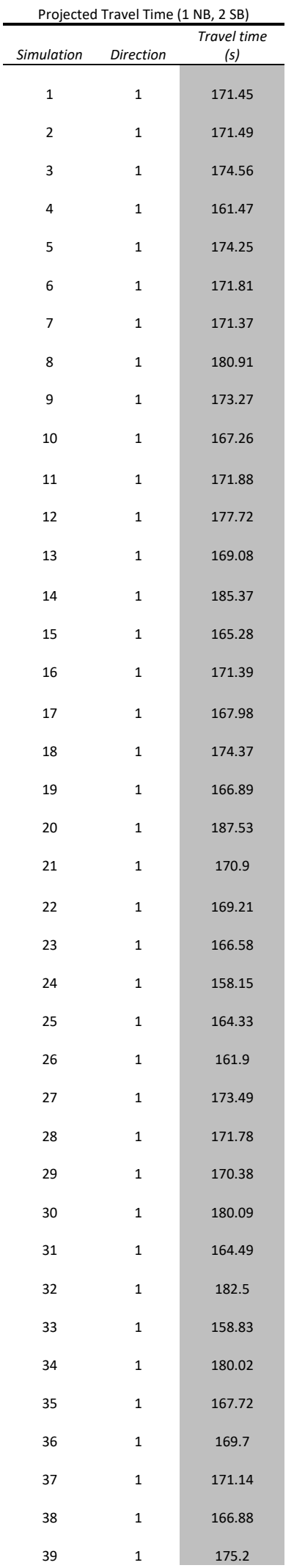




\begin{tabular}{|c|c|c|c|c|c|}
\hline 40 & 1 & 307.23 & 40 & 1 & 170.49 \\
\hline 41 & 1 & 296.85 & 41 & 1 & 172.01 \\
\hline 42 & 1 & 358.66 & 42 & 1 & 165.13 \\
\hline 43 & 1 & 399.8 & 43 & 1 & 178.39 \\
\hline 44 & 1 & 338.69 & 44 & 1 & 170.42 \\
\hline 45 & 1 & 460.32 & 45 & 1 & 177.71 \\
\hline 46 & 1 & 603.63 & 46 & 1 & 180.13 \\
\hline 47 & 1 & 249.78 & 47 & 1 & 159.91 \\
\hline 48 & 1 & 328.98 & 48 & 1 & 171.11 \\
\hline 49 & 1 & 260.29 & 49 & 1 & 160.09 \\
\hline 50 & 1 & 341.06 & 50 & 1 & 160.12 \\
\hline 51 & 1 & 509.56 & 51 & 1 & 175.33 \\
\hline 52 & 1 & 416.63 & 52 & 1 & 158.72 \\
\hline 53 & 1 & 381.15 & 53 & 1 & 170.31 \\
\hline 54 & 1 & 392.11 & 54 & 1 & 183.92 \\
\hline 55 & 1 & 500.92 & 55 & 1 & 177.73 \\
\hline 56 & 1 & 411.05 & 56 & 1 & 183.06 \\
\hline 57 & 1 & 381.03 & 57 & 1 & 169.21 \\
\hline 58 & 1 & 325.64 & 58 & 1 & 170.4 \\
\hline 59 & 1 & 364.48 & 59 & 1 & 170.28 \\
\hline 60 & 1 & 588.75 & 60 & 1 & 173.51 \\
\hline 61 & 1 & 317.58 & 61 & 1 & 180.47 \\
\hline 62 & 1 & 439.24 & 62 & 1 & 167.01 \\
\hline 63 & 1 & 249.17 & 63 & 1 & 181.34 \\
\hline 64 & 1 & 546.04 & 64 & 1 & 167.62 \\
\hline 65 & 1 & 524.2 & 65 & 1 & 161.29 \\
\hline 66 & 1 & 271.63 & 66 & 1 & 159.11 \\
\hline 67 & 1 & 348.47 & 67 & 1 & 172.92 \\
\hline 68 & 1 & 422.77 & 68 & 1 & 177.42 \\
\hline 69 & 1 & 357.86 & 69 & 1 & 163.34 \\
\hline & & & & & 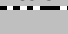 \\
\hline 1 & 2 & 202.42 & 1 & 2 & 200.77 \\
\hline 2 & 2 & 205.58 & 2 & 2 & 213.1 \\
\hline 3 & 2 & 236.8 & 3 & 2 & 261.73 \\
\hline 4 & 2 & 218.32 & 4 & 2 & 213.71 \\
\hline 5 & 2 & 214.99 & 5 & 2 & 276.6 \\
\hline 6 & 2 & 217.28 & 6 & 2 & 198.53 \\
\hline 7 & 2 & 301.84 & 7 & 2 & 245.77 \\
\hline 8 & 2 & 191.11 & 8 & 2 & 168.38 \\
\hline 9 & 2 & 189.63 & 9 & 2 & 234.98 \\
\hline 10 & 2 & 287.68 & 10 & 2 & 212.26 \\
\hline 11 & 2 & 193.3 & 11 & 2 & 198.5 \\
\hline
\end{tabular}




\begin{tabular}{|c|c|c|c|c|c|}
\hline 12 & 2 & 238.14 & 12 & 2 & 282.14 \\
\hline 13 & 2 & 232.79 & 13 & 2 & 324.11 \\
\hline 14 & 2 & 203.42 & 14 & 2 & 206.74 \\
\hline 15 & 2 & 200.68 & 15 & 2 & 269.39 \\
\hline 16 & 2 & 339.73 & 16 & 2 & 215.15 \\
\hline 17 & 2 & 179.48 & 17 & 2 & 177.03 \\
\hline 18 & 2 & 282.47 & 18 & 2 & 199.45 \\
\hline 19 & 2 & 174.28 & 19 & 2 & 176.43 \\
\hline 20 & 2 & 287.58 & 20 & 2 & 185.72 \\
\hline 21 & 2 & 190.6 & 21 & 2 & 232 \\
\hline 22 & 2 & 233.15 & 22 & 2 & 225.65 \\
\hline 23 & 2 & 223.28 & 23 & 2 & 325.79 \\
\hline 24 & 2 & 209.13 & 24 & 2 & 190.58 \\
\hline 25 & 2 & 186.92 & 25 & 2 & 202.34 \\
\hline 26 & 2 & 196.53 & 26 & 2 & 197.5 \\
\hline 27 & 2 & 218.49 & 27 & 2 & 193.54 \\
\hline 28 & 2 & 218.93 & 28 & 2 & 197.64 \\
\hline 29 & 2 & 188.19 & 29 & 2 & 187.52 \\
\hline 30 & 2 & 184.97 & 30 & 2 & 216.84 \\
\hline 31 & 2 & 276.57 & 31 & 2 & 247.21 \\
\hline 32 & 2 & 198.89 & 32 & 2 & 256.8 \\
\hline 33 & 2 & 213.12 & 33 & 2 & 207.36 \\
\hline 34 & 2 & 211.18 & 34 & 2 & 227.7 \\
\hline 35 & 2 & 192.96 & 35 & 2 & 225.61 \\
\hline 36 & 2 & 203.87 & 36 & 2 & 187.98 \\
\hline 37 & 2 & 175.32 & 37 & 2 & 165.16 \\
\hline 38 & 2 & 184.3 & 38 & 2 & 169.49 \\
\hline 39 & 2 & 177.48 & 39 & 2 & 185.53 \\
\hline 40 & 2 & 217.43 & 40 & 2 & 228.15 \\
\hline 41 & 2 & 192.75 & 41 & 2 & 191.45 \\
\hline 42 & 2 & 333.22 & 42 & 2 & 220.72 \\
\hline 43 & 2 & 189.75 & 43 & 2 & 207.36 \\
\hline 44 & 2 & 186.41 & 44 & 2 & 174.74 \\
\hline 45 & 2 & 236.85 & 45 & 2 & 268.68 \\
\hline 46 & 2 & 190.34 & 46 & 2 & 177.14 \\
\hline 47 & 2 & 242.29 & 47 & 2 & 216.59 \\
\hline 48 & 2 & 190.65 & 48 & 2 & 182.43 \\
\hline 49 & 2 & 186.24 & 49 & 2 & 184.18 \\
\hline 50 & 2 & 199.24 & 50 & 2 & 190.16 \\
\hline 51 & 2 & 175.25 & 51 & 2 & 196.35 \\
\hline 52 & 2 & 227.55 & 52 & 2 & 215.04 \\
\hline 53 & 2 & 199.41 & 53 & 2 & 184.82 \\
\hline 54 & 2 & 347.29 & 54 & 2 & 295.81 \\
\hline
\end{tabular}




\begin{tabular}{|c|c|c|}
\hline 55 & 2 & 182.58 \\
\hline 56 & 2 & 211.17 \\
\hline 57 & 2 & 178.82 \\
\hline 58 & 2 & 188.96 \\
\hline 59 & 2 & 189.2 \\
\hline 60 & 2 & 222.48 \\
\hline 61 & 2 & 189.08 \\
\hline 62 & 2 & 190.13 \\
\hline 63 & 2 & 181.51 \\
\hline 64 & 2 & 326.98 \\
\hline 65 & 2 & 186.73 \\
\hline 66 & 2 & 263.16 \\
\hline 67 & 2 & 189.9 \\
\hline 68 & 2 & 181.7 \\
\hline 69 & 2 & 266.5 \\
\hline 70 & 2 & 194.5 \\
\hline
\end{tabular}

\begin{tabular}{|c|c|c|}
\hline 55 & 2 & 178 \\
\hline 56 & 2 & 184.4 \\
\hline 57 & 2 & 177.7 \\
\hline 58 & 2 & 185.97 \\
\hline 59 & 2 & 196.47 \\
\hline 60 & 2 & 304.31 \\
\hline 61 & 2 & 186.57 \\
\hline 62 & 2 & 175.46 \\
\hline 63 & 2 & 267.84 \\
\hline 64 & 2 & 272.9 \\
\hline 65 & 2 & 187.36 \\
\hline 66 & 2 & 314.25 \\
\hline 67 & 2 & 189.76 \\
\hline 68 & 2 & 179.04 \\
\hline 69 & 2 & 317 \\
\hline 70 & 2 & 248.35 \\
\hline
\end{tabular}


Appendix C: Delay Data 


\begin{tabular}{|c|c|c|c|c|}
\hline Simulation & Direction & $\begin{array}{c}\text { Stop Delay } \\
\text { (s) }\end{array}$ & Stops & $\begin{array}{c}\text { Vehicle Delay } \\
(s)\end{array}$ \\
\hline 1 & 1 & 323.3 & 9.12 & 422.09 \\
\hline 2 & 1 & 203.37 & 5.17 & 263.98 \\
\hline 3 & 1 & 405.19 & 11.29 & 523.4 \\
\hline 4 & 1 & 160.51 & 3.93 & 208.66 \\
\hline 5 & 1 & 289.81 & 7.63 & 373.57 \\
\hline 6 & 1 & 279.19 & 7.08 & 358.65 \\
\hline 7 & 1 & 206.65 & 5.67 & 271 \\
\hline 8 & 1 & 251.11 & 6.1 & 322.83 \\
\hline 9 & 1 & 324.89 & 9.88 & 423.27 \\
\hline 10 & 1 & 194.47 & 4.53 & 248.91 \\
\hline 11 & 1 & 281.38 & 7.7 & 364.8 \\
\hline 12 & 1 & 305.51 & 7.7 & 388.03 \\
\hline 13 & 1 & 192.25 & 4.83 & 248.74 \\
\hline 14 & 1 & 275.51 & 6.88 & 356.92 \\
\hline 15 & 1 & 225.46 & 6.34 & 294.36 \\
\hline 16 & 1 & 307.12 & 8.45 & 399.39 \\
\hline 17 & 1 & 247.65 & 5.96 & 315.3 \\
\hline 18 & 1 & 311 & 8.38 & 406.46 \\
\hline 19 & 1 & 207.06 & 5.01 & 269.69 \\
\hline 20 & 1 & 359.64 & 10.76 & 470.29 \\
\hline 21 & 1 & 460.14 & 12.98 & 593.83 \\
\hline 22 & 1 & 174.93 & 4.2 & 224.47 \\
\hline 23 & 1 & 196.98 & 5.5 & 258.57 \\
\hline 24 & 1 & 238.25 & 6.03 & 309.9 \\
\hline 25 & 1 & 176.77 & 4.65 & 231.13 \\
\hline 26 & 1 & 216.53 & 5.53 & 278.17 \\
\hline 27 & 1 & 226.91 & 5.37 & 290.58 \\
\hline 28 & 1 & 337.93 & 8.95 & 435.57 \\
\hline 29 & 1 & 335.04 & 8.75 & 431.04 \\
\hline 30 & 1 & 380.47 & 10.66 & 491.32 \\
\hline 31 & 1 & 160.35 & 3.97 & 205.91 \\
\hline 32 & 1 & 240.93 & 6.19 & 310.4 \\
\hline 33 & 1 & 190.77 & 4.96 & 249.87 \\
\hline 34 & 1 & 217.99 & 5.28 & 282.49 \\
\hline 35 & 1 & 192.66 & 5.02 & 249.67 \\
\hline 36 & 1 & 248.33 & 6.6 & 323.47 \\
\hline 37 & 1 & 223.2 & 5.5 & 290.97 \\
\hline 38 & 1 & 350.93 & 10.83 & 462.62 \\
\hline 39 & 1 & 178.51 & 4.61 & 233.39 \\
\hline 40 & 1 & 196.29 & 4.63 & 253.96 \\
\hline
\end{tabular}

\begin{tabular}{|c|c|c|c|c|}
\hline Simulation & Direction & $\begin{array}{c}\text { Stop Delay } \\
(s)\end{array}$ & $\begin{array}{c}\text { Stops } \\
\text { (s) }\end{array}$ & $\begin{array}{c}\text { Vehicle Delay } \\
(s)\end{array}$ \\
\hline 1 & 1 & 93.63 & 2.08 & 115.5 \\
\hline 2 & 1 & 92.13 & 2.26 & 115.16 \\
\hline 3 & 1 & 96.39 & 2.11 & 118.51 \\
\hline 4 & 1 & 83.39 & 2.12 & 105.67 \\
\hline 5 & 1 & 95.89 & 2.19 & 118.23 \\
\hline 6 & 1 & 93.86 & 2.12 & 115.49 \\
\hline 7 & 1 & 92.34 & 2.26 & 115.13 \\
\hline 8 & 1 & 101.15 & 2.31 & 124.98 \\
\hline 9 & 1 & 94.4 & 2.24 & 117 \\
\hline 10 & 1 & 89.3 & 2.21 & 111.07 \\
\hline 11 & 1 & 92.72 & 2.22 & 115.64 \\
\hline 12 & 1 & 99.59 & 2.11 & 121.6 \\
\hline 13 & 1 & 89.89 & 2.24 & 113.15 \\
\hline 14 & 1 & 105.1 & 2.35 & 129.33 \\
\hline 15 & 1 & 85.81 & 2.25 & 109.26 \\
\hline 16 & 1 & 92.34 & 2.21 & 115.32 \\
\hline 17 & 1 & 90.08 & 2.19 & 111.89 \\
\hline 18 & 1 & 94.47 & 2.29 & 118.15 \\
\hline 19 & 1 & 87.82 & 2.29 & 110.94 \\
\hline 20 & 1 & 107.38 & 2.38 & 131.19 \\
\hline 21 & 1 & 93.24 & 2.12 & 114.77 \\
\hline 22 & 1 & 89.59 & 2.27 & 113 \\
\hline 23 & 1 & 88.23 & 2.2 & 110.57 \\
\hline 24 & 1 & 80.7 & 2.08 & 101.94 \\
\hline 25 & 1 & 86.66 & 2.06 & 108.18 \\
\hline 26 & 1 & 83.69 & 2.14 & 105.74 \\
\hline 27 & 1 & 93.42 & 2.31 & 117.19 \\
\hline 28 & 1 & 93.03 & 2.15 & 115.49 \\
\hline 29 & 1 & 91.56 & 2.26 & 114.38 \\
\hline 30 & 1 & 99.79 & 2.33 & 123.77 \\
\hline 31 & 1 & 86.11 & 2.12 & 108.51 \\
\hline 32 & 1 & 102.57 & 2.28 & 126.26 \\
\hline 33 & 1 & 81.45 & 1.96 & 102.84 \\
\hline 34 & 1 & 100.71 & 2.26 & 123.86 \\
\hline 35 & 1 & 88.89 & 2.25 & 111.62 \\
\hline 36 & 1 & 91.02 & 2.23 & 113.62 \\
\hline 37 & 1 & 91.83 & 2.3 & 115.21 \\
\hline 38 & 1 & 87.91 & 2.26 & 110.83 \\
\hline 39 & 1 & 95.1 & 2.34 & 118.95 \\
\hline 40 & 1 & 91.53 & 2.34 & 114.4 \\
\hline
\end{tabular}




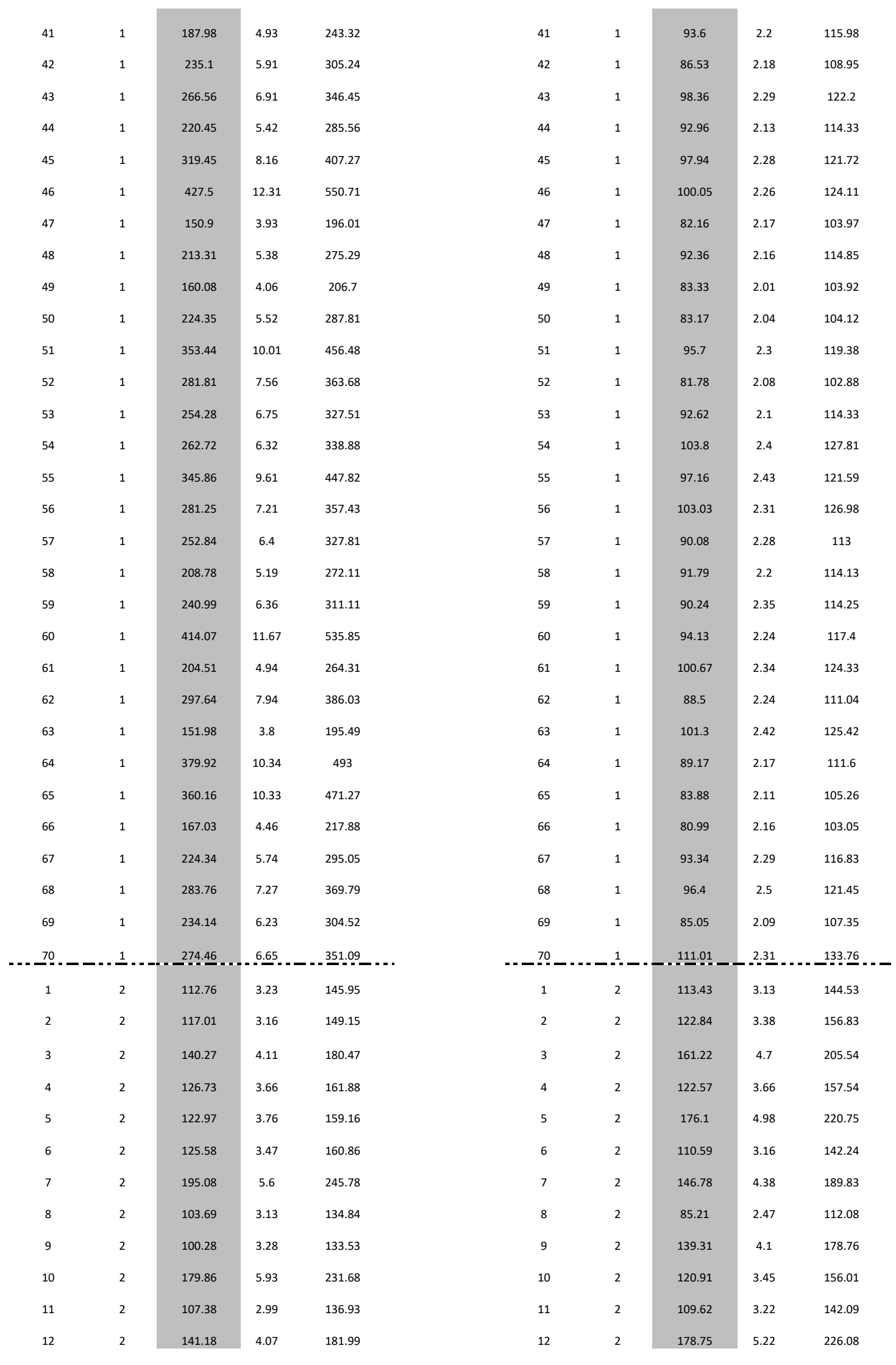




\begin{tabular}{|c|c|c|c|c|c|c|c|c|c|}
\hline 13 & 2 & 136.54 & 4.24 & 176.82 & 13 & 2 & 216.68 & 5.76 & 268.24 \\
\hline 14 & 2 & 114.65 & 3.17 & 147.04 & 14 & 2 & 114.38 & 3.59 & 150.52 \\
\hline 15 & 2 & 109.58 & 3.44 & 144.5 & 15 & 2 & 172.95 & 4.24 & 213.43 \\
\hline 16 & 2 & 229.9 & 6.11 & 283.22 & 16 & 2 & 123.26 & 3.53 & 158.85 \\
\hline 17 & 2 & 95.85 & 2.61 & 123.38 & 17 & 2 & 91.22 & 2.9 & 120.97 \\
\hline 18 & 2 & 180.57 & 4.85 & 226.32 & 18 & 2 & 108.85 & 3.25 & 143.32 \\
\hline 19 & 2 & 90.22 & 2.6 & 117.64 & 19 & 2 & 92.77 & 2.65 & 120.11 \\
\hline 20 & 2 & 182.31 & 5.14 & 231.34 & 20 & 2 & 99.49 & 2.92 & 129.3 \\
\hline 21 & 2 & 103.55 & 2.98 & 134.13 & 21 & 2 & 139.87 & 4.13 & 175.9 \\
\hline 22 & 2 & 138.89 & 3.96 & 176.72 & 22 & 2 & 134.08 & 3.54 & 169.4 \\
\hline 23 & 2 & 130.16 & 3.73 & 167.14 & 23 & 2 & 221.57 & 5.43 & 269.73 \\
\hline 24 & 2 & 118.94 & 3.38 & 152.92 & 24 & 2 & 107.11 & 2.55 & 134.35 \\
\hline 25 & 2 & 100.12 & 2.99 & 130.44 & 25 & 2 & 113.35 & 3.19 & 145.97 \\
\hline 26 & 2 & 108.54 & 3.09 & 140.23 & 26 & 2 & 109.06 & 3.06 & 141.11 \\
\hline 27 & 2 & 127.24 & 3.63 & 162.46 & 27 & 2 & 106.93 & 3.02 & 137.57 \\
\hline 28 & 2 & 122.69 & 4.1 & 162.75 & 28 & 2 & 108.81 & 3.12 & 141.34 \\
\hline 29 & 2 & 101.53 & 2.95 & 131.92 & 29 & 2 & 100.79 & 3.04 & 131.31 \\
\hline 30 & 2 & 99.13 & 2.84 & 128.54 & 30 & 2 & 127.34 & 3.49 & 160.53 \\
\hline 31 & 2 & 174.36 & 4.93 & 220.51 & 31 & 2 & 148.19 & 4.49 & 191 \\
\hline 32 & 2 & 108.88 & 3.31 & 142.62 & 32 & 2 & 157.13 & 4.68 & 200.6 \\
\hline 33 & 2 & 125.3 & 3.07 & 156.78 & 33 & 2 & 117.64 & 3.29 & 150.83 \\
\hline 34 & 2 & 118.56 & 3.8 & 154.87 & 34 & 2 & 132.7 & 3.93 & 171.56 \\
\hline 35 & 2 & 105.11 & 3.01 & 136.68 & 35 & 2 & 132.18 & 3.69 & 169.39 \\
\hline 36 & 2 & 115.54 & 3.28 & 147.64 & 36 & 2 & 100.8 & 2.99 & 131.65 \\
\hline 37 & 2 & 90.2 & 2.79 & 119.17 & 37 & 2 & 82.12 & 2.57 & 109.08 \\
\hline 38 & 2 & 98.33 & 2.82 & 128.17 & 38 & 2 & 86.67 & 2.52 & 113.27 \\
\hline 39 & 2 & 92.22 & 2.87 & 121.25 & 39 & 2 & 100.57 & 2.8 & 129.36 \\
\hline 40 & 2 & 127.09 & 3.46 & 161.01 & 40 & 2 & 133.59 & 3.8 & 171.58 \\
\hline 41 & 2 & 107.69 & 2.89 & 136.62 & 41 & 2 & 104.21 & 3.14 & 135.24 \\
\hline 42 & 2 & 220.27 & 6.37 & 277.08 & 42 & 2 & 131.37 & 3.39 & 164.47 \\
\hline 43 & 2 & 100.86 & 3.28 & 133.21 & 43 & 2 & 117.34 & 3.26 & 151.04 \\
\hline 44 & 2 & 100.28 & 2.82 & 130.31 & 44 & 2 & 90.81 & 2.63 & 118.37 \\
\hline 45 & 2 & 140.38 & 4.27 & 180.63 & 45 & 2 & 169.84 & 4.62 & 212.22 \\
\hline 46 & 2 & 102.41 & 2.97 & 133.97 & 46 & 2 & 92.85 & 2.71 & 120.85 \\
\hline 47 & 2 & 143.69 & 4.6 & 185.88 & 47 & 2 & 123.8 & 3.72 & 160.13 \\
\hline 48 & 2 & 101.7 & 3.12 & 134.23 & 48 & 2 & 96.79 & 2.89 & 126.15 \\
\hline 49 & 2 & 98.54 & 2.99 & 129.94 & 49 & 2 & 99.06 & 2.7 & 127.93 \\
\hline 50 & 2 & 109.74 & 3.21 & 142.93 & 50 & 2 & 101.77 & 2.88 & 133.97 \\
\hline 51 & 2 & 88.72 & 2.92 & 119.07 & 51 & 2 & 109.82 & 2.98 & 140.17 \\
\hline 52 & 2 & 134.17 & 3.73 & 171.36 & 52 & 2 & 122.24 & 3.52 & 158.71 \\
\hline 53 & 2 & 109.86 & 3.21 & 143.34 & 53 & 2 & 100.22 & 2.67 & 128.65 \\
\hline 54 & 2 & 234.72 & 6.49 & 291.17 & 54 & 2 & 190.28 & 5.36 & 239.61 \\
\hline
\end{tabular}




\begin{tabular}{|c|c|c|c|c|}
\hline 55 & 2 & 99.06 & 2.64 & 126.3 \\
\hline 56 & 2 & 120.04 & 3.5 & 154.96 \\
\hline 57 & 2 & 94.32 & 2.77 & 122.55 \\
\hline 58 & 2 & 102.72 & 2.91 & 132.65 \\
\hline 59 & 2 & 102.67 & 2.84 & 132.81 \\
\hline 60 & 2 & 129.64 & 3.75 & 166.26 \\
\hline 61 & 2 & 100.86 & 3.17 & 133.18 \\
\hline 62 & 2 & 103.78 & 2.93 & 133.93 \\
\hline 63 & 2 & 97.08 & 2.64 & 125.07 \\
\hline 64 & 2 & 218.03 & 5.73 & 271.03 \\
\hline 65 & 2 & 100.12 & 3.01 & 130.49 \\
\hline 66 & 2 & 161.25 & 4.93 & 206.96 \\
\hline 67 & 2 & 101.43 & 3.06 & 133.73 \\
\hline 68 & 2 & 98.04 & 2.52 & 124.81 \\
\hline 69 & 2 & 163.48 & 4.94 & 210.25 \\
\hline 70 & 2 & 109.94 & 2.72 & 138.43 \\
\hline
\end{tabular}

\begin{tabular}{|c|c|c|c|c|}
\hline 55 & 2 & 93.29 & 2.69 & 121.64 \\
\hline 56 & 2 & 97.6 & 2.99 & 128.08 \\
\hline 57 & 2 & 92.78 & 2.77 & 121.59 \\
\hline 58 & 2 & 100.3 & 2.95 & 129.74 \\
\hline 59 & 2 & 109.58 & 2.91 & 140.32 \\
\hline 60 & 2 & 196.5 & 5.55 & 248.23 \\
\hline 61 & 2 & 99.84 & 3.02 & 130.48 \\
\hline 62 & 2 & 90.34 & 2.83 & 119.17 \\
\hline 63 & 2 & 171.21 & 4.05 & 211.89 \\
\hline 64 & 2 & 171.61 & 4.8 & 216.66 \\
\hline 65 & 2 & 102.18 & 2.89 & 131.36 \\
\hline 66 & 2 & 207.12 & 5.92 & 257.97 \\
\hline 67 & 2 & 102.98 & 2.98 & 133.47 \\
\hline 68 & 2 & 96.35 & 2.49 & 122.28 \\
\hline 69 & 2 & 205.6 & 6.62 & 260.61 \\
\hline 70 & 2 & 151.71 & 4.19 & 192.3 \\
\hline
\end{tabular}


Appendix D: Vehicle Distribution Data 


\begin{tabular}{|c|c|c|c|}
\hline Simulation & Lane & Vehicles & $\begin{array}{c}\text { Lane } \\
\text { Utilization }\end{array}$ \\
\hline 1 & 1 & 610 & $72.6 \%$ \\
\hline 2 & 1 & 683 & $79.1 \%$ \\
\hline 3 & 1 & 588 & $73.1 \%$ \\
\hline 4 & 1 & 700 & $80.9 \%$ \\
\hline 5 & 1 & 612 & $73.9 \%$ \\
\hline 6 & 1 & 638 & $76.0 \%$ \\
\hline 7 & 1 & 691 & $79.2 \%$ \\
\hline 8 & 1 & 633 & $73.0 \%$ \\
\hline 9 & 1 & 681 & $84.5 \%$ \\
\hline 10 & 1 & 685 & $77.9 \%$ \\
\hline 11 & 1 & 686 & $80.5 \%$ \\
\hline 12 & 1 & 614 & $74.2 \%$ \\
\hline 13 & 1 & 610 & $74.0 \%$ \\
\hline 14 & 1 & 641 & $74.5 \%$ \\
\hline 15 & 1 & 646 & $77.7 \%$ \\
\hline 16 & 1 & 665 & $79.0 \%$ \\
\hline 17 & 1 & 611 & $75.0 \%$ \\
\hline 18 & 1 & 608 & $70.9 \%$ \\
\hline 19 & 1 & 680 & $74.9 \%$ \\
\hline 20 & 1 & 626 & $79.4 \%$ \\
\hline 21 & 1 & 596 & $76.3 \%$ \\
\hline 22 & 1 & 677 & $78.0 \%$ \\
\hline 23 & 1 & 591 & $74.2 \%$ \\
\hline 24 & 1 & 629 & $75.8 \%$ \\
\hline 25 & 1 & 686 & $79.3 \%$ \\
\hline 26 & 1 & 624 & $75.7 \%$ \\
\hline 27 & 1 & 678 & $75.7 \%$ \\
\hline 28 & 1 & 573 & $71.0 \%$ \\
\hline 29 & 1 & 633 & $75.6 \%$ \\
\hline 30 & 1 & 645 & $79.4 \%$ \\
\hline 31 & 1 & 693 & $79.1 \%$ \\
\hline 32 & 1 & 703 & $79.5 \%$ \\
\hline 33 & 1 & 644 & $74.5 \%$ \\
\hline 34 & 1 & 643 & $74.0 \%$ \\
\hline 35 & 1 & 611 & $73.3 \%$ \\
\hline 36 & 1 & 694 & $79.8 \%$ \\
\hline 37 & 1 & 606 & $71.3 \%$ \\
\hline 38 & 1 & 602 & $71.0 \%$ \\
\hline 39 & 1 & 693 & $78.9 \%$ \\
\hline 40 & 1 & 671 & $76.1 \%$ \\
\hline
\end{tabular}

\begin{tabular}{|c|c|c|c|}
\hline Simulation & Lane & Vehicles & $\begin{array}{c}\text { Lane } \\
\text { Utilization }\end{array}$ \\
\hline 1 & 1 & 453 & $47.7 \%$ \\
\hline 2 & 1 & 431 & $47.3 \%$ \\
\hline 3 & 1 & 439 & $46.6 \%$ \\
\hline 4 & 1 & 399 & $46.6 \%$ \\
\hline 5 & 1 & 426 & $47.2 \%$ \\
\hline 6 & 1 & 440 & $48.1 \%$ \\
\hline 7 & 1 & 414 & $46.3 \%$ \\
\hline 8 & 1 & 450 & $48.7 \%$ \\
\hline 9 & 1 & 421 & $48.2 \%$ \\
\hline 10 & 1 & 435 & $47.7 \%$ \\
\hline 11 & 1 & 442 & $47.5 \%$ \\
\hline 12 & 1 & 417 & $47.2 \%$ \\
\hline 13 & 1 & 399 & $46.7 \%$ \\
\hline 14 & 1 & 426 & $46.9 \%$ \\
\hline 15 & 1 & 417 & $47.2 \%$ \\
\hline 16 & 1 & 435 & $47.7 \%$ \\
\hline 17 & 1 & 407 & $47.0 \%$ \\
\hline 18 & 1 & 437 & $47.5 \%$ \\
\hline 19 & 1 & 436 & $47.6 \%$ \\
\hline 20 & 1 & 417 & $46.2 \%$ \\
\hline 21 & 1 & 433 & $47.2 \%$ \\
\hline 22 & 1 & 421 & $47.3 \%$ \\
\hline 23 & 1 & 409 & $46.5 \%$ \\
\hline 24 & 1 & 397 & $46.4 \%$ \\
\hline 25 & 1 & 410 & $45.9 \%$ \\
\hline 26 & 1 & 416 & $46.8 \%$ \\
\hline 27 & 1 & 446 & $47.5 \%$ \\
\hline 28 & 1 & 428 & $47.5 \%$ \\
\hline 29 & 1 & 437 & $46.5 \%$ \\
\hline 30 & 1 & 427 & $47.9 \%$ \\
\hline 31 & 1 & 411 & $46.3 \%$ \\
\hline 32 & 1 & 469 & $48.8 \%$ \\
\hline 33 & 1 & 418 & $47.6 \%$ \\
\hline 34 & 1 & 453 & $49.0 \%$ \\
\hline 35 & 1 & 420 & $48.2 \%$ \\
\hline 36 & 1 & 456 & $48.6 \%$ \\
\hline 37 & 1 & 422 & $48.1 \%$ \\
\hline 38 & 1 & 445 & $47.3 \%$ \\
\hline 39 & 1 & 422 & $46.9 \%$ \\
\hline 40 & 1 & 408 & $45.5 \%$ \\
\hline
\end{tabular}




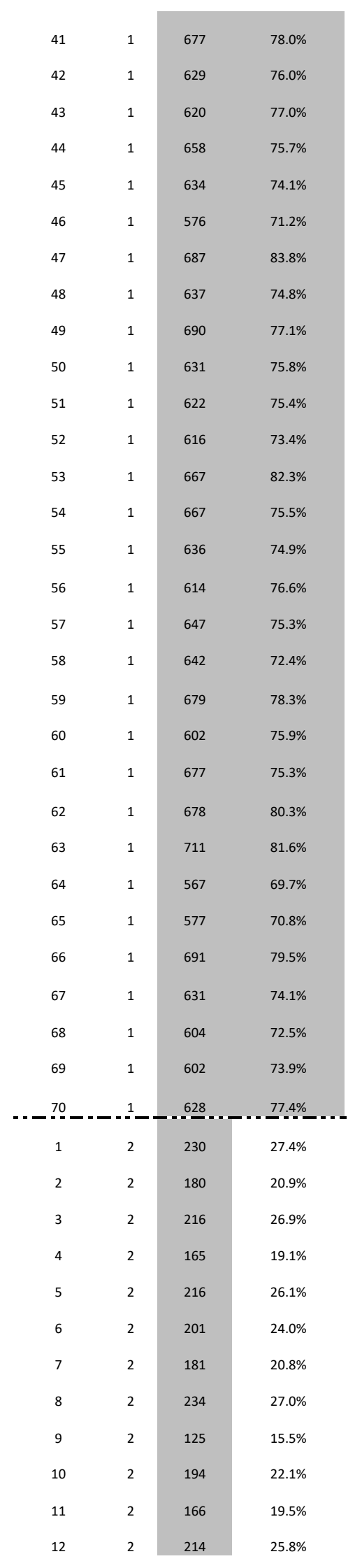

\begin{tabular}{|c|c|c|c|}
\hline 41 & 1 & 415 & $47.5 \%$ \\
\hline 42 & 1 & 424 & $48.3 \%$ \\
\hline 43 & 1 & 423 & $47.9 \%$ \\
\hline 44 & 1 & 409 & $46.3 \%$ \\
\hline 45 & 1 & 449 & $48.7 \%$ \\
\hline 46 & 1 & 436 & $48.1 \%$ \\
\hline 47 & 1 & 390 & $46.5 \%$ \\
\hline 48 & 1 & 435 & $47.3 \%$ \\
\hline 49 & 1 & 431 & $48.0 \%$ \\
\hline 50 & 1 & 404 & $47.8 \%$ \\
\hline 51 & 1 & 431 & $47.5 \%$ \\
\hline 52 & 1 & 438 & $47.8 \%$ \\
\hline 53 & 1 & 412 & $46.7 \%$ \\
\hline 54 & 1 & 470 & $48.1 \%$ \\
\hline 55 & 1 & 445 & $48.3 \%$ \\
\hline 56 & 1 & 436 & $47.8 \%$ \\
\hline 57 & 1 & 429 & $47.1 \%$ \\
\hline 58 & 1 & 418 & $46.2 \%$ \\
\hline 59 & 1 & 451 & $47.3 \%$ \\
\hline 60 & 1 & 434 & $46.8 \%$ \\
\hline 61 & 1 & 441 & $47.6 \%$ \\
\hline 62 & 1 & 444 & $48.6 \%$ \\
\hline 63 & 1 & 433 & $47.7 \%$ \\
\hline 64 & 1 & 459 & $47.9 \%$ \\
\hline 65 & 1 & 420 & $46.5 \%$ \\
\hline 66 & 1 & 413 & $46.9 \%$ \\
\hline 67 & 1 & 430 & $47.1 \%$ \\
\hline 68 & 1 & 444 & $48.6 \%$ \\
\hline 69 & 1 & 407 & $47.3 \%$ \\
\hline 70. & -1 & 436 & $-46.3 \%$ \\
\hline 1 & 2 & 497 & $52.3 \%$ \\
\hline 2 & 2 & 481 & $52.7 \%$ \\
\hline 3 & 2 & 503 & $53.4 \%$ \\
\hline 4 & 2 & 458 & $53.4 \%$ \\
\hline 5 & 2 & 477 & $52.8 \%$ \\
\hline 6 & 2 & 475 & $51.9 \%$ \\
\hline 7 & 2 & 480 & $53.7 \%$ \\
\hline 8 & 2 & 474 & $51.3 \%$ \\
\hline 9 & 2 & 452 & $51.8 \%$ \\
\hline 10 & 2 & 476 & $52.3 \%$ \\
\hline 11 & 2 & 488 & $52.5 \%$ \\
\hline 12 & 2 & 467 & $52.8 \%$ \\
\hline
\end{tabular}




\begin{tabular}{|c|c|c|c|c|c|c|c|}
\hline 13 & 2 & 214 & $26.0 \%$ & 13 & 2 & 455 & $53.3 \%$ \\
\hline 14 & 2 & 219 & $25.5 \%$ & 14 & 2 & 483 & $53.1 \%$ \\
\hline 15 & 2 & 185 & $22.3 \%$ & 15 & 2 & 467 & $52.8 \%$ \\
\hline 16 & 2 & 177 & $21.0 \%$ & 16 & 2 & 476 & $52.3 \%$ \\
\hline 17 & 2 & 204 & $25.0 \%$ & 17 & 2 & 459 & $53.0 \%$ \\
\hline 18 & 2 & 249 & $29.1 \%$ & 18 & 2 & 483 & $52.5 \%$ \\
\hline 19 & 2 & 228 & $25.1 \%$ & 19 & 2 & 480 & $52.4 \%$ \\
\hline 20 & 2 & 162 & $20.6 \%$ & 20 & 2 & 485 & $53.8 \%$ \\
\hline 21 & 2 & 185 & $23.7 \%$ & 21 & 2 & 484 & $52.8 \%$ \\
\hline 22 & 2 & 191 & $22.0 \%$ & 22 & 2 & 469 & $52.7 \%$ \\
\hline 23 & 2 & 205 & $25.8 \%$ & 23 & 2 & 471 & $53.5 \%$ \\
\hline 24 & 2 & 201 & $24.2 \%$ & 24 & 2 & 458 & $53.6 \%$ \\
\hline 25 & 2 & 179 & $20.7 \%$ & 25 & 2 & 484 & $54.1 \%$ \\
\hline 26 & 2 & 200 & $24.3 \%$ & 26 & 2 & 473 & $53.2 \%$ \\
\hline 27 & 2 & 218 & $24.3 \%$ & 27 & 2 & 493 & $52.5 \%$ \\
\hline 28 & 2 & 234 & $29.0 \%$ & 28 & 2 & 474 & $52.5 \%$ \\
\hline 29 & 2 & 204 & $24.4 \%$ & 29 & 2 & 503 & $53.5 \%$ \\
\hline 30 & 2 & 167 & $20.6 \%$ & 30 & 2 & 464 & $52.1 \%$ \\
\hline 31 & 2 & 183 & $20.9 \%$ & 31 & 2 & 476 & $53.7 \%$ \\
\hline 32 & 2 & 181 & $20.5 \%$ & 32 & 2 & 492 & $51.2 \%$ \\
\hline 33 & 2 & 221 & $25.5 \%$ & 33 & 2 & 461 & $52.4 \%$ \\
\hline 34 & 2 & 226 & $26.0 \%$ & 34 & 2 & 471 & $51.0 \%$ \\
\hline 35 & 2 & 222 & $26.7 \%$ & 35 & 2 & 451 & $51.8 \%$ \\
\hline 36 & 2 & 176 & $20.2 \%$ & 36 & 2 & 483 & $51.4 \%$ \\
\hline 37 & 2 & 244 & $28.7 \%$ & 37 & 2 & 455 & $51.9 \%$ \\
\hline 38 & 2 & 246 & $29.0 \%$ & 38 & 2 & 496 & $52.7 \%$ \\
\hline 39 & 2 & 185 & $21.1 \%$ & 39 & 2 & 478 & $53.1 \%$ \\
\hline 40 & 2 & 211 & $23.9 \%$ & 40 & 2 & 488 & $54.5 \%$ \\
\hline 41 & 2 & 191 & $22.0 \%$ & 41 & 2 & 459 & $52.5 \%$ \\
\hline 42 & 2 & 199 & $24.0 \%$ & 42 & 2 & 453 & $51.7 \%$ \\
\hline 43 & 2 & 185 & $23.0 \%$ & 43 & 2 & 460 & $52.1 \%$ \\
\hline 44 & 2 & 211 & $24.3 \%$ & 44 & 2 & 474 & $53.7 \%$ \\
\hline 45 & 2 & 222 & $25.9 \%$ & 45 & 2 & 473 & $51.3 \%$ \\
\hline 46 & 2 & 233 & $28.8 \%$ & 46 & 2 & 470 & $51.9 \%$ \\
\hline 47 & 2 & 133 & $16.2 \%$ & 47 & 2 & 449 & $53.5 \%$ \\
\hline 48 & 2 & 215 & $25.2 \%$ & 48 & 2 & 484 & $52.7 \%$ \\
\hline 49 & 2 & 205 & $22.9 \%$ & 49 & 2 & 466 & $52.0 \%$ \\
\hline 50 & 2 & 201 & $24.2 \%$ & 50 & 2 & 441 & $52.2 \%$ \\
\hline 51 & 2 & 203 & $24.6 \%$ & 51 & 2 & 476 & $52.5 \%$ \\
\hline 52 & 2 & 223 & $26.6 \%$ & 52 & 2 & 479 & $52.2 \%$ \\
\hline 53 & 2 & 143 & $17.7 \%$ & 53 & 2 & 471 & $53.3 \%$ \\
\hline 54 & 2 & 216 & $24.5 \%$ & 54 & 2 & 508 & $51.9 \%$ \\
\hline 55 & 2 & 213 & $25.1 \%$ & 55 & 2 & 477 & $51.7 \%$ \\
\hline
\end{tabular}




\begin{tabular}{lll}
56 & 2 & 188 \\
57 & 2 & 212 \\
58 & 2 & 245 \\
59 & 2 & 188 \\
60 & 2 & 191 \\
61 & 2 & 222 \\
62 & 2 & 166 \\
63 & 2 & 160 \\
64 & 2 & 247 \\
65 & 2 & 238 \\
66 & 2 & 178 \\
67 & 2 & 221 \\
68 & 2 & 229 \\
69 & 2 & 213 \\
70 & 2 & 183 \\
\hline
\end{tabular}

\begin{tabular}{l}
$23.4 \%$ \\
$24.7 \%$ \\
$27.6 \%$ \\
$21.7 \%$ \\
$24.1 \%$ \\
$24.7 \%$ \\
\hline $19.7 \%$ \\
\hline $18.4 \%$ \\
\hline $30.3 \%$ \\
\hline $29.2 \%$ \\
\hline $20.5 \%$ \\
\hline $25.9 \%$ \\
\hline $27.5 \%$ \\
\hline $26.1 \%$ \\
\hline $22.6 \%$
\end{tabular}

\begin{tabular}{lll|l}
56 & 2 & 476 & $52.2 \%$ \\
57 & 2 & 481 & $52.9 \%$ \\
58 & 2 & 487 & $53.8 \%$ \\
59 & 2 & 502 & $52.7 \%$ \\
60 & 2 & 494 & $53.2 \%$ \\
61 & 2 & 486 & $52.4 \%$ \\
62 & 2 & 470 & $51.4 \%$ \\
63 & 2 & 475 & $52.3 \%$ \\
64 & 2 & 500 & $52.1 \%$ \\
65 & 2 & 483 & $53.5 \%$ \\
66 & 2 & 468 & $53.1 \%$ \\
67 & 2 & 483 & $52.9 \%$ \\
68 & 2 & 470 & $51.4 \%$ \\
69 & 2 & 453 & $52.7 \%$ \\
70 & 2 & 506 & $53.7 \%$ \\
\hline
\end{tabular}


Appendix E: Traffic Signal Timings 
New Albany, Indiana - Actuated Signal Timing Record

\begin{tabular}{|c|c|c|c|}
\hline \multirow[b]{2}{*}{ INTERSECTION: } & State: & County: & \\
\hline & State St \& Daisy Ln & \multicolumn{2}{|c|}{ INTERSECTION CODE } \\
\hline & & DATE SET: & $11 / 8 / 18$ \\
\hline CONTROLLER TYPE: & Cobalt & TIME: & $4 p$ \\
\hline
\end{tabular}

\begin{tabular}{|c|c|c|c|c|c|c|c|c|}
\hline PHASE MOVEMENT/INTERVAL & 1 & 2 & 3 & 4 & 5 & 6 & 7 & 8 \\
\hline & NBLT & SB & & WB & SBLT & NB & & $\overline{E B}$ \\
\hline MIN. GREEN & 4 & 10 & & 7 & 5 & 10 & & 7 \\
\hline WALK & & 5 & & 5 & & 5 & & 5 \\
\hline PED CLEAR & & 11 & & 15 & & 11 & & 15 \\
\hline PASSAGE & 3.0 & 3.0 & & 3.0 & 3.0 & 3.0 & & 3.0 \\
\hline MAX I & 15 & 40 & & 30 & 15 & 40 & & 30 \\
\hline MAX II & 15 & 40 & & 30 & 15 & 40 & & 30 \\
\hline \multicolumn{9}{|l|}{ MAX III } \\
\hline \multicolumn{9}{|l|}{ MAX EXT. } \\
\hline AMBER & 3.5 & 4.0 & & 4.0 & 3.5 & 4.0 & & 4.0 \\
\hline RED CLEAR & 0.5 & 3.0 & & 3.0 & 0.5 & 3.0 & & 3.0 \\
\hline \multicolumn{9}{|l|}{ SECONDS PER ACT } \\
\hline \multicolumn{9}{|l|}{ MAX. VAR. INITIAL } \\
\hline \multicolumn{9}{|l|}{ BEFORE REDUCTION } \\
\hline \multicolumn{9}{|l|}{ TIME TO REDUCE } \\
\hline MIN. GAP & 3.0 & 3.0 & & 3.0 & 3.0 & 3.0 & & 3.0 \\
\hline \multicolumn{9}{|l|}{ MEMORY } \\
\hline VEH RECALL & & $\mathrm{x}$ & & & & $x$ & & \\
\hline \multicolumn{9}{|l|}{\begin{tabular}{|l} 
SOFT RECALL \\
\end{tabular}} \\
\hline \multicolumn{9}{|l|}{ PED RECALL } \\
\hline DUAL ENTRY & & $\mathrm{x}$ & & $\mathrm{x}$ & & $\mathrm{x}$ & & $\mathrm{x}$ \\
\hline \multicolumn{9}{|l|}{ CNA I } \\
\hline & & & & & & & & \\
\hline THIS FLASHES & & $\mathrm{R}$ & & $\mathrm{R}$ & & $\mathrm{R}$ & & $\mathrm{R}$ \\
\hline
\end{tabular}

NOTES:

Cy1/Sp1/Of1 CY 100 Of 90

Cy2/Sp1/Of1

Cy 90 of 75

$\mathrm{NIC}(\mathrm{CY} / \mathrm{SP} / \mathrm{OF})$
Phase 1

8
8
$6002 / 1 / 1$
$13001 / 1 / 1$

2
62
53

3
0
0

4
30
29

5
25
24

6
46
36

$\begin{array}{lr}7 & 8 \\ 0 & 29 \\ 0 & 30\end{array}$


New Albany, Indiana - Actuated Signal Timing Record

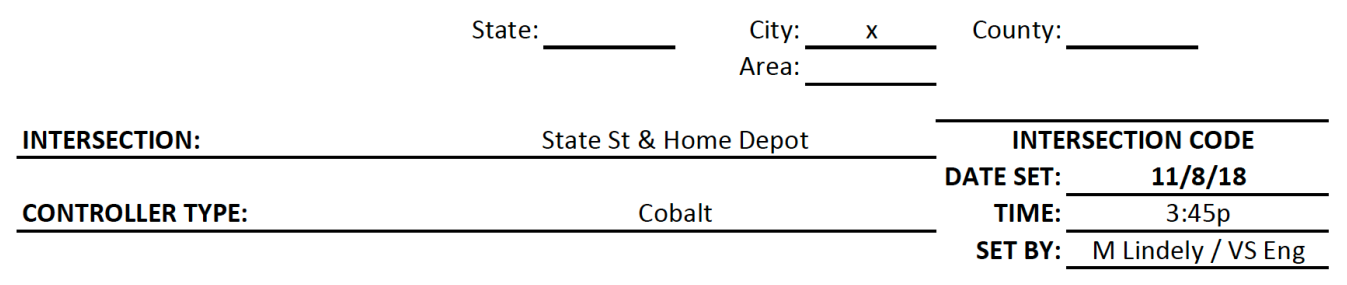

\begin{tabular}{|c|c|c|c|c|c|c|c|c|}
\hline PHASE MOVEMENT/INTERVAL & 1 & 2 & 3 & 4 & 5 & 6 & 7 & 8 \\
\hline & NBLT & SB & & WB & SBLT & NB & & $\mathrm{EB}$ \\
\hline MIN. GREEN & 5 & 20 & & 8 & 5 & 20 & & 8 \\
\hline WALK & & 5 & & 5 & & 5 & & 5 \\
\hline PED CLEAR & & 11 & & 15 & & 11 & & 15 \\
\hline PASSAGE & 2.0 & 5.0 & & 2.0 & 2.0 & 5.0 & & 2.0 \\
\hline MAX I & 25 & 50 & & 30 & 25 & 50 & & 30 \\
\hline MAX II & 25 & 50 & & 30 & 25 & 50 & & 30 \\
\hline \multicolumn{9}{|l|}{ MAX III } \\
\hline \multicolumn{9}{|l|}{ MAX EXT. } \\
\hline AMBER & 3.0 & 4.0 & & 3.2 & 3.0 & 4.0 & & 3.2 \\
\hline RED CLEAR & 3.0 & 3.0 & & 3.0 & 3.0 & 3.0 & & 3.0 \\
\hline SECONDS PER ACT & & 2.0 & & & & 2.0 & & \\
\hline \multicolumn{9}{|l|}{ MAX. VAR. INITIAL } \\
\hline \multicolumn{9}{|l|}{ BEFORE REDUCTION } \\
\hline \multicolumn{9}{|l|}{ TIME TO REDUCE } \\
\hline MIN. GAP & 1.5 & 1.5 & & 1.5 & 1.5 & 1.5 & & 1.5 \\
\hline MEMORY & & $\mathrm{x}$ & & & & $\mathrm{x}$ & & \\
\hline VEH RECALL & & $\mathrm{x}$ & & & & $x$ & & \\
\hline \multicolumn{9}{|l|}{ SOFT RECALL } \\
\hline \multicolumn{9}{|l|}{ PED RECALL } \\
\hline DUAL ENTRY & & & & $x$ & & & & $x$ \\
\hline \multicolumn{9}{|l|}{ CNA I } \\
\hline THIS FLASHES & & $\mathrm{R}$ & & $\mathrm{R}$ & & $\mathrm{R}$ & & $\mathrm{R}$ \\
\hline
\end{tabular}

NOTES:

Cy1/Sp1/Of1 CY 100 Of 86

Cy2/Sp1/Of1

Cy 90 of 85

$\mathrm{NIC}$ (CY/SP/OF)
Mon-Sat
Phase 1

12

14

$6002 / 1 / 1$

$13001 / 1 / 1$

2300 CKT 13 OFF FREE

$\begin{array}{rrrrr}4 & 5 & 6 & 7 & 8 \\ 39 & 11 & 50 & 0 & 39 \\ 32 & 14 & 44 & 0 & 32\end{array}$

Sun

$6002 / 1 / 1$

$13001 / 1 / 1$

2300 CKT 13 OFF FREE 
New Albany, Indiana - Actuated Signal Timing Record

\begin{tabular}{|c|c|c|c|c|c|}
\hline \multirow[b]{2}{*}{ INTERSECTION: } & State: & \multicolumn{2}{|c|}{ City: $\quad x$} & County: & \\
\hline & \multicolumn{3}{|c|}{ State St \& Target } & \multicolumn{2}{|c|}{ INTERSECTION CODE } \\
\hline & & & & DATE SET: & $11 / 8 / 18$ \\
\hline \multirow[t]{2}{*}{ CONTROLLER TYPE: } & \multirow{2}{*}{\multicolumn{2}{|c|}{ Cobalt }} & & TIME: & $3: 30 p$ \\
\hline & & & & SET BY: & M Lindely / VS Eng \\
\hline
\end{tabular}

\begin{tabular}{|c|c|c|c|c|c|c|c|c|}
\hline PHASE MOVEMENT/INTERVAL & 1 & 2 & 3 & 4 & 5 & 6 & 7 & 8 \\
\hline & NBLT & SB & WBLT & $\mathrm{EB}$ & SBLT & NB & EBLT & WB \\
\hline MIN. GREEN & 7 & 10 & 7 & 6 & 7 & 10 & 5 & 6 \\
\hline WALK & & 5 & & 5 & & 5 & & 5 \\
\hline PED CLEAR & & 15 & & 18 & & 15 & & 18 \\
\hline PASSAGE & 2.0 & 2.0 & 2.0 & 2.0 & 2.0 & 2.0 & 2.0 & 2.0 \\
\hline MAX I & 20 & 40 & 20 & 30 & 20 & 40 & 20 & 30 \\
\hline MAX II & 30 & 40 & 30 & 30 & 30 & 40 & 30 & 30 \\
\hline \multicolumn{9}{|l|}{ MAX III } \\
\hline \multicolumn{9}{|l|}{ MAX EXT. } \\
\hline AMBER & 3.0 & 4.0 & 3.0 & 3.0 & 4.0 & 4.0 & 3.0 & 3.0 \\
\hline RED CLEAR & 3.0 & 3.0 & 3.0 & 3.0 & 3.0 & 3.0 & 3.0 & 3.0 \\
\hline \multicolumn{9}{|l|}{ SECONDS PER ACT } \\
\hline \multicolumn{9}{|l|}{ MAX. VAR. INITIAL } \\
\hline \multicolumn{9}{|l|}{ BEFORE REDUCTION } \\
\hline \multicolumn{9}{|l|}{\begin{tabular}{|l} 
TIME TO REDUCE \\
\end{tabular}} \\
\hline MIN. GAP & 3.0 & 3.0 & 3.0 & 3.0 & 3.0 & 3.0 & 3.0 & 3.0 \\
\hline \multicolumn{9}{|l|}{ MEMORY } \\
\hline VEH RECALL & & $\mathrm{x}$ & & & & $\mathrm{x}$ & & \\
\hline SOFT RECALL & & $x$ & & & & $x$ & & \\
\hline \multicolumn{9}{|l|}{ PED RECALL } \\
\hline DUAL ENTRY & & $\mathrm{x}$ & & $\mathrm{x}$ & & $\mathrm{x}$ & & $\mathrm{x}$ \\
\hline \multicolumn{9}{|l|}{ CNA I } \\
\hline & & & & & & & & \\
\hline THIS FLASHES & & $\mathrm{R}$ & & $\mathrm{R}$ & & $\mathrm{R}$ & & $\mathrm{R}$ \\
\hline
\end{tabular}

NOTES:

Cy1/Sp1/Of1 CY 100 Of 86

Cy2/Sp1/Of1

Cy 90 of 19

$\mathrm{NIC}(\mathrm{CY} / \mathrm{SP} / \mathrm{OF})$
Phase 1
$6002 / 1 / 1$
$13001 / 1 / 1$

17
13

2
41
37

3
13
13

4
29
27

5
17
15

6
41

7
13


New Albany, Indiana - Actuated Signal Timing Record

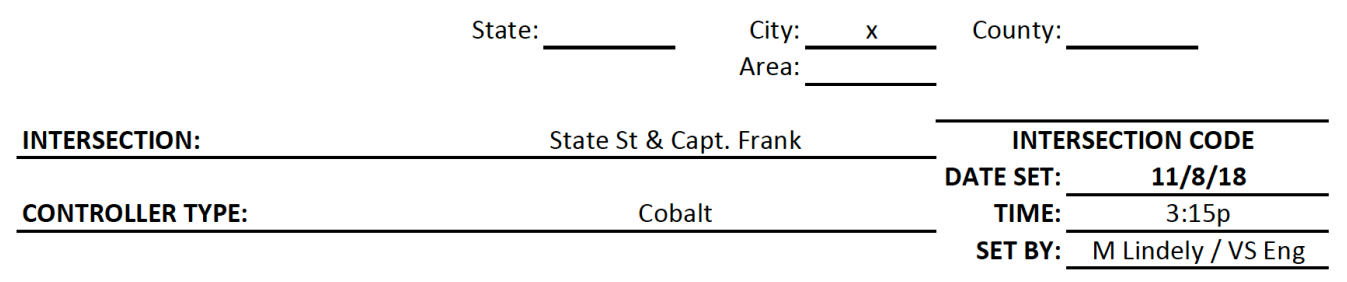

\begin{tabular}{|c|c|c|c|c|c|c|c|c|}
\hline PHASE MOVEMENT/INTERVAL & 1 & 2 & 3 & 4 & 5 & 6 & 7 & 8 \\
\hline & NBLT & SB & & $\mathrm{EB} / \mathrm{WB}$ & SBLT & NB & & \\
\hline MIN. GREEN & 2 & 22 & & 13 & 2 & 22 & & 13 \\
\hline WALK & & 5 & & 5 & & 5 & & 5 \\
\hline PED CLEAR & & 16 & & 17 & & 16 & & 17 \\
\hline PASSAGE & 2.0 & 4.0 & & 4.0 & 2.0 & 4.0 & & 4.0 \\
\hline MAX I & 20 & 20 & & 30 & 20 & 20 & & 30 \\
\hline MAX II & 30 & 30 & & 30 & 30 & 30 & & 30 \\
\hline \multicolumn{9}{|l|}{ MAX III } \\
\hline \multicolumn{9}{|l|}{ MAX EXT. } \\
\hline AMBER & 4.0 & 4.0 & & 4.0 & 4.0 & 4.0 & & 4.0 \\
\hline RED CLEAR & 3.0 & 3.0 & & 3.0 & 3.0 & 3.0 & & 3.0 \\
\hline \multicolumn{9}{|l|}{ SECONDS PER ACT } \\
\hline \multicolumn{9}{|l|}{ MAX. VAR. INITIAL } \\
\hline \multicolumn{9}{|l|}{ BEFORE REDUCTION } \\
\hline \multicolumn{9}{|l|}{ TIME TO REDUCE } \\
\hline \multicolumn{9}{|l|}{ MIN. GAP } \\
\hline \multicolumn{9}{|l|}{ MEMORY } \\
\hline VEH RECALL & & $x$ & & & & $x$ & & \\
\hline \multicolumn{9}{|l|}{ SOFT RECALL } \\
\hline PED RECALL & & $x$ & & $x$ & & $x$ & & $x$ \\
\hline DUAL ENTRY & & $\mathrm{x}$ & & $\mathrm{x}$ & & $\mathrm{x}$ & & $\mathrm{x}$ \\
\hline \multicolumn{9}{|l|}{ CNA I } \\
\hline & & & & & & & & \\
\hline THIS FLASHES & & $\mathrm{R}$ & & $\bar{R}$ & & $\mathrm{R}$ & & $\mathrm{R}$ \\
\hline
\end{tabular}

NOTES:

Cy1/Sp1/Of1 CY 100 of 18

Phase 1

Cy2/Sp1/Of1 Cy 90 Of 28

9

2

2
50
39

3
0

4
41
33

5

$\begin{array}{rrr}6 & 7 & 8 \\ 50 & 0 & 41 \\ 48 & 0 & 37\end{array}$

$\mathrm{NIC}(\mathrm{CY} / \mathrm{SP} / \mathrm{OF})$

$6002 / 1 / 1$

$13001 / 1 / 1$ 


\section{I-265 EB Ramp \& State St}

Plan 2

\begin{tabular}{|c|c|c|c|c|c|c|c|c|c|c|c|c|c|c|c|c|}
\hline Phase & 1 & 2 & 3 & 4 & 5 & 6 & 7 & 8 & 9 & 10 & 11 & 12 & 13 & 14 & 15 & 16 \\
\hline \multicolumn{17}{|l|}{ Direction } \\
\hline Min Green & 5 & 5 & 5 & 5 & 5 & 5 & 5 & 5 & 5 & 5 & 5 & 5 & 5 & 5 & 5 & 5 \\
\hline $\begin{array}{l}\text { BK Min } \\
\text { Green }\end{array}$ & 0 & 0 & 0 & 0 & 0 & 0 & 0 & 0 & 0 & 0 & 0 & 0 & 0 & 0 & 0 & 0 \\
\hline $\begin{array}{l}\text { CS Min } \\
\text { Green }\end{array}$ & 0 & 0 & 0 & 0 & 0 & 0 & 0 & 0 & 0 & 0 & 0 & 0 & 0 & 0 & 0 & 0 \\
\hline Delay Green & 0 & 0 & 0 & 0 & 0 & 0 & 0 & 0 & 0 & 0 & 0 & 0 & 0 & 0 & 0 & 0 \\
\hline Walk & 0 & 10 & 0 & 10 & 0 & 10 & 0 & 10 & 0 & 10 & 0 & 10 & 0 & 10 & 0 & 10 \\
\hline Walk 2 & 0 & 0 & 0 & 0 & 0 & 0 & 0 & 0 & 0 & 0 & 0 & 0 & 0 & 0 & 0 & 0 \\
\hline Walk Max & 0 & 0 & 0 & 0 & 0 & 0 & 0 & 0 & 0 & 0 & 0 & 0 & 0 & 0 & 0 & 0 \\
\hline Ped Clear & 0 & 16 & 0 & 16 & 0 & 16 & 0 & 16 & 0 & 16 & 0 & 16 & 0 & 16 & 0 & 16 \\
\hline Ped Clear 2 & 0 & 0 & 0 & 0 & 0 & 0 & 0 & 0 & 0 & 0 & 0 & 0 & 0 & 0 & 0 & 0 \\
\hline $\begin{array}{l}\text { Ped Clear } \\
\text { Max }\end{array}$ & 0 & 0 & 0 & 0 & 0 & 0 & 0 & 0 & 0 & 0 & 0 & 0 & 0 & 0 & 0 & 0 \\
\hline Ped CO & 0 & 0 & 0 & 0 & 0 & 0 & 0 & 0 & 0 & 0 & 0 & 0 & 0 & 0 & 0 & 0 \\
\hline Vehicle Ext & 5.0 & 5.0 & 5.0 & 5.0 & 5.0 & 5.0 & 5.0 & 5.0 & 5.0 & 5.0 & 5.0 & 5.0 & 5.0 & 5.0 & 5.0 & 5.0 \\
\hline $\begin{array}{l}\text { Vehicle Ext } \\
2\end{array}$ & 0.0 & 0.0 & 0.0 & 0.0 & 0.0 & 0.0 & 0.0 & 0.0 & 0.0 & 0.0 & 0.0 & 0.0 & 0.0 & 0.0 & 0.0 & 0.0 \\
\hline Max 1 & 35 & 35 & 35 & 35 & 35 & 35 & 35 & 35 & 35 & 35 & 35 & 35 & 35 & 35 & 35 & 35 \\
\hline Max 2 & 40 & 40 & 40 & 40 & 40 & 40 & 40 & 40 & 40 & 40 & 40 & 40 & 40 & 40 & 40 & 40 \\
\hline Max 3 & 0 & 0 & 0 & 0 & 0 & 0 & 0 & 0 & 0 & 0 & 0 & 0 & 0 & 0 & 0 & 0 \\
\hline DYM Max & 0 & 0 & 0 & 0 & 0 & 0 & 0 & 0 & 0 & 0 & 0 & 0 & 0 & 0 & 0 & 0 \\
\hline DYM Stp & 0.0 & 0.0 & 0.0 & 0.0 & 0.0 & 0.0 & 0.0 & 0.0 & 0.0 & 0.0 & 0.0 & 0.0 & 0.0 & 0.0 & 0.0 & 0.0 \\
\hline Yellow & 3.0 & 3.0 & 3.0 & 3.0 & 3.0 & 3.0 & 3.0 & 3.0 & 3.0 & 3.0 & 3.0 & 3.0 & 3.0 & 3.0 & 3.0 & 3.0 \\
\hline Red Clear & 1.0 & 1.0 & 1.0 & 1.0 & 1.0 & 1.0 & 1.0 & 1.0 & 1.0 & 1.0 & 1.0 & 1.0 & 1.0 & 1.0 & 1.0 & 1.0 \\
\hline Red Max & 0.0 & 0.0 & 0.0 & 0.0 & 0.0 & 0.0 & 0.0 & 0.0 & 0.0 & 0.0 & 0.0 & 0.0 & 0.0 & 0.0 & 0.0 & 0.0 \\
\hline Red Revert & 2.0 & 2.0 & 2.0 & 2.0 & 2.0 & 2.0 & 2.0 & 2.0 & 2.0 & 2.0 & 2.0 & 2.0 & 2.0 & 2.0 & 2.0 & 2.0 \\
\hline ACT B4 & 0 & 0 & 0 & 0 & 0 & 0 & 0 & 0 & 0 & 0 & 0 & 0 & 0 & 0 & 0 & 0 \\
\hline $\mathrm{SEC} / \mathrm{ACT}$ & 0.0 & 0.0 & 0.0 & 0.0 & 0.0 & 0.0 & 0.0 & 0.0 & 0.0 & 0.0 & 0.0 & 0.0 & 0.0 & 0.0 & 0.0 & 0.0 \\
\hline Max Int & 0 & 0 & 0 & 0 & 0 & 0 & 0 & 0 & 0 & 0 & 0 & 0 & 0 & 0 & 0 & 0 \\
\hline Time B4 & 0 & 0 & 0 & 0 & 0 & 0 & 0 & 0 & 0 & 0 & 0 & 0 & 0 & 0 & 0 & 0 \\
\hline Cars Wt & 0 & 0 & 0 & 0 & 0 & 0 & 0 & 0 & 0 & 0 & 0 & 0 & 0 & 0 & 0 & 0 \\
\hline STPT Duc & 0.0 & 0.0 & 0.0 & 0.0 & 0.0 & 0.0 & 0.0 & 0.0 & 0.0 & 0.0 & 0.0 & 0.0 & 0.0 & 0.0 & 0.0 & 0.0 \\
\hline $\begin{array}{l}\text { Time To } \\
\text { Reduce }\end{array}$ & 0 & 0 & 0 & 0 & 0 & 0 & 0 & 0 & 0 & 0 & 0 & 0 & 0 & 0 & 0 & 0 \\
\hline Min Gap & 0.0 & 0.0 & 0.0 & 0.0 & 0.0 & 0.0 & 0.0 & 0.0 & 0.0 & 0.0 & 0.0 & 0.0 & 0.0 & 0.0 & 0.0 & 0.0 \\
\hline
\end{tabular}




\section{I-265 WB Ramp \& State St}

Plan 2

\begin{tabular}{|c|c|c|c|c|c|c|c|c|c|c|c|c|c|c|c|c|}
\hline Phase & 1 & 2 & 3 & 4 & 5 & 6 & 7 & 8 & 9 & 10 & 11 & 12 & 13 & 14 & 15 & 16 \\
\hline \multicolumn{17}{|l|}{ Direction } \\
\hline Min Green & 5 & 5 & 5 & 5 & 5 & 5 & 5 & 5 & 5 & 5 & 5 & 5 & 5 & 5 & 5 & 5 \\
\hline \begin{tabular}{|l|} 
BK Min \\
Green
\end{tabular} & 0 & 0 & 0 & 0 & 0 & 0 & 0 & 0 & 0 & 0 & 0 & 0 & 0 & 0 & 0 & 0 \\
\hline \begin{tabular}{|l|} 
CS Min \\
Green
\end{tabular} & 0 & 0 & 0 & 0 & 0 & 0 & 0 & 0 & 0 & 0 & 0 & 0 & 0 & 0 & 0 & 0 \\
\hline Delay Green & 0 & 0 & 0 & 0 & 0 & 0 & 0 & 0 & 0 & 0 & 0 & 0 & 0 & 0 & 0 & 0 \\
\hline Walk & 0 & 10 & 0 & 10 & 0 & 10 & 0 & 10 & 0 & 10 & 0 & 10 & 0 & 10 & 0 & 10 \\
\hline Walk 2 & 0 & 0 & 0 & 0 & 0 & 0 & 0 & 0 & 0 & 0 & 0 & 0 & 0 & 0 & 0 & 0 \\
\hline Walk Max & 0 & 0 & 0 & 0 & 0 & 0 & 0 & 0 & 0 & 0 & 0 & 0 & 0 & 0 & 0 & 0 \\
\hline Ped Clear & 0 & 16 & 0 & 16 & 0 & 16 & 0 & 16 & 0 & 16 & 0 & 16 & 0 & 16 & 0 & 16 \\
\hline Ped Clear 2 & 0 & 0 & 0 & 0 & 0 & 0 & 0 & 0 & 0 & 0 & 0 & 0 & 0 & 0 & 0 & 0 \\
\hline $\begin{array}{l}\text { Ped Clear } \\
\text { Max }\end{array}$ & 0 & 0 & 0 & 0 & 0 & 0 & 0 & 0 & 0 & 0 & 0 & 0 & 0 & 0 & 0 & 0 \\
\hline Ped CO & 0 & 0 & 0 & 0 & 0 & 0 & 0 & 0 & 0 & 0 & 0 & 0 & 0 & 0 & 0 & 0 \\
\hline Vehicle Ext & 5.0 & 5.0 & 5.0 & 5.0 & 5.0 & 5.0 & 5.0 & 5.0 & 5.0 & 5.0 & 5.0 & 5.0 & 5.0 & 5.0 & 5.0 & 5.0 \\
\hline $\begin{array}{l}\text { Vehicle Ext } \\
2\end{array}$ & 0.0 & 0.0 & 0.0 & 0.0 & 0.0 & 0.0 & 0.0 & 0.0 & 0.0 & 0.0 & 0.0 & 0.0 & 0.0 & 0.0 & 0.0 & 0.0 \\
\hline Max 1 & 35 & 35 & 35 & 35 & 35 & 35 & 35 & 35 & 35 & 35 & 35 & 35 & 35 & 35 & 35 & 35 \\
\hline $\operatorname{Max} 2$ & 40 & 40 & 40 & 40 & 40 & 40 & 40 & 40 & 40 & 40 & 40 & 40 & 40 & 40 & 40 & 40 \\
\hline $\operatorname{Max} 3$ & 0 & 0 & 0 & 0 & 0 & 0 & 0 & 0 & 0 & 0 & 0 & 0 & 0 & 0 & 0 & 0 \\
\hline DYM Max & 0 & 0 & 0 & 0 & 0 & 0 & 0 & 0 & 0 & 0 & 0 & 0 & 0 & 0 & 0 & 0 \\
\hline DYM Stp & 0.0 & 0.0 & 0.0 & 0.0 & 0.0 & 0.0 & 0.0 & 0.0 & 0.0 & 0.0 & 0.0 & 0.0 & 0.0 & 0.0 & 0.0 & 0.0 \\
\hline Yellow & 3.0 & 3.0 & 3.0 & 3.0 & 3.0 & 3.0 & 3.0 & 3.0 & 3.0 & 3.0 & 3.0 & 3.0 & 3.0 & 3.0 & 3.0 & 3.0 \\
\hline Red Clear & 1.0 & 1.0 & 1.0 & 1.0 & 1.0 & 1.0 & 1.0 & 1.0 & 1.0 & 1.0 & 1.0 & 1.0 & 1.0 & 1.0 & 1.0 & 1.0 \\
\hline Red Max & 0.0 & 0.0 & 0.0 & 0.0 & 0.0 & 0.0 & 0.0 & 0.0 & 0.0 & 0.0 & 0.0 & 0.0 & 0.0 & 0.0 & 0.0 & 0.0 \\
\hline Red Revert & 2.0 & 2.0 & 2.0 & 2.0 & 2.0 & 2.0 & 2.0 & 2.0 & 2.0 & 2.0 & 2.0 & 2.0 & 2.0 & 2.0 & 2.0 & 2.0 \\
\hline ACT B4 & 0 & 0 & 0 & 0 & 0 & 0 & 0 & 0 & 0 & 0 & 0 & 0 & 0 & 0 & 0 & 0 \\
\hline SEC/ACT & 0.0 & 0.0 & 0.0 & 0.0 & 0.0 & 0.0 & 0.0 & 0.0 & 0.0 & 0.0 & 0.0 & 0.0 & 0.0 & 0.0 & 0.0 & 0.0 \\
\hline Max Int & 0 & 0 & 0 & 0 & 0 & 0 & 0 & 0 & 0 & 0 & 0 & 0 & 0 & 0 & 0 & 0 \\
\hline Time B4 & 0 & 0 & 0 & 0 & 0 & 0 & 0 & 0 & 0 & 0 & 0 & 0 & 0 & 0 & 0 & 0 \\
\hline Cars Wt & 0 & 0 & 0 & 0 & 0 & 0 & 0 & 0 & 0 & 0 & 0 & 0 & 0 & 0 & 0 & 0 \\
\hline STPT Duc & 0.0 & 0.0 & 0.0 & 0.0 & 0.0 & 0.0 & 0.0 & 0.0 & 0.0 & 0.0 & 0.0 & 0.0 & 0.0 & 0.0 & 0.0 & 0.0 \\
\hline $\begin{array}{l}\text { Time To } \\
\text { Reduce }\end{array}$ & 0 & 0 & 0 & 0 & 0 & 0 & 0 & 0 & 0 & 0 & 0 & 0 & 0 & 0 & 0 & 0 \\
\hline Min Gap & 0.0 & 0.0 & 0.0 & 0.0 & 0.0 & 0.0 & 0.0 & 0.0 & 0.0 & 0.0 & 0.0 & 0.0 & 0.0 & 0.0 & 0.0 & 0.0 \\
\hline
\end{tabular}




\section{CURRICULUM VITAE}

Larry Michael Summers

Cell: 812.987 .3567

1summers13@gmail.com

\section{EDUCATION}

Ph.D. in Civil Engineering, University of Louisville, KY

Expected 2024

MS in Civil Engineering, University of Louisville, KY

Expected 2021

Graduate Certificate in Transportation Engineering

December 2020

BS in Civil Engineering, University of Evansville, IN

May 2006

BS in Engineering Management, University of Evansville, IN

May 2006

LEADERSHIP:

President, Chi Epsilon

2005-2006

President, Dean's Advisory Council

2005-2006

Supreme Court Justice, Student Government Ass.

2005-2006

Engineering Representative, University Honor Council 2005-2006

President,

The Village

Council 2004-2006

Mentor, Twenty-first Century Scholars

2004-2006

Honor Societies: Chi Epsilon, Civil Engineering

Kappa Mu Epsilon, Mathematics

Phi Eta Sigma

National Society of Collegiate Scholars

Phi Kappa Phi

HONORS AND AWARDS:

Scholarship, AISES 2005-2006

\section{A.T. Anderson Memorial}

First Choice Award, University of Evansville

2002-2006

Full tuition, room, and meal plan

Dean's List

Fall 2004

Dean's List

Fall 2003

Dean's List

Fall 2002

First Place Bridge: Design

Fall 2002

First Place Bridge: Efficiency

Fall 2002

First Place Bridge: Strength

Fall 2002

Outstanding Borden Scholar, Borden Lions Club

2002

\section{PUBLICATIONS AND PRESENTATIONS}

Gahan, J., Rosenbarger, J., Speck, J., \& Summers, L. M. (2019, June). TOUR: New

Albany. In L. Volk, 27 ${ }^{\text {th }}$ Annual Congress, CNU 27.Louisville. The Congress for the New Urbanism, Louisville, KY. 


\section{CURRENT RESEARCH INTERESTS}

Safety improvements of urban transportation systems

\section{PROFESSIONAL ENGINEERING EXPERIENCE}

\section{CITY ENGINEER}

2014-Present

City of New Albany, New Albany, IN

Supervisor: Jeff Gahan, Mayor

- $\quad$ Established an Engineering Department and instituted standards, policies, and procedures for design and construction activity

- Coordinated Engineering Department activities with other city departments and outside agencies

- Investigated critical infrastructure deficiencies

- $\quad$ Evaluated and selected appropriate consulting engineers

- Negotiated contracts with consulting engineers and construction companies to optimize the services provided within the allocated budget

- $\quad$ Managed the Engineering Department and engineering consultants throughout the project development process

- Administered Public Works construction projects from pre-construction meetings through close-out documentation

Relevant Projects:

Reconstruction
2019-Present

State St. and Oak St. Signal Modernization*

State St. and Cherry St. Signal Modernization*

Bank St. and Main St. Signal Installation

Market St. Streetscape

Grant Line Rd. Corridor Signal Modernization

Grant Line Rd. Reconstruction*

Mt. Tabor Rd. Reconstruction*

State Street Corridor Signal Modernization*

Downtown One-way to Two-way Conversion*

- 2017 KIPDA Kentucky-Indiana Transportation Excellence Award

Ohio River Greenway from E. $8^{\text {th }}$ St. to E. $18^{\text {th }}$ St.

Spring St. and Silver St. Signal (Spring St. Road Diet)*

-2017 KIPDA Kentucky-Indiana Transportation Excellence

Award

McDonald Lane Reconstruction*

2015-2016

- 2017 National Asphalt Pavement Association Quality in

Construction Award

East Main Street Improvements

- 2016 ACEC Engineering Excellence Merit Award

Charlestown Rd. and Beechwood Ave. Signal Modernization* 2014

*Indicates federal funds associated with the project
Slate Run Rd. 


\section{PROFESSIONAL ENGINEERING EXPERIENCE (CONTINUED)}

\section{TRANSPORTATION PLANNING ENGINEER}

Louisville Metro Government, Louisville, KY

Supervisor: Jennifer Caummisar, PE, Engineering Supervisor

- $\quad$ Reviewed and approved preliminary plans for rezoning, subdivisions, development plans, and conditional use permits

- $\quad$ Reviewed and approved construction plans, including new road construction, roadway and shoulder widening, sidewalks, and site design

- $\quad$ Scoped and reviewed traffic analyses and traffic models

PROJECT MANAGER

$2008-2011$

Presnell Design Group, Louisville, KY

Supervisor: Matthew Riddell, Director of Native American Services Division

- Designed roadway and site plans throughout the United States for Bureau of Indian Affairs and independent tribal governments

- $\quad$ Prepared geometric and hydraulic designs, plans, and quantity/cost estimates

- Collaborated with federal, state, local, and tribal government entities with stakes in the project as well as sub-consultants and staff for design

Relevant Projects: $\quad$ Round Valley Indian Reservation 2010

Santa Ysabel Indian Reservation 2009

PROJECT ENGINEER, 2006-2008

HMB Professional Engineers, New Albany, IN

Supervisor: Paul Lincks, PE, Regional Office Manager

- $\quad$ Participated in the design of roadways throughout Kentucky and Indiana for KYTC, INDOT, IDNR, and local government entities

- Gathered data for the preparation of geometric and hydraulic designs, plans, and quantity/cost estimates

- $\quad$ Facilitated communication among federal, state, and local government entities with stakes in the project as well as sub-consultants and staff for design

Relevant Projects: $\quad$ KY-55 Reconstruction, Realignment, and Bridge Replacement 2008 I-64 Reconstruction from Corydon to Leavenworth

\section{PROFESSIONAL ORGANIZATIONS}

American Society of Civil Engineers (ASCE)

National Society of Professional Engineers (NSPE)

Indiana Society of Professional Engineers (ISPE)

Indiana Association of City Engineers (IACE)

Accelerate Indiana Municipalities (AIM)

Chi Epsilon

American Indian Science and Engineering Society (AISES)

Out in Science, Technology, Engineering, and Mathematics (oSTEM) 


\section{PROFESSIONAL REGISTRATIONS}

Indiana PE No. 11400401

Kentucky PE No. 27708

NCEES Recorder Holder No. 45043

\section{COMMUNITY INVOLVEMENT AND VOLUNTEERING}

President, Indiana Association of City Engineers 2021-Present Member, New Albany City Plan Commission 2021-Present Mentor, New Albany Floyd County School System Mentor Mii Program 2019-Present Member, KIPDA Transportation Technical Coordinating Committee 2014-Present Member, KIPDA Transportation Policy Committee 2014-Present Advisor, New Albany Board of Public Works and Safety 2014-Present Advisor, New Albany Redevelopment Commission 2014-Present Advisor, New Albany Sewer Board 2015-Present Advisor, New Albany Storm Water Board 2015-Present Vice President, New Albany City Plan Commission 2014-2021 Vice President, Indiana Equality Action Board of Directors 2013-2016 Vice President, New Albany Sewer Board 2014-2015 Vice President, New Albany Storm Water Board 2014-2015 Volunteer/Engineer, G.O. Ministries, Inc. 2009-2010 